Portland State University

PDXScholar

Spring 6-20-2013

\title{
The Spatial Distribution of Tobacco Pipe Fragments at the Hudson's Bay Company Fort Vancouver Village Site: Smoking as a Shared and Social Practice
}

Katie Ann Wynia

Portland State University

Follow this and additional works at: https://pdxscholar.library.pdx.edu/open_access_etds

Part of the Archaeological Anthropology Commons, and the Social and Cultural Anthropology Commons

Let us know how access to this document benefits you.

\section{Recommended Citation}

Wynia, Katie Ann, "The Spatial Distribution of Tobacco Pipe Fragments at the Hudson's Bay Company Fort Vancouver Village Site: Smoking as a Shared and Social Practice" (2013). Dissertations and Theses. Paper 1085.

https://doi.org/10.15760/etd.1085

This Thesis is brought to you for free and open access. It has been accepted for inclusion in Dissertations and Theses by an authorized administrator of PDXScholar. Please contact us if we can make this document more accessible: pdxscholar@pdx.edu. 
The Spatial Distribution of Tobacco Pipe Fragments at the Hudson's Bay Company Fort Vancouver Village Site: Smoking as a Shared and Social Practice

by

Katie Ann Wynia

A thesis submitted in partial fulfillment of the requirements for the degree of

\author{
Master of Arts \\ in \\ Anthropology \\ Thesis Committee: \\ Kenneth M. Ames, Chair \\ Douglas C. Wilson \\ Shelby Anderson \\ Portland State University \\ 2013
}




\begin{abstract}
This thesis represents one of the first systematic, detailed spatial analyses of artifacts at the mid-19th century Hudson's Bay Company's Fort Vancouver Village site, and of clay tobacco pipe fragments in general. Historical documents emphasize the multicultural nature of the Village, but archaeologically there appears to be little evidence of ethnicity (Kardas 1971; Chance and Chance 1976; Thomas and Hibbs 1984:723). Following recent approaches to cultural interaction in which researchers examined the nuanced uses of material culture (Lightfoot et al 1998; Martindale 2009; Voss 2008); this study analyzed the spatial distribution of tobacco pipe fragments for behavioral information through a practice theory approach (Bourdieu 1977; Ortner 2006). The analysis aimed to determine the role of tobacco smoking in the Village. It evaluated tobacco smoking as a significant and social behavior, the visibility of maintenance behaviors in the clay pipe distributions, and evidence of ethnic variation in tobacco consumption.

Spatial patterning characteristics were compiled from the few behavioral studies of clay pipe fragments (Davies 2011; Fox 1998: Hamilton 1990; Hartnett 2004; Hoffman and Ross 1973, 1974; King and Miller 1987), and indications of ethnic specific behaviors from archaeological and historical evidence (Burley et al 1992; Jacobs 1958; Jameson 2007). Distributional maps examined three pipe assemblage characteristics: fragment frequency, use wear fragment frequency, and the bowl to stem fragment ratio, to define smoking locations on the Village landscape. Visibility of maintenance and refuse disposal behaviors in the size distribution of fragments was measured through the Artifact Size
\end{abstract}


Index (ASI) (Bon Harper and McReynolds 2011). This analysis also tested two possible indications of ethnic variation: differential use of stone vs. clay pipes, and consumption rates as reflected through clay pipe assemblages.

The commonality of tobacco smoking locations across the landscape suggests a significant, social, and shared practice between households. Analysis of maintenance behaviors and ethnic variation proved inconclusive. This study demonstrates the value of spatially analyzing clay pipe fragment distributions for behavioral information. The insight gained from examining multiple spatial patterns suggests future studies can benefit from analyzing the spatial distribution of diagnostic characteristics of pipes and other artifact types. 


\section{Acknowledgements}

Thank you to everyone that helped me along the way, I never could have accomplished this thesis without you. Special thanks goes to my thesis committee, Dr. Ken Ames, Dr. Shelby Anderson, and especially my advisor Dr. Doug Wilson, for all their time, feedback, and patience. Thank you to Connie Cash for all the help and kindness you provide to the anthropology students at Portland State. To everyone in the Cultural Resources Division at Fort Vancouver National Historic Site, thank you for the many years of your support and guidance, and inspiration at my field school to pursue archaeology. Thanks also goes to my anthropology classmates and friends, in particular Cassie Manetas, Stephanie Simmons, Katie Wojcik, Dana Holschuh, Kristen Fuld, and Alex Stevenson for paper edits, hours spent in the library together, and laughs during study breaks. Finally, I want to express my gratitude to my family, particularly my husband Erik, whose patience and support got me through these past five years. 


\section{Table of Contents}

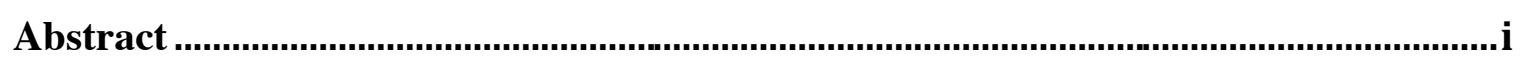

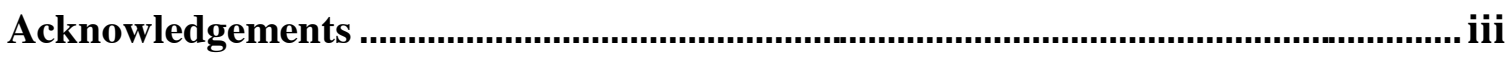

List of Tables..................................................................................................... vi

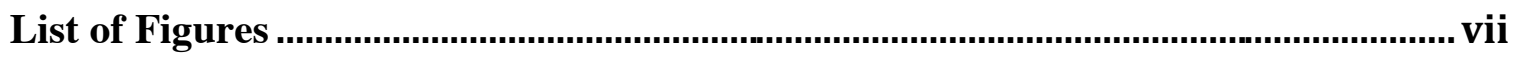

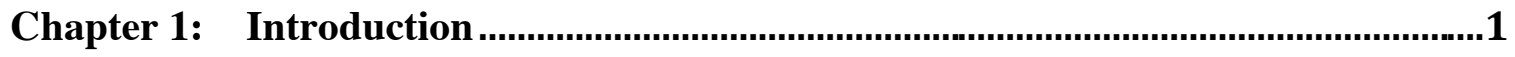

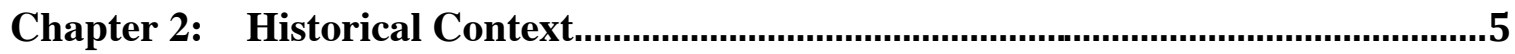

The History of the Village................................................................................................5

The History of Tobacco Consumption ............................................................................... 14

Clay Tobacco Pipes ......................................................................................................17

The Role of Tobacco in the Fur Trade.............................................................................19

Tobacco Consumption Practices of Sociocultural Groups at Fort Vancouver ......................... 23

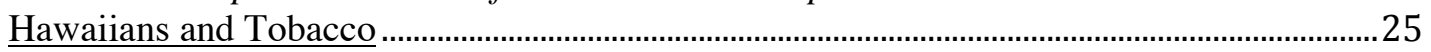

Pacific Northwest Native Groups and Tobacco ……………………………………………….....2

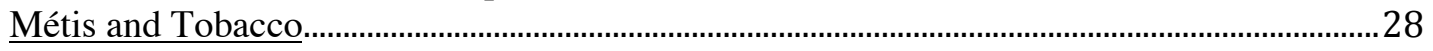

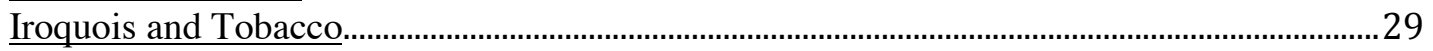

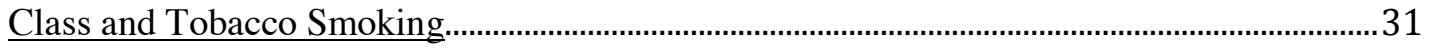

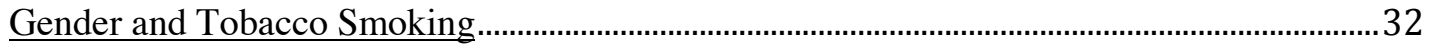

Summary …...................................................................................................................... 33

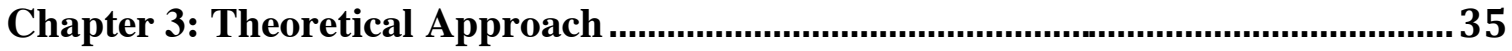

Practice Theory........................................................................................................ 35

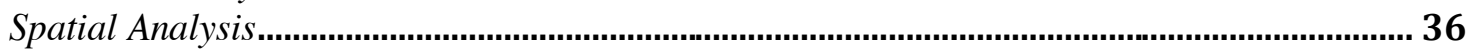

Spatial Patterning and Tobacco Pipes..............................................................................................38

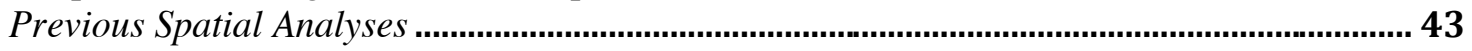

Studies of Cultural Interaction in Contact and Fur Trade Archaeology.................................. 44

Post-Depositional Effects ...................................................................................................... 50

Research Questions ……………………………........................................................................ 51

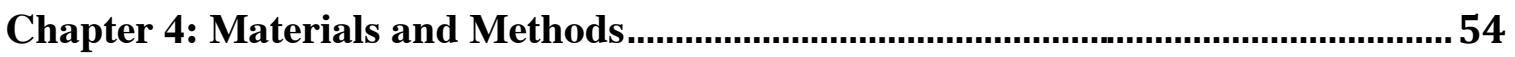

Projects Associated with the Study Assemblage................................................................. 54

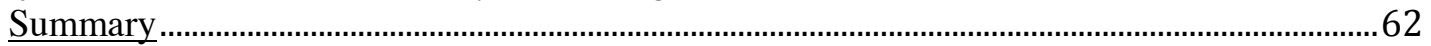

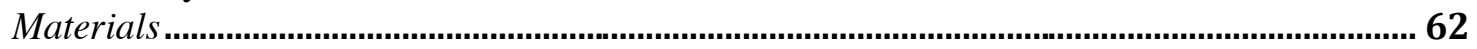

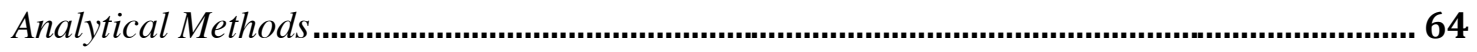

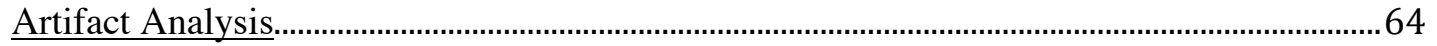

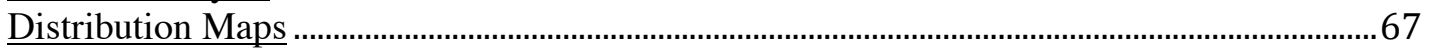

Analytical Strategies Associated with Research Questions.......................................................70

Chapter 5. Results................................................................................................. 79

Tobacco as Significant and Social Practice ……............................................................... 79

Variation in Maintenance Behaviors .................................................................................. 92

Tobacco Consumption Tied to Ethnic Differences .................................................................... 97

Summary …..........................................................................................................100

Chapter 6. Discussion ............................................................................................... 101

Tobacco Consumption as a Shared and Social Practice ………...........................................101

ASI Values as Indicators of Traffic Patterns ........................................................................103 


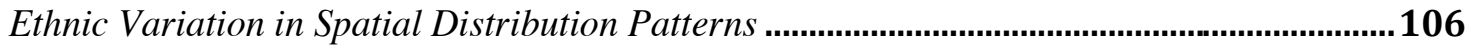

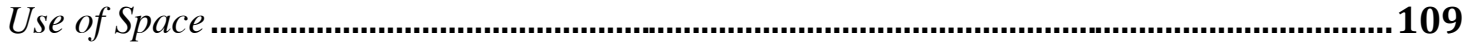

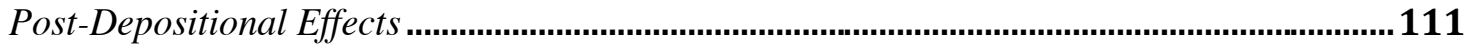

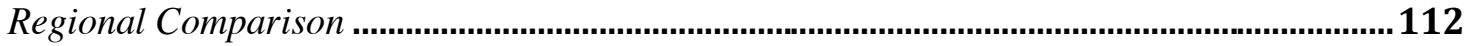

Summary

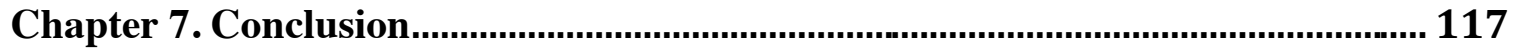

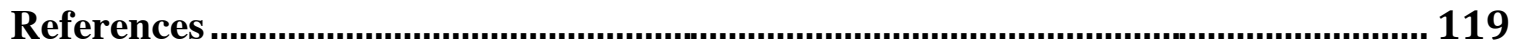

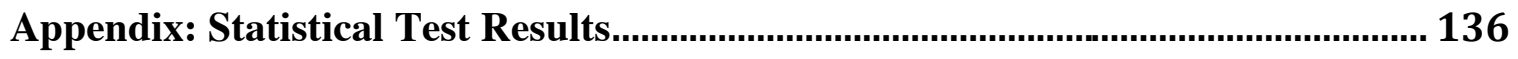




\section{List of Tables}

TABLE 1 PROJECTS ASSOCIATED WITH THE STUDY ASSEMBLAGE .................. 57

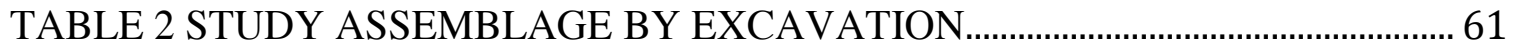

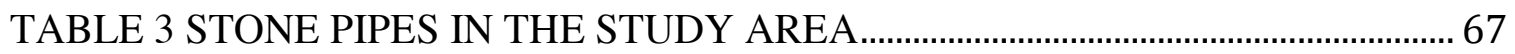

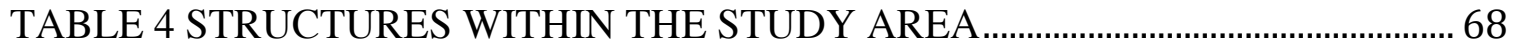

TABLE 5 HYPOTHETICAL CHARACTERISTICS OF PIPE FRAGMENT

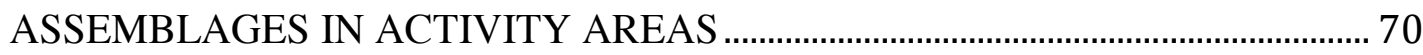

TABLE 6 SMOKING ACTIVITY AREAS …................................................................... 91 TABLE 7 MEAN AND MEDIAN FRAGMENT SIZE BY SCREENING TECHNIQUE

TABLE 8 SMOKING ACTIVITY AREA CLAY PIPE ASSEMBLAGES BY HOUSE99 TABLE 9 REPORTED PIPE ASSEMBLAGES OF FUR TRADE ERA SITES IN THE PACIFIC NORTHWEST 


\section{List of Figures}

FIGURE 1. Hudson's Bay Posts, Settlements, and Military Posts in the Columbia Department

FIGURE 2. The Study Area on the Modern Landscape

FIGURE 3. The Village in 1846. Based on a drawing by Richard Covington in the Hudson's Bay Company Archives 9

FIGURE 4. An Intact, Late 19th Century Clay Pipe Similar to those from the Village Site

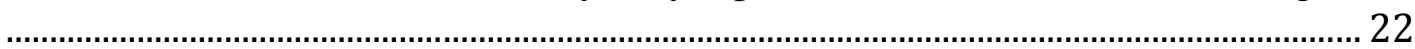

FIGURE 5. Stone Pipe Fragments from FOVA 3023, ST 93 and ST 121 ........................43

FIGURE 6. Stone Pipe Fragment from FOVA 3164, EU C7 ……...................................... 43

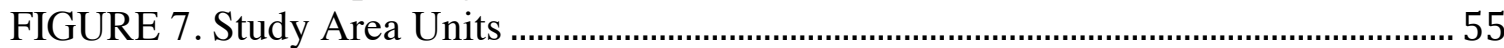

FIGURE 8. Pipe Fragments by Size Class from FOVA 3120............................................. 66

FIGURE 9. The Historical Landscape with the Study Area .................................................. 69

FIGURE 10. Shovel Test Fragment Frequency Distribution ............................................... 81

FIGURE 11. Shovel Test Use Wear Fragment Frequency Distribution .............................. 82

FIGURE 12. Shovel Test Bowl to Stem Ratio Distribution ................................................ 83

FIGURE 13. All Study Unit Data Fragment Frequency Distribution .................................. 84

FIGURE 14. All Study Unit Data Use Wear Fragment Frequency Distribution............... 85

FIGURE 15. All Study Unit Data Bowl to Stem Ratio Distribution...................................... 86

FIGURE 16. Pipe Fragment Smoking Location Attributes ................................................ 88

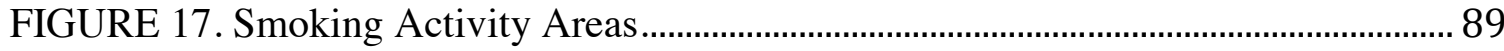

FIGURE 18. Percentage of Pipe Fragments by Size Class for Each Screening Method 93

FIGURE 19. Shovel Test ASI Value Distribution................................................................. 95

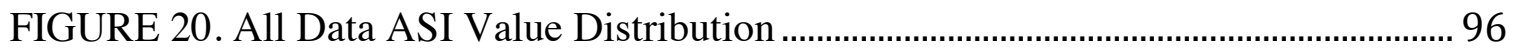

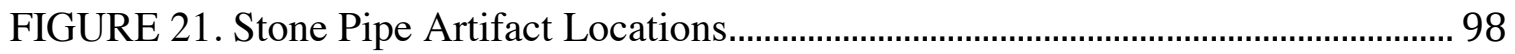

FIGURE 22. Fragment and Use Wear Fragment Frequencies for ST 117 and Interior

Smoking Activity Areas ............................................................................................ 103

FIGURE 23. Map of Hypothetical Pathways Based on Small Pipe Fragment Clusters 105 


\section{Chapter 1: Introduction}

In the mid-19th century the employee Village at the Hudson's Bay Company's (HBC) Fort Vancouver was home to people from a diversity of backgrounds. Native Hawaiians, Iroquois, Chinook, French-Canadians, Scots, and others resided within the Village site west of the fort stockade (Hussey 1957). Historical documents contain few details on life in the Village, but do emphasize the multi-cultural nature of the community. Archaeologically, there appears to be little evidence of ethnicity, however previous researchers often focused on the European origin of items (Kardas 1971; Chance and Chance 1976; Thomas and Hibbs 1984:723). This thesis follows recent approaches to cultural interaction and expressions of identity in which the nuanced uses of material culture (Lightfoot et al 1998; Martindale 2009; Voss 2008) are examined rather than viewing objects as "ethnic markers" (Silliman 2005). The study analyzed the spatial distribution of tobacco pipe fragments for behavioral information to determine the role of tobacco smoking in the Village. It evaluated tobacco smoking as a significant and social behavior, the visibility of maintenance behaviors in the clay pipe distributions, and evidence of ethnic variation in tobacco consumption. Variation in spatial distributions would show the influence of ethnic background on behaviors, exhibiting either a high degree of variation tied to differing worldviews, or similarity in distribution indicating possible ethnogenesis (Voss 2008) of a more unified Village identity or culture.

The study used a practice theory approach to analyze individuals' actions, and the influence of cultural ideology at both conscious and subconscious levels (Bourdieu 1977; Ortner 2006). Daily practices, influenced by cultural ideology, left their mark in the 
archaeological record indicating use of space related to worldviews (Deetz 1996;

Lightfoot et al 1998). Clay tobacco pipe fragments were chosen for this study, as the artifact type is known to display spatial patterning. At Fort Vancouver and other sites, archaeologists inferred that the patterning is related to two daily behaviors: smoking and refuse disposal behaviors (Davies 2011; Fox 1998: Hamilton 1990; Hartnett 2004; Hoffman and Ross 1973, 1974; King and Miller 1987). These patterns can potentially contain information on ethnic variation tied to cultural worldview (Burley et al 1992; Beck and Hill 2004; Crane 2000).

Behavioral analysis of clay pipes is often neglected (Rafferty and Mann 2008). Researchers commonly focus on pipes for chronological measures, and create distributional maps only of fragment frequency, limiting the inference of behaviors. Further, although people of varying ethnic backgrounds may have used clay tobacco pipes, historical documents record variation in tobacco consumption behaviors between the ethnic groups represented in the Village population. While the abundance of clay tobacco pipe fragments may represent the adoption of European smoking pipes, their context of use was likely much more complex. Material practices can involve similar artifacts utilized in different ways according to worldviews (Voss 2008:4).

Distributional analysis examined three pipe assemblage characteristics compiled from previous studies, and the size of fragments to assess size-sorting behaviors. Maps of fragment frequency, use wear fragment frequency, and the bowl to stem fragment ratio distributions defined smoking locations on the Village landscape. Visibility of maintenance and refuse disposal behaviors in the size distribution of fragments was measured through the Artifact Size Index (ASI) (Bon Harper and McReynolds 2011). 
These distributions were assessed for indications of ethnic variation.

While the archaeological and documentary records suggest most fur trade employees used tobacco, consumption behaviors potentially differed according to ethnic practices. For example, smoking held symbolic importance to the Iroquois (Winter 2000a) and other Native American groups (Dunn 1845; Rubin 1999), while European cultures tended to view it as a recreational and social activity (Goodman 1993:85). Use of stone pipes is connected to Native Americas and Métis in the fur trade (Burley et al 1992; Jameson 2007), and historical evidence suggests behavioral prescriptions, such as religion (Jacobs 1958), possibly limited consumption rates. This analysis tested these two possibilities for ethnic variation, examining the spatial patterning of stone vs. clay pipes, and consumption rates as reflected through clay pipe assemblages.

This study represents one of the first systematic, detailed spatial analyses of artifacts at the Village site, and of clay tobacco pipe fragments in general. Examining the three assemblage characteristics allowed determination of more specific smoking locations. Analysis of maintenance behaviors and ethnic variation proved inconclusive. The presence of tobacco smoking locations across the landscape suggests a significant, social, and shared practice between households.

This thesis is divided into seven chapters. Chapter 2 provides a historical background on Fort Vancouver, the Village, and tobacco use. Chapter 3 discusses the theoretical approach of the analysis involving practice theory and spatial patterning in the archaeological record, as well as the research questions. Next, Chapter 4 outlines the materials under analysis, the archaeological background of the artifact assemblages, and methods of analysis including the use of Geographical Information Systems (GIS), and 
approaches to answering the research questions. The results of the analysis are presented in Chapter 5, detailing the patterns found in the spatial distribution of the tobacco pipe artifacts. Chapter 6 discusses the results of the study and Chapter 7 summarizes conclusions based on the results. 


\section{Chapter 2: Historical Context}

This chapter establishes the historical context of the study. A history of the Village site is first provided. Next, a brief history of tobacco consumption is outlined, as well as the history and manufacture of clay pipes. This is followed by an explanation of the economic role of tobacco in the fur trade and its related significance for people involved in the fur trade. Finally, a description of tobacco consumption practices, and related attitudes, of cultural groups at Fort Vancouver is provided to address potential variation in consumption behaviors.

\section{The History of the Village}

The Village formed ca. 1827, a few years after the establishment of the Fort Vancouver in the spring of 1825 (Merk 1931:124). Earlier, the Hudson's Bay Company (HBC) was established in 1670 (Rich 1958: 53), trading in Eastern Canada around the Hudson's Bay. This British fur-trading venture expanded over the next 130 years, and merged with their rival trading company, the Northwest Company, in 1821. Through the merger, the HBC gained new territory in the Pacific Northwest (Burley 1997:5; Erigero 1992a:3). This area included the region known as the Columbia Department (Figure 1). Within this department, the HBC established Fort Vancouver (hereafter referred to as the Fort) on the north shore of the Columbia River. The Fort served as the Columbia Department headquarters beginning in 1828 (Erigero 1992a:7). The scope of this study precludes a detailed history of the HBC and establishment of Fort Vancouver, which may be found in other works such as: Burley (1997); Erigero (1992a); Hussey (1957); 


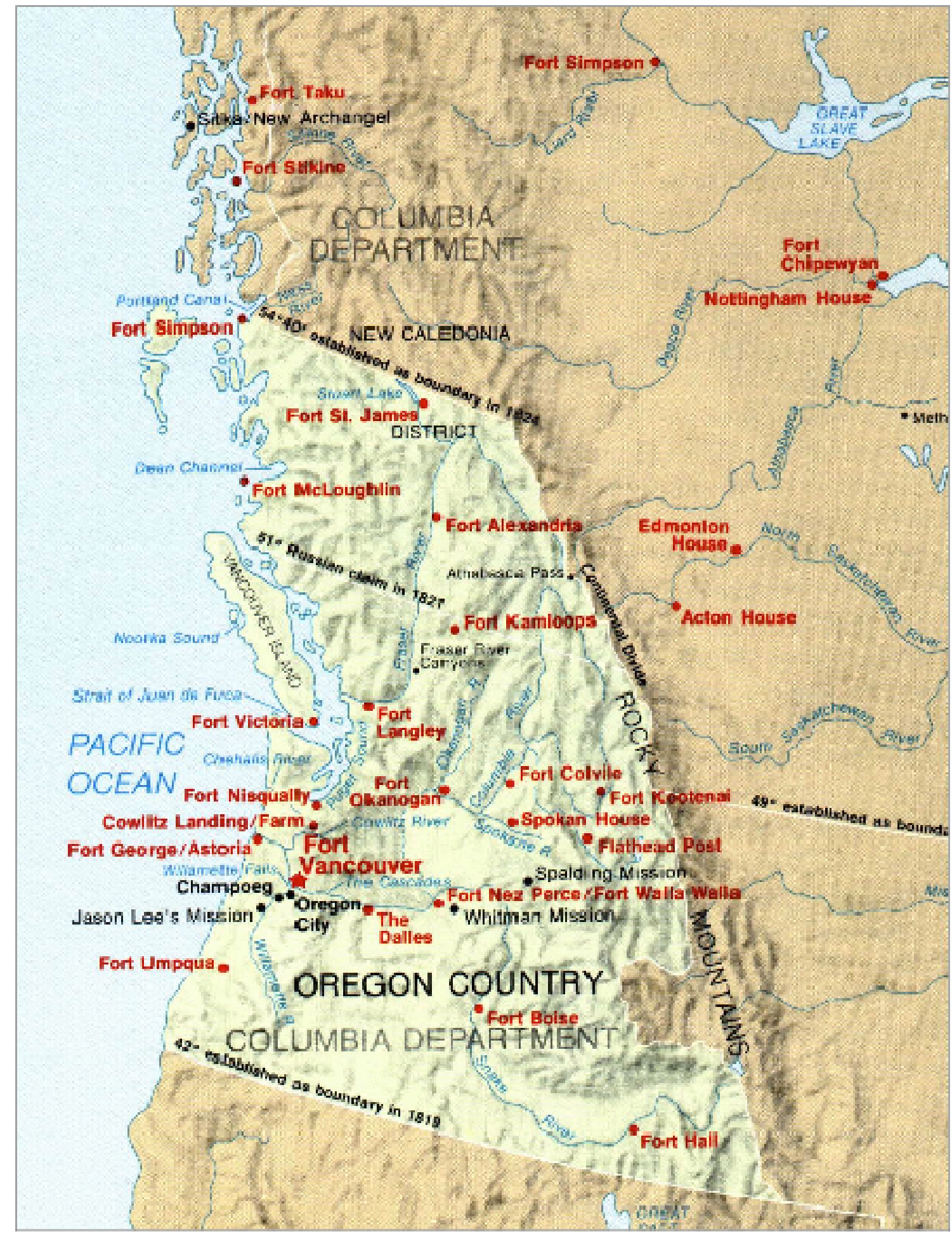

FIGURE 1. Hudson's Bay Posts, Settlements, and Military Posts in the Columbia Department (Courtesy of Fort Vancouver National Historic Site) 
MacKay (1938), Merk (1931); and Rich (1958). The Village site (45CL300) is currently located within the Fort Vancouver National Historic Site in Vancouver, Washington (Figure 2). The original boundaries of the Village stretched from the northern bank of the Columbia River northward to an HBC road located close to the present-day East 5th Street, westward to modern Interstate-5, and eastward to a fence line that stood roughly $860 \mathrm{ft}$. (262.1 m) west of the Fort palisade (Cromwell 2006:41). An estimated 40-60 structures stood in the Village area, possibly ordered in rows along streets, until its destruction in 1860 (Hussey 1957:217-219; Townsend 1839:189).

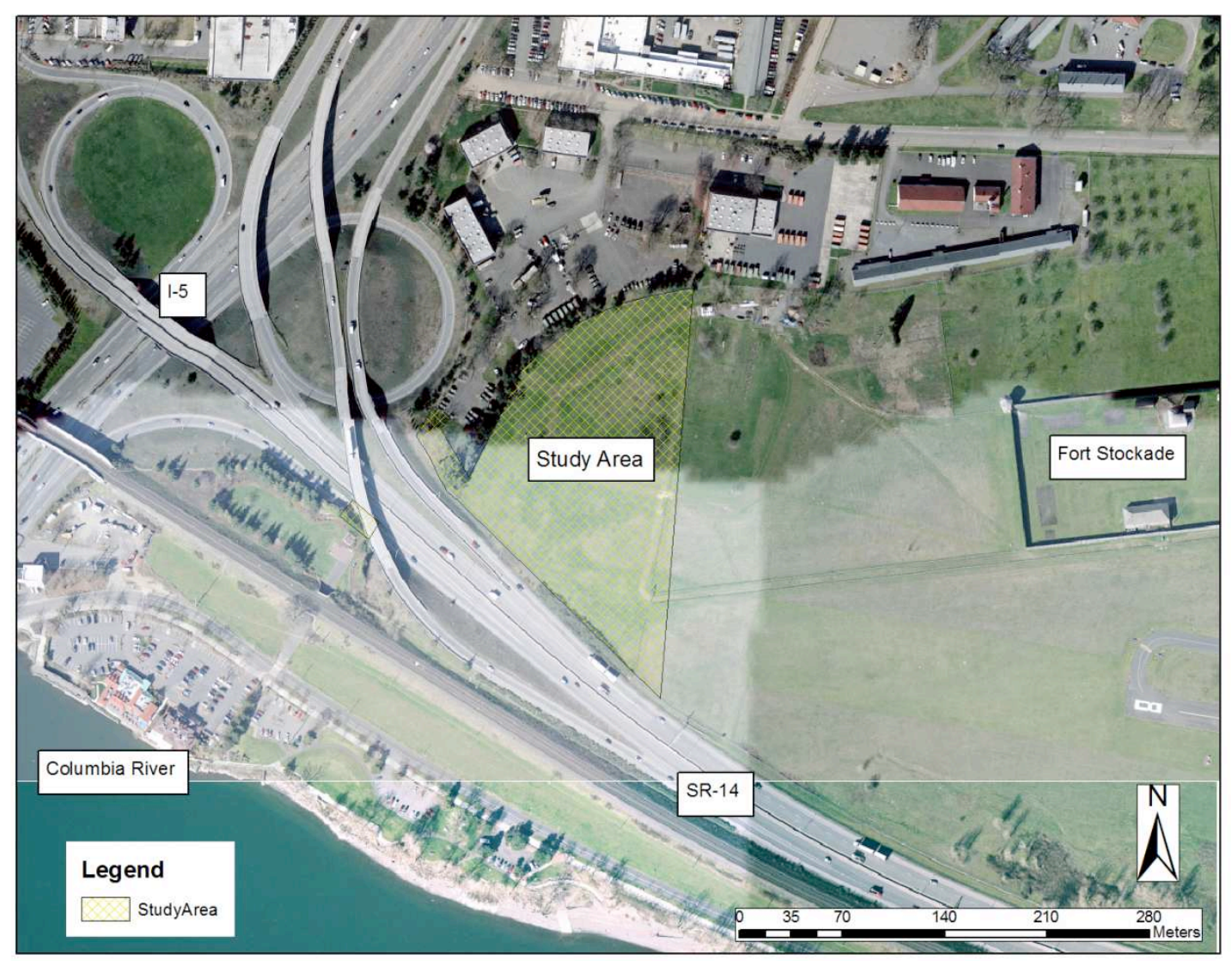

FIGURE 2. The Study Area on the Modern Landscape (Map by author, 2013)

Employees built houses in the Village area as early as 1827 (Hussey 1957:217), 
and certainly by 1829 when the Fort was moved from a terrace to a lower plain adjacent to the Columbia River (Thomas and Hibbs 1984:30-31). Only the high ranking gentlemen, and their families, were allowed to live within the Fort palisade (Cromwell 2006:84-85; Hussey 1957). Other employees were required to find housing outside, many building their homes to the west of the Fort palisade. The earliest recorded mention of the area dates to 1832 with John Ball observing employees residing in "little houses outside the fort" (Powers 1902:98). The houses were home to male employees, their wives, and children, forming a multi-ethnic community.

Historical accounts and maps present the possibility of ethnic neighborhoods, or clustering, within the Village (Thomas and Hibbs 1984). The 1846 Covington Map (Figure 3) displays houses labeled with the owners' names. These names can be attributed to different ethnic groups and, following this assumption, group together by ethnic affiliation. Further, William F Crate, a former millwright at Fort Vancouver, described the Village as follows: "In the lower town was a street for Canadians, and one for Kanakas, and one for English and Americans. Most of the English and Americans were spotted around, above and behind the fort" (British and American Joint Commission 1865-1869[2]:108). These lines of evidence may indicate residents held some sort of ethnic identity and behaved in culturally prescribed manners. However, it is difficult to track such neighborhoods if they existed through time. Historical maps of the area suggest the layout shifted over time, likely reflecting changes in personnel. Additionally, most, if not all, wives of the employees were of Native American or Métis decent, and the children of such unions were considered Métis, blurring cultural lines within households. 


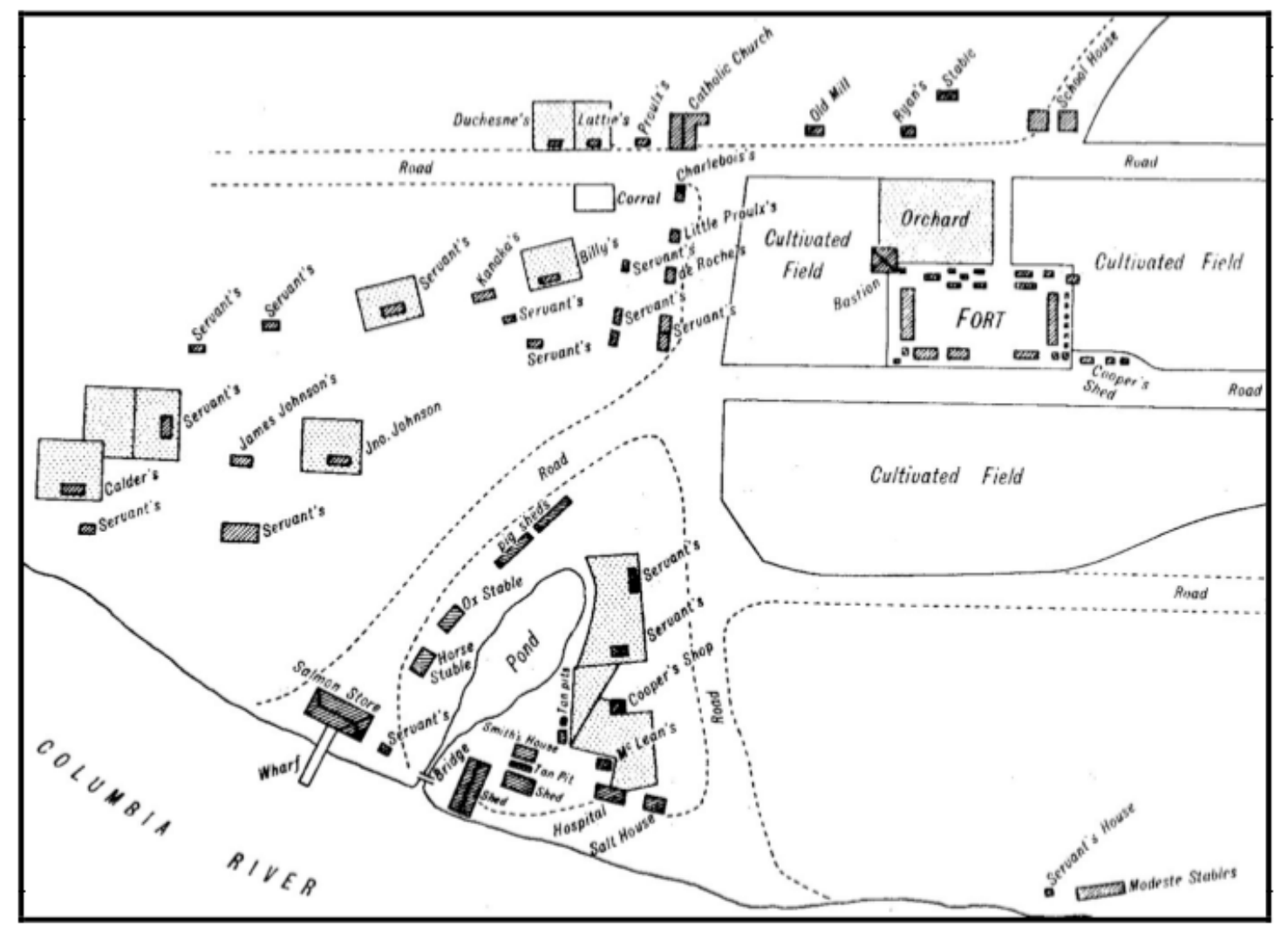

FIGURE 3. The Village in 1846. Based on a drawing by Richard Covington in the Hudson's Bay Company Archives (Photocopy courtesy of Fort Vancouver National Historic Site.)

The population of the Village rose and fell with the extent of operations and the power of the HBC (Cromwell 2006), but exact numbers are unknown. Historical documents more often record male employees than their wives or children, providing an inexact count that must be estimated by other means (Thomas and Hibbs 1983; Kardas 1971). At its peak in the early 1840 s, over two hundred male employees are listed (Towner 1984), and it is estimated the Village contained 600-1000 people (Cromwell 2006). This range includes employees who came and went on brigade, seasonally shrinking and swelling the population. In the 1850s employee numbers declined significantly (Cromwell 2006:66) but the large proportion of Hawaiians in the Village at 
the time earned it the lasting name of "Kanaka Village" (Thomas and Hibbs 1984:31). Hawaiians were just one of the many ethnic groups present at Fort Vancouver.

The people in the Village represented various ethnicities over its history. These include male employees of Scottish, Orcadian, English, Irish, Métis, French-Canadian, Iroquois, Cree, Hawaiian and Native American decent (Cromwell 2006; Erigero 1992; Hussey 1957). Employees' wives came from local Native American groups, as the HBC encouraged such marriages for trade relations (Kardas 1971:130-132). In total, over thirty Native American groups are represented in historical documents, including both employees and wives of employees. Warner and Munnick (1972) report Native Americans from the following ethnohistoric groups: Cascades, Californian, Carrier, Chaudieres, Chehalis, Chinook, Clallam, Cowlitz, Grande Dalles, Iroquois, Kalapuya, Kholtl, Klickitat, Mowatwos, Nisqually, Rogue, Shasta, Snohomish, Spokane, Tillamook, Tsnoomus, Umpqua, and Walla Walla. Other affiliations of wives, listed in Catholic Church records of burials, marriages, and baptisms include the Kathlamet, Kalama, Clatsop, Clackamas, Snake, Nez Perce Okanogan, Pend Oreille, Saulk, Yulate, and the Cayuse (Towner 1984:793-811). The Village community made Fort Vancouver one of the largest, and most diverse settlements of the region in the 1830s and 1840s (Wilson 2010).

Company records demonstrate Village inhabitants performed a variety of jobs (Towner 1984). Business at Fort Vancouver included the fur trade as well as agricultural and industrial pursuits. A shift away from fur trading and toward the other operations occurred throughout 1829-1846 (Erigero 1992a:9). Crops and livestock were raised in fields surrounding the Fort, providing food for the employees and additional articles for 
sale. Other operations included a sawmill and salmon fisheries. Millwrights, coopers, interpreters, steersmen, and general laborers were just a few of the occupations listed (Cromwell 2006:85). General trends in occupations and ethnic groups are seen in the company records (Towner 1984:797). French-Canadians and Iroquois performed primarily water-based jobs, while Hawaiians and Europeans tended toward terrestrial positions.

The HBC often recruited employees based on supposed characteristics of their nationality and their skills, real or imagined. Orkney Islanders were thought to be suited for the fur trade because of the harsh climate of their homeland and because their hierarchical society meant they were easily subordinated (Burley 1997:3). FrenchCanadians and Iroquois were valued for their canoe skills, making excellent voyageurs (Burley 1997:76; Jameson 2007; Roulstone 1975:33). While Hawaiians were valued for their small boat skills (Rogers 1993:40), they were employed in other tasks as well; they were seen as cheap labor, suited for "common drudgery" (Burley 1997:95; Roulstone 1975:34). Native Americans from the surrounding areas were often hired seasonally for agricultural work (Roulstone 1975:35).

A hierarchical system ranked employees by their job (Ross 1976:7), dictating wages, cost of items at the store, and place of residence. The lower servant class was the most ethnically diverse group (Thomas and Hibbs 1984:791-811), leading to a degree of ethnic segregation at Fort Vancouver. The elite Scottish and English employees of the gentlemen class, along with their Native American or Métis wives and children dwelled inside the stockade. All others were relegated to the outside, forbidden within the walls after dark (Hussey 1972:135). For the company there was a general sense of an ethnic 
hierarchy with Europeans at the top, then French-Canadians, followed by Hawaiians, and finally Native Americans at the bottom (Cromwell 2006:85, figure 14; Roulstone 1975:37). Additionally, the Native American heritage of the wives and children crossed these ethnic divisions, while also providing new divisions, such as those of gender. However, self-understanding and senses of belonging to a group can differ significantly from external categorization (Brubaker and Cooper 2000). Village inhabitants' views of themselves did not necessarily coincide with the HBC classification.

Little is known about the lives of the lower class at Fort Vancouver. The majority of Village residents were illiterate, leaving virtually no written record of their experiences. Some details can be gleaned from $\mathrm{HBC}$ records and observations left by outside observers.

Historical accounts of cleaning and maintenance activities in the Village suggest some wives kept their households to European American standards but other residents did not, possibly maintaining their ethnic behaviors. John Kirk Townsend provides one insight on daily routines in the Village from his visit in 1834. Comparing the community to his native Philadelphia, he states: "the most fastidious cleanliness appears to be observed; the women may be seen sweeping the streets and scrubbing the door-sills as regularly as in our own proverbially cleanly city" (Townsend 1839:189). However, later he would note: "after inspecting the internal economy of the dwellings what at first struck me as neat and clean...soon revealed itself in its proper light, and I can freely confess that my first estimate was too high" (Townsend 1839:189). Hussey (1977:51) notes various witness accounts of Native American and Métis wives in the Village as neat housekeepers, while another visitor in 1845 stated that the Native American wives could 
not be persuaded to adopt European housekeeping practices. Nearby in the Willamette Valley, Father J.B. Bolduc stated in 1845 that the Native American wives of Canadian men had "no proper knowledge of how to keep a household in order" (Hussey 1977:51). These women likely came from the same Native groups as wives in the Village, suggesting the existence of similar household maintenance behaviors that did not match European American practices. Variation in the maintenance behaviors of wives in the Village likely existed, through continuation of original practices and/or the adoption or creation of new practices.

Stone's (2010) research into employee records suggests lengths of residency in the Village may have created Village-wide behavioral norms, but the constant population flux possibly allowed for exchange and maintenance of individuals' practices. The average length of residency in the records for an individual is 2.4 years (Stone 2010:104). The short stays exposed residents to new people with a variety of behaviors, but also potentially allowed individuals to avoid any long-term changes to their behavior (Stone 2010:118-120). Conversely, "there were some residents that stayed for a long time...In other words, given a few residents who would 'anchor' the social community there probably was a community 'feel'” (Stone 2010:104). Longtime residents possibly formed behavioral norms for the community, while short-term residents periodically brought other practices into the Village, depending on their origin. These origins would have included places like: another fur trade post, a brigade, a Native American village, or a ship, each potentially influencing practice at Fort Vancouver. 


\section{The History of Tobacco Consumption}

To understand tobacco smoking at Fort Vancouver, it is helpful to consider its historical context. The following is a brief history of tobacco consumption up through the time of Fort Vancouver.

People in the Americas used tobacco for at least 4000 years, if not longer, prior to European contact (Goodman 1993:3; Pettigrew 1990:520; Rafferty 2004:2; Rafferty and Mann 2004:xi). The five primary consumption methods were smoking, chewing, inhalation, enemas, and drinking (Goodman 1993:33). The native peoples used tobacco for medicinal and ceremonial purposes. Tobacco use by indigenous peoples is thought to have possibly produced hallucinations (Goodman 1993:25; Janiger and Dobkin de Rios $1973,1976)$. In these altered states, some users believed they communicated with supernatural forces (Von Gernet 1988:7). Tobacco was also ceremonially offered to spirits through burning or placing it on the ground (Paper 1988). Medicinally, people implemented tobacco for all treatment stages from diagnosis to remedy (Goodman 1993:27). The specific practices of groups involved with Fort Vancouver will be discussed later in this chapter.

Among the results of Columbus' trip in 1492 was the introduction of tobacco to Europe, and in less than 150 years tobacco consumption spread worldwide (Winter 2000a:3). In the late 1500s, native groups and settlers in the Americas began growing tobacco in large quantities turning it into a lucrative commodity, with significant quantities reaching European markets in the 1590s (Norton 2008:11, 148-156). By 1630 tobacco was available almost everywhere in the world (Goodman 1993:52). People consumed tobacco from Spain to Japan, even reintroducing Nicotiana tabacum to native 
North Americans (Nassaney 2004:130). After the mid-17th century, almost anyone with the desire could obtain tobacco.

Soon after its introduction to Europe, Europeans associated tobacco with gatherings, causing it to become "a uniquely social substance" (Norton 2008:159, 183). People grouped around tobacco in taverns, inns, in the street, and even elite social settings. Social use was also coupled with beliefs of health benefits. Positive effects associated with the hot and dry characteristics of tobacco according to the humoral theory of the human body helped to fuel tobacco use (Goodman 1993:85). However, not all Europeans saw tobacco in an optimistic light.

Despite its early sociability and popularity, some of the first opinions of tobacco were negative. King James's (1616) A Counterblaste to Tobacco, is one example of the early medical arguments against tobacco, describing it as harmful to the user's lungs and brain. Medical dissections found blackened lungs in the bodies of habitual users as early as 1682 (Chamberlayne 1682:23). Into the 17th century tobacco was sometimes associated with beliefs of indigenous American paganism and vice, and also mistaken as a form of henbane, connecting it to witchcraft and the devil (Norton 2008:61, 86). Tobacco remained a popular drug despite the efforts of its opponents, perhaps in part because of its addictive quality.

The fashionableness of smoking tobacco fluctuated through time. Documented by Europeans in the late 15 th and early 16 th centuries, smoking was one of the earliest recorded consumption techniques, and became one of the popular methods throughout the world (Walker 1977:51). It was the most common form of consumption until the 18th century (Goodman 1993:70-73). In 1682, Chamberlayne (22) states, "the [native] 
Virginians were observ'd to have Pipes of Clay before ever the English came there, and from those Barbarians we Europeans have borrow'd our mode and fashion of smoking." Snuff soon gained primacy in most of Europe in the late 17th and early 18th centuries (Cleland 1840:32) as a sign of propriety as it was first used by royalty and clergy, and as a panacea according to medical beliefs (Goodman 1993:75-81). People continued to smoke, especially in the lower classes, and it slowly regained favor through the 19th century. Respectability was regained in the second half of the century (Walker 1977:261). Conversely, colonial America preferred smoking and then shifted to chewing tobacco in the 19th century (Goodman 1993:92). However, pipe tobacco was the cheapest form, maintaining popularity with lower classes in America up to the Civil War (Jacobstein 1968). Expensive snuff and cigars were used mostly by the upper classes. Cigarettes were rare before the mid-19th century in both Europe and North America, not gaining popularity until the 20th century (Goodman 1993:93, 98-99).

Two issues in the 19th century affected beliefs surrounding tobacco consumption. Debates over the health effects of tobacco led to scientific testing, which reconfirmed 17th century findings of the poisonous quality of what is now known as nicotine, and anti-tobacco groups formed in the United States and Europe (Goodman 1993:115-117). Medicinal use of tobacco declined in this period because of the shift away from the humoral view of the human body (Goodman 1993:85). Tobacco became a purely recreational drug for many European cultures.

It is important to recognize that addiction to tobacco is a significant factor in the history of its human consumption. Addiction likely played a part in the domestication and spread of tobacco throughout the Americas (Winter 2000), and its quick spread 
throughout the world (Goodman 1993:59). Today it is known that the nicotine in tobacco can lead to addiction and the chemical changes it causes in the body can produce feelings of well being and alertness (Goodman 1993:6). These factors surely negatively affected the ability and desire of a user to stop consuming tobacco. Additionally, it was not until the 20th century that the detrimental health effects of tobacco were widely accepted (Whelan 1984). It is unlikely that negative health effects and addiction were concerns for the majority of tobacco users until recently.

\section{Clay Tobacco Pipes}

Clay pipes were some of the earliest tobacco delivery devices manufactured in Europe. Their manufacture began in London around the 1570s and spread through England and into Holland amongst other countries (Goodman 1993:64-65). Thousands of pipe manufacturers were in business by the mid-1600s in Europe (Trubowitz 2004:146). Workshops were eventually opened in the United States (Pfeiffer 1982) and Canada in the 19th century (Von Gernet 1988:285).

One of the first mass-produced items before the Industrial Revolution (Fox 2000:62), clay pipes were cheap, fragile, disposable, and produced and sold by the gross (Von Gernet 1988:284). They are often erroneously referred to as "kaolin" pipes, but were in fact manufactured from white ball clay, not kaolin clay (Trubowitz 2004:146). The pipes were produced using two-piece molds to form clay into pipes (Crossley 1990:281). A wire threaded through the stem portion created the bore, and a stopper was forced into the bowl to form its interior (Crossley 1990:281). After drying, the pipe was fired in a kiln. The mouthpieces of some stems were coated with brown or green lead glaze or dipped in red wax for around one inch up the stem (Hume 1970:302). 
The shape of clay pipes varied through time. Bowls began relatively small, short, and barrel-shaped in the 17th century, shifting to a conical shape at the end of the century. This bowl form continued through the end of the 19th century (Bradley $2000: 114,116)$. The size of the conical bowl, and "the obtuseness of its angle to the stem," generally increased through time (Bradley 2000:116). The length of the stem also increased through time, but a range of lengths were manufactured for differing purposes. Pipes started with shorter stems, averaging 3.5 in. $(8.9 \mathrm{~cm})$ in the late 16 th century, lengthening to an average of $13-13.5 \mathrm{in} .(33-34.3 \mathrm{~cm})$ in the first half of the 18 th century (Hume 1970:296). By the second half of the 18th century there were pipes as long as $2 \mathrm{ft}$. $(61 \mathrm{~cm})$, but shorter pipes measuring 9 in. $(22.9 \mathrm{~cm})$ were available (Hume 1970:296297). In the 19th century, pipe stem lengths reached up to 33 in. $(83.8 \mathrm{~cm})$, however long pipes were primarily used by the upper class seated in places like taverns (Walker 1977:13-14). Shorter length pipes could be smoked while moving around and working, often clenched in-between the teeth, and were thus favored by the average pipe smoker (Walker 1977:14). Apperson states (1914:162), “In the [eighteen] 'fifties the pipes smoked were mostly clays. There were long clays, or 'churchwardens,' to be smoked in hours of ease and leisure; and the short clays- 'cutties'- which could be smoked while a man was at work." Additionally, after the 1780 s, a type of pipe with a short stem, referred to as a "Virginia" pipe was specifically made for export to America (Jackson and Price 1974:83). However, the authors did not mention the exact proportions of this type of pipe.

Various aspects of clay pipes can be used to date the artifacts, serving as chronometric devices for sites. Makers commonly marked the pipes through stamping or 
as part of the mold, allowing archaeologists to trace the origin and date of pipe fragments found at sites (Hume 1970:304-305). Archaeologists have also used the bore width of pipe stems for dating. J.C. Harrington (1954) found pipe bore stems regularly reduced from 1620 to 1800 in an assemblage from sites in the US and England. Binford (1978) built from Harrington's findings, creating a regression formula to determine the date of manufacture from the stem hole diameter. However, Binford also found that this method is unsuccessful with pipes manufactured after 1780 as bore widths begin to widely vary (Binford 1978).

\section{The Role of Tobacco in the Fur Trade}

Tobacco played a significant role in the fur trade as a highly valued trade good and as a medium through which traders forged relationships. Further, employees consumed tobacco, likely keeping morale high and easing long, arduous workdays through the effects of the drug. The commonality of tobacco amongst virtually all players made it an inseparable aspect of the fur trade. Tobacco was part of business, daily life, and perhaps provided a shared practice between a diversity of people.

From the start, tobacco played an important role in fur trading as a trade good and a ceremonial aspect of exchanges. The first Hudson's Bay Company ships carried tobacco for trading in Northern Canada in the 17th century, two hundred years prior to Fort Vancouver (Von Gernet 1988). Native groups were the main source of furs for the fur trading companies, and they desired tobacco for exchange. A quote from fur trader Alexander Ross shows the continued relevance of tobacco for the fur trade in the 19th century in the Pacific Northwest. He stated: "smoking...is the introductory step to all important affairs, and no business can be entered upon with these people before the 
ceremony of smoking is over" (Ross 1855:75). Ross comments on his experience with Native Americans in the Pacific Northwest ca. 1811-1825 when he worked for the Pacific Fur Company, the Northwest Company, and the Hudson's Bay Company. He suggests tobacco was necessary for the business transactions that were vital for the company's operations.

Chief Factor McLoughlin's letters attest to the significance of tobacco for trade at Fort Vancouver. During the first few years at Fort Vancouver, tobacco was in high demand for trade and the Fort often ended up short at the end of the year (McLoughlin 1941:1, 27). In July of 1828, Chief Factor John McLoughlin (1941:56) wrote to the Governor and Committee saying, our Inventories of the Spring are so much less than anticipated that we are deficient in many articles for supplies to Servants \& the Indian Trade...I have sent a list of the most Indispensible articles (particularly Tobacco) to York Factory I hope it will be found practicable to assist us.

The quality of tobacco was also important at Fort Vancouver. In 1843, Sir George Simpson recommended switching from carrot tobacco to a plug tobacco that was less expensive to ship for future supplies (McLoughlin 1943:164). McLoughlin objected, fearing no one would purchase the plug tobacco as it was inferior in quality. Fort Vancouver had to compete with American traders who brought superior tobacco from the United States (McLoughlin 1943:164). Without quality tobacco, Fort Vancouver could not successfully navigate fur trade relationships.

Although not often emphasized, tobacco also played a role after the furs were obtained from trade partners. At Fort Vancouver, the leaves of the tobacco plant were 
used as an insecticide (Dorset 2012). Placed among fur bales, insects that might otherwise harm the furs ate the leaves instead and consequently died. Tobacco not only facilitated the acquisition of furs, but also protected the furs during transport.

Trade partners were not the only tobacco consumers in the fur trade. Employees were frequent users as well. Caywood (1955:60) notes: "Tobacco was one of the most important items in the fur trade economy. From the accounts of some of the trappers and traders it appears to have become one of the few luxuries in the lives of the Indians as well as the whites." Voyagers in particular eventually measured distances on canoe trips in "pipes" (Nute 1931:50). A "pipe" referred to the distance covered between rests, around 4-5 miles, during which they smoked tobacco (Ross 1856: 19). Tobacco usage was a shared practice for fur trade employees and trade partners.

Employees at Fort Vancouver could purchase tobacco and clay pipes (Figure 4) at the Fort's sale shop. Three main types of tobacco were available: plug tobacco for chewing; roll, twist, or carrot tobacco for pipe smoking; and snuff for inhalation through the nose (Ross 1976:799, 801). The high frequency of tobacco pipes uncovered at Fort Vancouver attest to the popularity of tobacco smoking, however the usage of chewing tobacco and snuff leaves little evidence in the archaeological record. Import records list five different types of clay pipes imported into the Columbia Department: Hunters clay, Long clay, 18 inches, Negro, and Dutch pipes (Ross 1976:804). Unfortunately, it is unknown whether these were true exclusive types, or merely descriptive terms, and thus cannot be correlated to pipes found archaeologically. The cost to the company in 1832 for a clay "hunters pipe" was 0.3968 pence (HBCA B223/d/2b). In the 1844 inventory, a single "hunters clay pipe" cost 0.1875 pence (HBCA B223/d/155). For tobacco, the 1832 
inventory lists leaf tobacco at 3.94 pence per pound (HBCA B223/d/2b). Leaf tobacco listed in 1844 cost 5 pence per pound (HBCA B223/d/155).

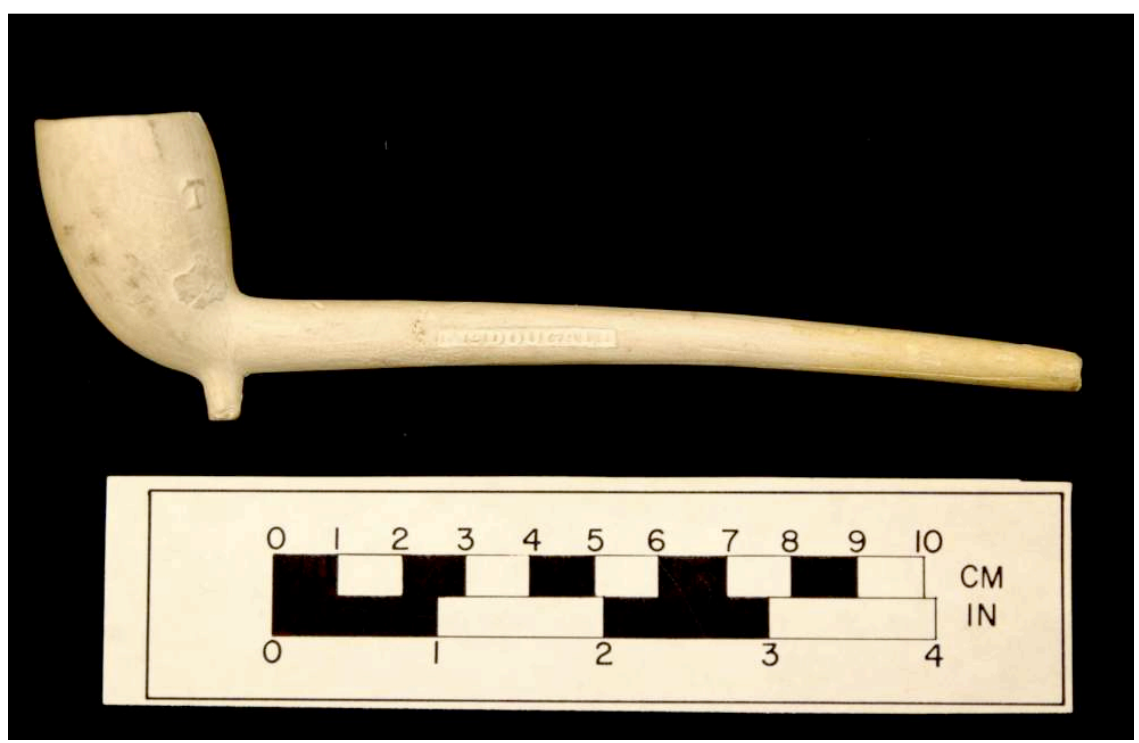

FIGURE 4. An Intact, Late 19th Century Clay Pipe Similar to those from the Village Site (Photo by author, 2013)

The price paid by an employee would vary depending on their sociocultural status. They were charged the cost to the company plus a percentage (Hussey 1972:190191, Ross 1976:149-150). Servant class employees were charged an extra 50\% on imported goods, while Native Hawaiians were charged an extra 200\%. In 1844, Village employees would thus pay about one pence for two or three pipes, and 7.5 to 15 pence for a pound of tobacco.

Smoking breaks were a scheduled activity in the workday at Fort Vancouver. One half-hour break occurred between 9:00 AM and 1:00 PM, and a second in the midafternoon (Roulstone 1975:135-136). These were likely welcomed respites in a day that began at dawn and continued until 6:00 PM, Monday through Saturday. Various historical accounts record tobacco smoking accompanying social activities as well (Roulstone 1975). For employees, smoking tobacco, or at least the opportunity, was part 
of their daily work routine, and possibly their leisure time. The abundance of clay pipe fragments and stone pipes in the Village suggest tobacco smoking was a significant part of daily life for the residents.

Von Gernet's (1988) study of the transculturation of the tobacco pipe smoking complex suggests fur traders exploited the meanings already held by Native Americans about tobacco to their advantage. For various native groups, tobacco was a valued substance used to cement alliances, a medium to communicate with the spirit world (Von Gernet 1988), an important medical agent (Goodman 1993), and/or consumed outside ceremonial contexts (Von Gernet 1995). Taking advantage of these connotations, fur traders and other Europeans more easily achieved their goals in North America by utilizing tobacco. Further, Von Gernet (1988:245) suggests the common usage of tobacco provided a kind of shared "language and humanity" between Native Americans and Europeans. The practice crossed cultural boundaries between the otherwise differentiated groups. Evidence suggests that a similar implementation of tobacco occurred at Fort Vancouver in their business transactions with trading partners. Instead of focusing on trade relations, this study examines the use of tobacco amongst fur trade employees. It is possible that tobacco acted as a shared practice between the ethnically diverse Village residents, as Von Gernet suggests for Native Americans and European trade partners.

\section{Tobacco Consumption Practices of Sociocultural Groups at Fort Vancouver}

Similarities and differences in opinions and behaviors toward tobacco consumption by varying sociocultural groups at Fort Vancouver are expected to pattern the archaeological record. The great cultural diversity at Fort Vancouver provides an almost endless number of ways to divide the population, for example, by age, occupation, 
status, etc. Instead, the author will discuss the more basic divisions often addressed in anthropological studies: gender, class, and ethnicity. The background provided above gives a general idea of the social context European employees perhaps brought with them to the Village. However, other ethnic groups, gender divisions, and class distinctions need to be considered. Information regarding tobacco use by a selection of the most prevalent ethnic groups at Fort Vancouver, men vs. women, and different classes is provided below.

For most if not all Village residents, tobacco smoking was a known activity before they arrived at Fort Vancouver. Involvement with the fur trade, precontact practices, and previous introduction to the plant familiarized individuals with tobacco and pipe smoking. They brought unique experiences to Fort Vancouver, including varying behaviors and views associated with tobacco smoking. The commonality of the practice might have eventually provided a shared behavior that crossed cultural boundaries of the Villagers. Dunn (1845:145) observed at Fort Vancouver:

The voyageur and the trapper, who have traversed thousands of miles through wild and unfrequented regions; and the mariner, who has circumnavigated the globe, may be found grouped together, smoking, joking, singing, and story telling; and in every way banishing dull care till the period of their again setting out for their respective destinations arrive [emphasis added].

Tobacco smoking behaviors could provide an opportunity for differentiation or connection. 


\section{$\underline{\text { Hawaiians and Tobacco }}$}

Although not native to Hawaii, tobacco was growing in Hawaii prior to the establishment of Fort Vancouver. In 1809, Campbell observed tobacco growing "in abundance on the [main] island" (1822:135). He also saw Hawaiians smoking tobacco with pipes composed of vine, iron, ivory, and hardwood. Later in 1820, missionaries noted tobacco growing in the gardens around natives' houses in Honolulu (Wynndette 1968). By the 1830s and 40s tobacco was a major export (Wyndette 1968:142, 174; Broeze 1988:110) but ultimately failed to provide a base for the Hawaiian economy (Hussey 1962:39).

One historical account regarding Hawaiians and tobacco in the Pacific Northwest comes from Gabriel Franchére (1969:75), a clerk associated with Astor's Pacific Fur Company in the early 1800s. Franchére observed Hawaiian employees leaving tobacco as part of a grave offering of a fellow Hawaiian in 1811 near Cape Disappointment. Rogers (1993:70) comments, in his thesis on Hawaiians in the Pacific Northwest, that Franchére's description of the burial is “identical to the form of traditional burial practice." This event suggests the possibility that some Hawaiians in the Pacific Northwest integrated tobacco into traditional practices. The Hawaiians that arrived at Fort Vancouver at least knew of tobacco and the practice of smoking, if they did not partake in the practice.

\section{$\underline{\text { Pacific Northwest Native Groups and Tobacco }}$}

At least some, if not many, Pacific Northwest Native groups consumed tobacco prior to European contact. Stone smoking pipes have been found throughout the Pacific Northwest region at pre-contact sites (Mitchell 1990:345, 351; Paper 1988:12; Ross 
1990:556; Suttles and Lane 1990:495). Other traditional consumption methods are believed to be dissolving pellets of tobacco and lime in the mouth on the Northwest Coast (Linton 1924:99), chewed or inhaled as snuff amongst the Tlingit (De Laguna 1990:224), and mixed with lime and chewed on the northern Oregon coast (Suttles 1990:24). Various groups cultivated tobacco as well; often being the sole cultivated plant (Ross 1990:573; Suttles 1990:24; Zenk 1990:548). Recent residue analysis (Tushingham et al 2013) provides evidence of tobacco smoking on the southern Pacific Northwest Coast by at least $\mathrm{AD} 860$.

Evidence from the fur trade period, as well as later ethnographies, support common use of tobacco amongst Native American groups of the Lower Columbia. Lieutenant William Broughton prophetically stated in 1792 that tribes of the Chinookan family "took great pleasure in smoking our tobacco...it might become a valuable article of traffic amongst them" (Vancouver 1798:770). These groups became some of the main trading partners of early maritime and terrestrial traders in the region, including Fort Vancouver, and its predecessor Fort Astoria/George (Kardas 1971). Broughton described the pipes he observed as an elbow type with a stem of elderberry wood two feet long with a bowl of decorated hardwood (Vancouver 1798:770). Other ethnographically recorded tobacco pipes include carved steatite pipes (Rubin 1999:214). Broughton observed the Chinook smoking what he called a local herb. It may have been kinnikinnick, as Lower Chinook are ethnographically recorded smoking the plant (Ray 1938:97). Other leaves smoked by native inhabitants, along with tobacco, include bearberry, manzanita, dogwood, madrona, salal, and the back of the red willow (Rubin 1999:213). 
Later European accounts of the Chinook also record the presence of tobacco. When Lewis and Clark arrived in the area in 1805 , the Chinook they encountered had tobacco in their possession. They noted that the Chinook were "excessively fond of smoking," and Lewis and Clark traded for a pouch of native produced tobacco during their journey (Thwaites 1959:299, 336). By 1825 David Douglas found Native Americans along the Columbia cultivating tobacco in soil enriched with ash to enhance its growth (Douglas 1904:269-270). The Chinook traded their tobacco with the other tribes when they traveled to The Dalles (Winters 2000b:25).

Tobacco also held religious value and ritual significance to groups of the region. The Clackamas are recorded to have associated tobacco smoking with spirits, and users who smoked without a spirit's command would suffer negative consequences (Jacobs 1958: 507). As he traveled through the Pacific Northwest, Douglas carried tobacco with him to trade for assistance, describing it as "the currency of this country and particularly scarce...therefore almost invaluable" (Douglas 1904:347). Smoking played a ceremonial role as well, as Dunn (1845:73) records for the Native Americans of the Lower Columbia: "smoking rites precede every matter of great importance; and sometimes they are politic." As mentioned above, Alexander Ross also noted the significance of smoking to important meetings for native peoples of the region.

Thus, it is likely that individuals from native Pacific Northwest groups arriving at Fort Vancouver were familiar with smoking and tobacco. Pre-contact practices included smoking various plants, use of stone and wooden pipes, and various other forms of tobacco consumption. At the time of contact and during the fur trade, native groups of the region considered tobacco as a valuable commodity, and the act of smoking a significant 
part of important affairs. Trade relations introduced clay pipes and evidence of their use is found at contact-era village sites such as Middle Village (Wilson et al 2009) and 45SA11 (Minor et al 1989), along with stone pipes.

\section{Métis and Tobacco}

Another cultural group represented at Fort Vancouver were the Métis, descended from the unions of European American traders and native North American wives. There were already Métis families in the region prior to the establishment of Fort Vancouver as a result of earlier fur trading by the Pacific Fur Company and the Northwest Company (Pollard 2003:58). Considering themselves neither European American nor Native American, the Métis formed a separate cultural identity (Pollard 2003:59). Métis were also involved in the fur trade in Canada, associated with the Red River Colony (Burley 1997). It is believed that some wives in the Village may have come from Red River (Hussey 1977:81) However, Pollard (1990:xviii) states that these were not identical cultures as the fur trade culture in the Columbia District was more maritime based rather than terrestrial.

Historical information on Métis tobacco practices in the region is scant. This may be because of the general lack of recording everyday behaviors, especially those considered “inferior." References can be made to the Red River Métis, however as Pollard cautions, it is too simplistic to assume their cultures were identical. One similarity between these groups was their high levels of mobility. Pollard (1990:80) mentions that for mobile fur trade Métis families in the Pacific Northwest, it was impractical to own many possessions. This may have resulted in a preference for stone pipes rather than carrying numerous clay pipes, as appears to be the case for Red River Métis. At their 
wintering sites, clay pipe fragments are rarely uncovered, in contrast to a few stone pipes and pre-forms (Burley et al 1992). This is thought to reflect the demands of seasonal mobility that made transporting numerous fragile clay pipes impractical. Another reference to smoking behaviors in the Red River Settlement comes from Alexander Ross (1957:94-95), who describes an entire family, father, mother and child, sharing a tobacco pipe. Likely influenced by the behaviors of their parents and the fur trade culture, Métis individuals may have seen tobacco smoking as a behavioral norm, associated with recreation and/or symbolic importance. However, exact practices and opinions concerning tobacco consumption from the historical record remain uncertain.

\section{$\underline{\text { Iroquois and Tobacco }}$}

The Iroquois culture group has perhaps one of the longest known histories of tobacco use of the many cultures present in the Village. Pipes of ceramic and stone are often found at precontact Iroquoian sites as early as AD 1300 (Tuck 1971:64). Early European observations included descriptions of Iroquois with pipes constantly in their mouths (Von Gernet 1995:70). Tobacco played a vital role in ceremonial and spiritual contexts. Smoking is recorded as an important activity for the dealings of the Iroquois League of Five Nations, which formed around the late 16th century (Jameson 2007; Kuhn and Sempowski 2001). Pipes accompanied various meetings, councils, and other gatherings (Von Gernet 1982). Tobacco smoking allowed the Iroquois to communicate with the Great Spirit as the smoke carried their needs up into the sky, and during the Maple Ceremony helped cleanse sins (Jameson 2007:28, 31). De Cost Smith recorded that the Iroquois smoked native North American tobacco, rather than the European imported variety, to help to ensure the success of hunting trips in 1889 (Rutsch 1973:25). 
Change to Iroquoian smoking practices undoubtedly occurred through time. The establishment of Fort Orange in 1624 made European clay pipes available for the first time to the Iroquois (Von Gernet 1988:286). Other goods obtained from Europeans, like beads, led to new embellishments in Iroquois effigy pipe designs (Richter 1992:81). Around the 18th century, the Iroquois adopted a new tobacco practice related to the fur trade. As they began to partake in the western fur trade, the Iroquois adopted the calumet ceremony from the Great Plains for alliance and trade (Blakeslee 1981; Rutsch 1973). The term calumet refers to a highly decorated pipe stem attached to a pipe bowl that is presented and smoked when groups came together (Turnbaugh 1979). For Plains Indian groups during the protohistoric/historic period, the smoking of the calumet allowed a period of peaceful trading between people who were otherwise enemies (Brown 1989:314). Trubowitz (2004:158) suggests that for the region of eastern North America, the persistence of native forms of pipes despite the incorporation of other European technologies reflects the importance and survival of sacred themes of the pipe/tobacco/smoking complex. Smoking tobacco with a calumet pipe thus became an important aspect of the fur trade for the Iroquois. For the Pacific Northwest, Jameson (2007) suggests that stone pipes found at fur trade sites mark the presence of Iroquois employees.

The long history of tobacco use by the Iroquois and their involvement in the fur trade, as individuals and as a culture, influenced their views and uses of the substance. Nevertheless, continuity often accompanies change (Silliman 2009). Thus, the possible ceremonial use of tobacco by Iroquois in the Village, contrasted to more recreational behavior, was considered when examining differential patterning in the archaeological 
record.

\section{Class and Tobacco Smoking}

Information on socioeconomic differences in tobacco consumption in the 19th century suggests general tendencies. Pipe tobacco was the cheapest form, thus favored by the lower classes (Jacobstein 1968:42). Snuff and cigars were more expensive, used by those who could afford the cost. As mentioned above, snuff was also associated with respectability. Smoking on the other hand, Apperson (1916:156) suggests, was seen as a vice to those of Victorian sensibilities. Despite these negative views, "popular British tobacco customs of the day primarily consisted of the taking of snuff and the smoking of pipes, but cigars were also becoming popular and among the lower economic classes, an occasional chew was tolerated" (Ross 1979:799). In general, smoking and chewing were associated with lower classes, while snuff and cigars were considered more upper class.

According to the inventory records of Fort Vancouver, snuff was the most expensive form of tobacco, followed by twist, roll and plug at a similar value, then carrot, followed by leaf tobacco (HBCA B223/d series). Cost may have placed some forms of tobacco out of the price range of lower paid workers, especially snuff tobacco. Clay tobacco pipes were not cost-prohibitive as an employee could buy two or three pipes for a pence at the Fort's Sale Shop. Both the gentlemen and servant classes smoked pipes according to the historical and the archaeological records. Thus, smoking tobacco at Fort Vancouver may not have been as strongly associated with class than in other European American settings. Class is not examined in the analysis as the Village site represents one class within the $\mathrm{HBC}$ hierarchy, but a few comparisons are made to smoking locations within the Fort stockade. 


\section{Gender and Tobacco Smoking}

Although interpretations at Fort Vancouver often associate tobacco smoking with men (Stone 2010), this study assumes at least some women in the Village smoked as well. Smoking was increasingly associated with masculinity by Europeans in the 19th century, however evidence is murky on differences in actual consumption rates between the genders (Goodman 1993:106). Smoking was previously an ungendered practice in Europe and European colonies in the 17th and 18th centuries, as literary references and paintings depict women smoking without any negative connotations (Goodman 1993:62$63,106)$. Attitudes toward female smoking in the 19th century at the very least appear to be negative. A Dr. Henry W. Cleland, in 1840 (18-19), wrote in a medical essay on tobacco that he cannot be convinced that European women smoked in the previous centuries, despite a number of historical accounts that he cites. Apperson states (1916: 156): "By the nineteenth century, the use of tobacco had become an accepted custom among most European American males. Tobacco was smoked, inhaled and chewed; but generally not in the presence of women. During the Victorian era, smoking was considered a social vice, to be done in inconspicuous places and not too publicly." Additionally, while the wives of Andrew Jackson and Zachary Taylor are known to have smoked pipes in the White House, smoking became unpopular for women as time passed in the 19th century (Whelan 1984:36).

The wives in the Village however were of native or Métis descent. Archaeological and historical evidence from the region suggests both Native American men and women practiced tobacco smoking, before and during the HBC-era (Stone 2010:158-159). Prior to the establishment of Fort Vancouver, Ross Cox, a trader with Astor's Pacific Fur 
Company, records that a son of Chief Concomly proposed marriage to the first European woman to visit the Columbia, promising that she would never have to work, and that she would "be allowed to smoke as many pipes of tobacco during the day as she thought proper" (1957:157). This suggests the Chinook did not hold negative opinions about women smoking, and that the practice was viewed positively. Smoking tobacco was a practice associated with a leisurely life and could be offered in persuasion. However, women in the Village may have been pressured to conform to the European American ideals of their husbands. One anecdote from historical documents records Pierre Pambrun's attempt to end his wife's smoking habit at Fort Vancouver:

Catherine smoked a pipe, as many pioneer women did. Pierre wanted her to give it up, but she couldn't seem to do so. He made a trip to England, and when he came back he brought a pair of diamond ear-rings. "These are for you," he said "if you give up smoking." She tried, but the habit was too strong, and the ear-rings were laid aside. (Warner and Munnick 1972:A-37)

Both men and women at Fort Vancouver smoked tobacco, thus the pipe artifact assemblage is assumed to reflect the behaviors of both genders and is not examined in this study for differential spatial patterning.

\section{Summary}

At the time of the establishment of the Village, smoking tobacco was a prevalent practice and clay pipes had been used for hundreds of years. Tobacco was a vital substance for the fur trade, utilized in forging trading relationships and obtaining necessary goods. Employees and others involved with Fort Vancouver likely held 
previous knowledge and experience of tobacco consumption. The HBC further enabled its use through trade relations, as a product for trade, as a good available for purchase by employees, and as part of employees' daily routines through their smoking breaks.

Despite the commonality of consuming this addictive substance, the ethnic backgrounds of employees and their family members potentially influenced their behaviors surrounding tobacco consumption. Generally, tobacco was a recreational and social substance for Europeans, while for native groups the plant had other ceremonial and spiritual connotations. One common delivery device for tobacco was the massproduced European white clay pipes. They were an inexpensive, disposable product and were available for purchase at the Fort's sale shop. In contrast to clay pipe usage, researchers suggest stone pipes are hallmarks of Métis and Native American tobacco consumption in the fur trade. As will be outlined below, their use and deposition provide a spatial record of past behaviors in the Village. Class and gender were not focused on for this analysis, as these behavioral differences were not expected to be visible through the methods used in this study. 


\section{Chapter 3: Theoretical Approach}

This chapter explains the theoretical approach of this study. First, the use of practice theory to examine daily behaviors in the archaeological record is discussed. Considered next are the concepts underlying the use of spatial analysis and the processes leading to spatial patterning in tobacco pipe fragments. Recent approaches to cultural contact and ethnic identity are summarized, with specific examples from fur trade archaeology. These are then compared to the approach of this study. Finally, the research questions of this study and expectations are outlined.

\section{Practice Theory}

The majority of Village residents were illiterate, leaving virtually no written evidence of their daily lives at Fort Vancouver. We know little about their behaviors and practices from historical documents except for what can be gleaned from brief observations. However, historical documents tend to omit details of daily life in general. As Deetz (1996:11) states "people doing simple things... are not the kinds of things anyone thought worthy of noting." Archaeology of the historical period can serve to fill this gap by providing information on daily activities (McGuire 1982). Archaeology uncovers physical evidence of these past behaviors otherwise left in obscurity. Practice theory is an anthropological approach that correlates well with this role for historical archaeology.

Focusing on daily practice, practice theory examines how individuals both reproduce and change their societal norms through their everyday actions (Ortner 2006). Bourdieu (1977) introduced the term habitus to conceptualize the influence of cultural 
worldviews on peoples' actions. An individual's daily behaviors, or habits, are predicated on their understanding of how to act within their society. This can exist at a less conscious level, but also at a more intentional level as in Ortner's (1996) serious game concept. Social actors have goals like survival or advancement. To succeed, actors must play by the rules, or their societal norms, of the game. Struggles over conflicting goals and the power relations within the games can result in resistance and change.

Societal norms and worldviews are potentially visible in the archaeological evidence of daily practices. Re-occurring activities create a great deal of the material culture in the archaeological record (Lightfoot et al 1998:201). However, it is more than just a simple record of past activities. An individual's habitus influenced their use of material culture and subsequently how it was deposited in the archaeological record. Archaeologists uncover materials that facilitated the social practices that both structured and at times were created by agents' actions (Barrett 2001:156-157). Through these practices, especially those that occurred daily, people made sense of their lives (Deetz 1996; Lightfoot et al 1998; Barrett 2001). An examination of the archaeological record can find past activities, and possibly hint at the ideology behind practices.

\section{Spatial Analysis}

One way to look at behaviors associated with the use of objects is through spatial analysis of artifact distributions. Early spatial archaeological work in the late 19th century and early 20th century looked at the locations of objects to define cultural complexes and the distribution of sites to examine social and settlement patterns (Clarke 1977:2-3). In the 1970s it became apparent that there was information in the spatial relationship between things rather than just within things, corresponding with an interest 
in these relationships (Clarke 1977:6; Hodder and Orton 1976). Seibert (2006:xiii) sums up the discipline's history with spatial analysis as:

spatial analyses of archaeological remains are as old as the discipline itself, as the context and provenience of artifacts have been recorded in excavations of archaeological sites since the beginnings of modern archaeology....In these early examples of archaeological research concerned with space, the spatial arrangements of artifacts, features and architecture were recorded with functional interpretations in mind, but were not conceived of as being the key to either sociocultural systems, as the later functionalist and processualist archaeologists believed, or imbued with multifaceted sociocultural meanings, as many postprocessual archaeologists believe.

Today there are numerous theories, methods, and statistical tests to study spatial distributions and draw information from their relationships.

More recent archaeological work continues to use spatial analysis to explore past behaviors (Hietala 1984; Kent 1990; Robertson et al 2006; Robinson 1994). Replicated behaviors in particular are more likely to leave behind visible detectable evidence, and are perhaps more important to understanding life in the past than any one single event (Kent 1990). These include such activities as: knapping, which creates a buildup of lithic debitage (Carr 1991), the cleaning of activity areas (Hutson et al 2007), and the deposition of refuse in middens (Beck and Hill 2004). Patterns left by regular practices do not allow archaeologists to find single occasions, but show the larger picture of site use. 
Spatial analysis can find patterning that reveals how occupants utilized the area around them and subsequently their conceptions of space. Patterning in use of space is indicative of the organizational principles of individuals' ideologies (Lightfoot 1995). Conception of space influenced the performance of daily activities, especially appropriate locations or settings. Acceptable refuse disposal areas are one example, dependent on cultural ideals like cleanliness, and distances between garbage and living areas (Beck and Hill 2004: 328; Crane 2000, Wilson 1994). Activities can take on different meanings in different settings as well (Rapoport 1990). For instance, an activity carried out in a more visible, public area like a yard can potentially convey a symbolic message (Heath and Bennett 2000). Artifacts with spatial distributional patterns can point to regular behaviors predicated on sociocultural beliefs.

\section{$\underline{\text { Spatial Patterning and Tobacco Pipes }}$}

Archaeologists often utilize clay tobacco pipes as chronological measures through stem bore diameters and maker's marks (Binford 1962; Deetz 1996; Harrington 1954; Mallios 2005). While the dates that stem-bore diameters and maker's marks provide are certainly instructive, clay pipes can provide other types of information. Rafferty and Mann (2004:xiv) suggest that the emphasis on the chronometric aspects of clay pipes have been at the expense of behavioral and cultural studies of tobacco use. A few studies support the analysis of clay pipes beyond chronological information, finding information on trade histories (Pfeiffer 1982), socioeconomic changes (Fox 2002), and subversive political acts (Hartnett 2004). Bradley (2000:104) states:

The cheap, fragile, and expendable nature of clay pipes...coupled with the character of the smoking activity which generally deposited discarded 
pipes where they were consumed, have combined to produce an extensive record from which to draw valuable insight into the social lifeways and material consumption patterns of past cultures.

This artifact type is suited for spatial analyses as its disposable nature, and behaviors surrounding its use, often created patterning in the archaeological record.

Clay tobacco pipes are well suited for spatial analysis for multiple reasons. The pipes became one of the first mass-produced items before the Industrial Revolution and are thus quite common at sites around the world (Fox 2000:62; Walker 1977:3). People treated clay pipes as disposable items. They had a short use life, as little as three days, because of their fragile nature (Fox 2002; Pfeiffer 1982). Subsequently, pipe fragments were more rapidly disposed of and deposited into the archaeological record than many other artifact types. Users broke pipes accidently, but also purposely by snapping off a part of the stem. In some instances, pipe stems were shorted to increase delivery of nicotine (Davies 2011:93). Archaeological evidence suggests that some users continued using their pipes with broken stems by filing or grinding down the broken edge to reshape it into a mouth piece (Hume 1970:302). Because of the long stem on pipes, smokers could continue using a pipe after breakage of stem pieces. Finally, fired clay preserves well in the archaeological record (Fox 2002:62), reducing the chance of deterioration that would lead to unrepresentative assemblages of pipes used at a particular site. These factors add up to create a valuable source of information at historical sites.

Previous researchers inferred that high concentrations of clay pipe fragments often indicate smoking and refuse locations. These sites range from Port Royal, Jamaica (Fox 1998), seventeenth-century Galway, Ireland (Hartnett 2004), the Hyde Park 
Barracks in Sydney Australia (Davies 2011), and the Grant/McLeod wintering fur trade station in Saskatchewan (Hamilton 1990). One characteristic of clay pipe smoking is the discard of pipe fragments in the location where they were consumed (Bradley 2000:104). As the fragile pipes broke, the pieces were discarded on the ground, creating concentrations of fragments, especially as the same area was used repeatedly. Pipe fragments are also found at refuse disposal areas (King and Miller 1987; Pogue 1988). At the van Sweringen site, a late 17th century and early 18th century household in Maryland, King and Miller (1987) used the spatial distribution of pipe stem fragments to examine refuse practices. Using the stem-bore diameter measurement formula to date the pipe stem fragments, they were able to track changes over time in use of space, including changing perceptions on the acceptable locations for refuse disposal. Unfortunately, pipes manufactured after ca. 1780 do not fit the stem-bore diameter formula (Binford 1962), so this method cannot be applied at 19th century sites like Fort Vancouver.

Regularly used smoking locations are assumed to contain higher densities of pipe fragments with use wear, based on findings of a few previous studies (Davies 2011, Pfeiffer 1982). But as Pfeiffer (1982) suggested over thirty years ago, other researchers do not appear to give this aspect of clay pipes much emphasis, rarely mentioning signs of use wear in their studies. Use wear on pipe fragments include blackening from burning especially on the interior of bowl fragments, and wear on one end of a pipe stem fragment from prolonged use or reshaping of the mouthpiece after a stem broke. More intensely used pipes will have staining on the bowls from the absorption of tobacco oils and tars into the clay (Bradley 2000; Davies 2011). Relying on fragments with use wear has at least one issue: not all fragments from a used pipe will display use wear. For 
instance, from the author's personal observations, not all fragments from a used bowl will display the blacking on the interior side from burning. Additionally, Davies (2011: 92) mentions the possibility of clay pipes whitening when buried in the ground, or burned in a fire. The use of multiple pipe assemblage characteristics to determine smoking locations in this study helped to mitigate this issue.

Another characteristic of smoking locations is posited by the work of Ritchie (1978), which mapped the ratio of bowl fragments to stem fragments to show where pipes were regularly used and the level of mobility in a population. The bowl of a clay pipe is essential for function, while pieces of a stem can be broken and discarded without affecting functionality. Bowl fragments then will then theoretically be deposited at a lower frequency than stem fragments that were often removed from a pipe's stem at the user's whim. Additionally, stem fragments from the same pipe could be spread across multiple locations if the user was not restricted to one location. It is thus expected that in areas where smoking occurred regularly or more frequently, more bowl fragments would be deposited through time, resulting in a more equal deposition of bowl and stem fragments. Ritchie determined a ratio of one bowl fragment to two stem fragments based on the historically documented size of a clay pipe of the post-1780 era (stems averaged 68 in. long) and the mean sizes of bowl and stem fragments found on his sites (Ritchie 1978: 135). A location with this ratio has equal deposition of bowl and stem fragments, indicating more regular use of the area for smoking.

Stone smoking pipes are also found at Fort Vancouver (Figure 5 and 6), but may be indicative of different behaviors. Their basic function, smoking tobacco, is identical to clay pipes, however their characteristics significantly vary. Stone pipes are not fragile, 
but durable, and are hand carved rather than mass-produced. Unlike clay pipes, a stone pipe could not be purchased at the sale shop. At least some of the stone pipes at Fort Vancouver are of Native American manufacture (Pierson 2010). As mentioned in Chapter 2, various ethnic groups are recorded using stone pipes including the Chinook, Métis, and Iroquois. Stone pipes may have been associated with their ceremonial uses or as a marker of their culture.

Employees with mobile occupations perhaps favored stone pipes over clay pipes because of their portability and durability. Narcissa Whitman, a missionary in the region during the time period, noted "the custom of the country [is] to possess nothing and then you will lose nothing while traveling" (Pollard 1990:80). One stone pipe would be much easier to carry than a supply of clay pipes. As mentioned above, in the similar fur trade setting of the Red River Métis wintering sites, a lack of clay pipe fragments accompanied by a few stone pipes and pre-forms is thought to reflect impracticality of transporting numerous clay pipes (Burley et al 1992).

The use of stone pipes is more difficult to measure directly in the archaeological record than clay pipe usage. As mentioned above, the use of disposable clay pipes leaves behind a large amount of material evidence in the archaeological record. A stone pipe was likely used for a longer period of time, as it remained functional longer because of its higher degree of durability (Schiffer 1987:48-49). Fewer stone pipes are required over time and are discarded into the archaeological record at a slower rate. The position of a stone pipe in the record may not indicate a use setting as clay pipes are known to indicate, but rather the location of discard or accidental loss. Hamilton (1990) suggests a lack of clay pipes in an area may indicate the usage of stone pipes. While this could serve as an 
indirect measure of stone pipe usage, it might be hard to separate from the signature of an overall lower rate of tobacco consumption.
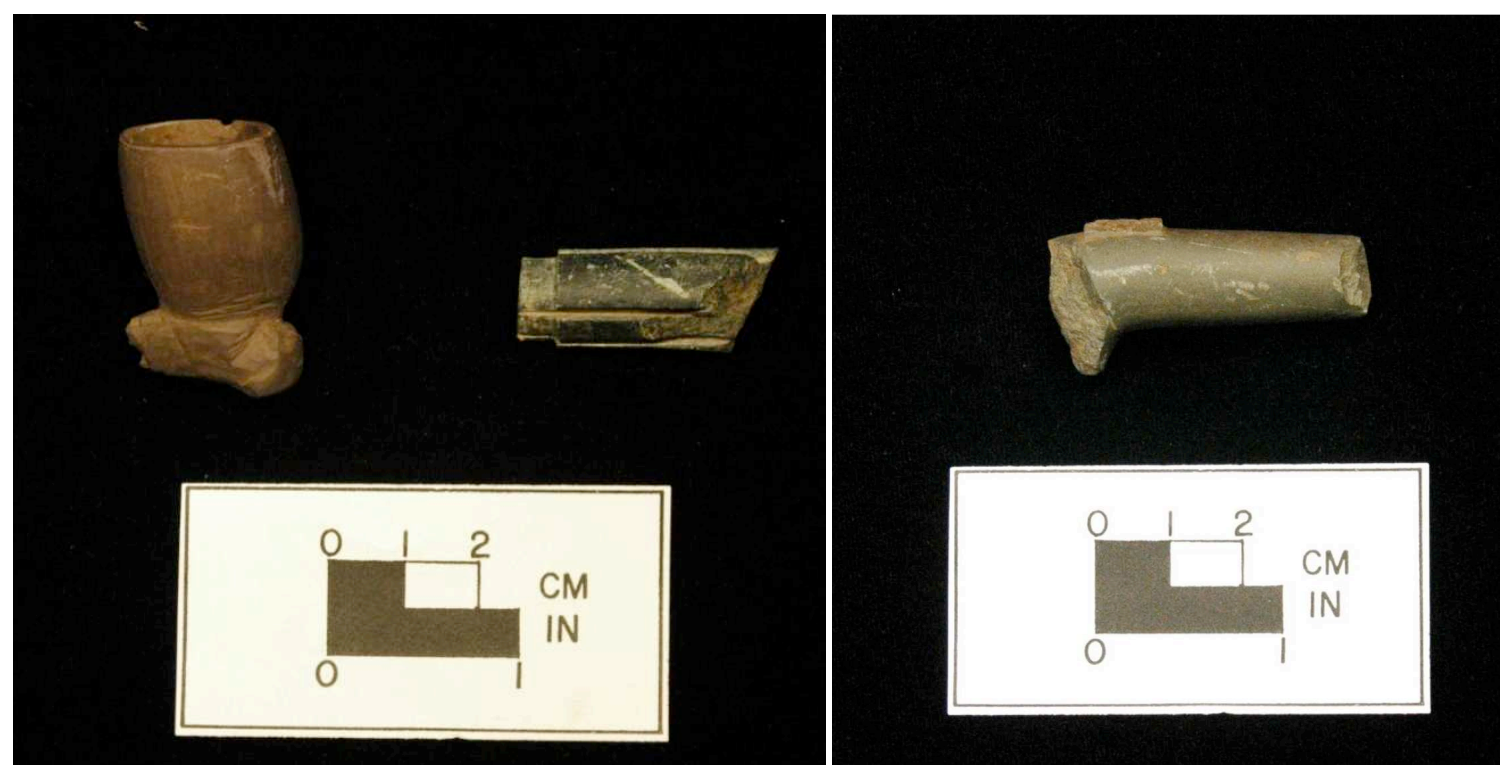

FIGURE 5. Stone Pipe Fragments from FOVA FIGURE 6. Stone Pipe Fragment from 3023, ST 93 and ST 121 (Photo by author, 2013) FOVA 3164, EU C7 (Photo by author, 2013)

\section{Previous Spatial Analyses}

Previous researchers performed limited spatial analysis of tobacco pipe artifacts at Fort Vancouver from particular excavations. These analyses mapped only the pipe fragments counts or frequencies, and did not take into account any diagnostic characteristics of the assemblage such as use wear frequencies or bowl to stem fragment ratios. Clay pipe distributions within the Fort stockade indicated smoking and social gathering locations. The southeast fence corner in front of the Chief Factor's house (Hoffman and Ross 1973:162) and the area around the Sale shop door (Hoffman and Ross 1974:74) had high frequencies of clay pipe fragments. The fence corner was likely a convenient meeting location on the path between the Chief Factor's house and the Bachelor's Quarters. Outside the Sale Shop door, it is thought that buyers smoked while 
waiting their turn to enter the shop. From these interpretations we see some of the behaviors perhaps associated with smoking within the stockade: sociality and passing the time. High concentrations of pipe fragments at the very least evince a commonly used location for smoking, and subsequent deposition of fragments.

Spatial analysis in the Village also focused on the frequencies of pipe fragments. Thomas and Hibbs (1984) examined the distribution of fragment frequencies for each of their operations. At Operation 14, or the John Johnson House, Thomas and Hibbs (1984:250) found pipe frequency distributions were similar to the distribution of all pre1860 artifacts. In some places, the pipe fragment frequencies matched those of smoking locations inside the Fort stockade. Based on the distribution of all artifacts at each house site, Thomas and Hibbs' (1984:726-728) suggest trash disposal behaviors created a surface midden at each house that surrounds the structure. As a consequence, the presence of a house is often signaled by the presence of its midden.

Gembala et al (2004) mapped the spatial distribution of various artifact types, including pipe fragments, using field counts, from the 2001-2003 excavations. Preliminary interpretation found high densities of pipe fragments along roads and near houses (Gembala et al 2004:33). This pattern was found for other 19th century artifacts such as transferprint ceramics and square nails. The present analysis builds on past research by examining the results of multiple excavations across the site and assessing the spatial distributions of pipe fragments in detail by mapping fragment frequencies and other informative characteristics of the pipe fragment assemblage.

\section{Studies of Cultural Interaction in Contact and Fur Trade Archaeology}

In contact and colonialist archaeology, unidirectional acculturation is no longer 
accepted as the automatic outcome of cultural interaction (Lightfoot 1995; Silliman 2009), nor are artifacts viewed as simplistic ethnic markers (Silliman 2005). Instead, the agency of cultural groups to respond to cultural interaction is conceptualized through notions of entanglement (Martindale 2009), ethnogenesis (Voss 2008), and creolization (Wilkie 2000). Fur trade studies in particular, including those at Fort Vancouver, have examined the use of material culture in the negotiation of interaction and assertion of identity (Burley et al 1992; Carlson 2006; Cromwell 2006; Mann 2008; Martindale and Jurakic 2006; Mullaley 2011; Mullins and Bynter 2000; Turgeon 2004), and spatial analysis has found variation in behavior not immediately apparent in similar artifact assemblages (Lightfoot et al 1998; Hamilton 2000). This study builds off of these ideas, viewing tobacco pipes not as ethnic markers but objects used in daily behaviors potentially tied to the negotiation of ethnicity in the multi-cultural Village.

Researchers have created new conceptualizations of relationships in cultural contact and the use of material culture. One concept is entanglement, recognizing the agency of both individuals and communities (Martindale 2009) in the process of cultural interaction in which cultural groups became tied together as they built a shared history of their effects on one another (Thomas 1991; Silliman 2005). In entanglement, objects like European goods were recontextualized into the receiver's culture and given new meaning according to that culture's ideology (Stahl 2002:829). Another alternative to acculturation is cultural creolization, conceptualized as both retention and change. New ideas and objects are adopted, and previous practices and values are expressed in new ways (Ferguson 1992; Wilkie 2000). A third conception is ethnogenesis. As Voss $(2008: 1,3)$ states, "colonial encounters produced conditions under which social identities 
had to be refashioned in response to intercultural contact," a process referred to as "ethnogenesis." New identities are achieved through the use of material practice as "silent tools" to rework their identity (Voss 2008:4). This process can entail the use similar artifacts amongst different cultural groups, but groups can use the objects differently according to their specific worldviews.

The examination of more nuanced uses of material culture in the negotiation of ethnic identity has accompanied this acknowledgement of the varied responses to cultural interaction. Objects cannot be viewed as exact reflections of culture, or ethnic markers, in archaeological studies (Silliman 2005:68). Researchers must look at who used them and how, not just where they came from, as "objects are constituents and proxies of practice, not obvious symbols or meanings without them" (Silliman 2009: 216). This is especially important because the production and maintenance of culture and identity is a complicated, ongoing process that can involve objects of various origins (Silliman 2009; Voss 2008).

Studies of cultural interaction and negotiation of identity in fur trade archaeology have measured persistence and change in a variety of material culture types. Examples include creation of new architectural forms in the Red River Settlement (Burley 2000) and the Great Lakes region (Mann 2008). Among the Haida, trade with Europeans and the introduction of European tobacco led to the creation of carved argillite pipes in forms of both Haida cosmological symbolism and of European motifs (Fladmark 1973; Mullins and Bynter 2000). Diet measured through faunal remains has indicated persistence in food ways in the Secwepemc village site at Thompson's River Post (Carlson 2006) and assertion of different ethnic identities at Fort Michilimackinac (Scott 2001). Additionally, 
researchers have examined the recontextualization of foreign objects into cultural systems. These analyses include the adoption of metal or glass as replacements for antler or lithic technologies (Wagner 1998; Martindale and Jurakic 2006); new symbols of identity such as the use of European ceramic tea wares amongst the Métis (Burley et al 1992) and the use of beads by Native Americans in the 16th century (Turgeon 2004); and symbols of power like a European umbrella as evidence of access to trade for the Northern Tsimshian (Martindale 2009).

In fur trade sites where differential use of material objects is not immediately apparent because of similar artifact assemblages, spatial analysis has found variation in behavior. At Fort Ross, Lightfoot et al (1998) found that despite the prevalence of European objects in interethnic employee households, spatial analysis indicated that Kashaya Pomo women continued their traditional refuse disposal behaviors and the neighborhood layout reflected the traditions of the Native Alaskan men. At 19th century British fur trade posts in western Canada, Hamilton (2000) determined that the distributions of faunal remains and beads indicated differing conceptions of refuse and cleanliness to express status between officers and lower ranking employees in the absence of status items.

Recent analyses of the Village at Fort Vancouver follow this trend in shifting from objects as ethnic markers, to examining more complex uses of material culture. Archaeological excavations in the Village uncovered primarily European artifacts that were available at the Fort's Sale Shop. Thus, some researchers concluded there is little archaeological evidence of the multi-cultural nature of the Village (Chance and Chance 1976; Kardas 1971; Thomas and Hibbs 1984:723). They explained this murkiness of 
cultural indicators by hypothesizing that HBC employees were unskilled in their native traditions, consequently adopting the British/European behaviors of the HBC (Kardas 1971) or that subtle ethnic trends in the archaeological record existed based on problematic assumptions; for instance, Native Americans used more trade beads while Europeans used more ceramic objects (Thomas and Hibbs 1984:23). However, recent research on behavior through ceramic (Cromwell 2006) and architectural analysis (Mullaley 2011) provides new insight into cultural interaction in the Village.

Cromwell (2006) examined the non-pipe ceramic assemblages from the Village to examine consumer choice in the acquisition and use of European ceramics. The artifacts suggest while Village residents used the same types of ceramics as the higher ranked employees, they used vessel forms in different ways (Cromwell 2006). Cromwell (2006:266) infers that Village households commonly utilized inexpensive slop bowls, made for loose-leaf tea, as soup bowls. Whether because of expense and/or disregard for the intended purpose of the vessels in the practice of drinking tea, Village residents used the same ceramic slop bowls as higher-ranked employees, but in their own way.

Mullaley's (2011) analysis of architectural styles in the Village used practice theory to look for community-level relationships in possible differentiation or creolization in vernacular architecture. Early architecture in the Village reflected a common fur trade architectural culture of the French-Canadian "Red River Frame", with later varied changes and enhancements when the Village population shifted (Mullaley 2011:227). The research concluded that architectural attributes in the Village were influenced by many other factors than community social relations, including power relations between the $\mathrm{HBC}$ and employees that restricted the need for new employees to 
build their own homes (Mullaley 2011:232), possibly curtailing expressions of identity through architecture.

This study follows this recent trend in contact studies, examining the use of tobacco pipes not as ethnic markers, but as objects that were used to negotiate identity. The author assumes Village residents left similar objects in the archaeological record primarily because they bought their goods at virtually the only available store in the area shop (Chance and Chance 1976; Hoffman and Ross 1973), without assuming similarity in behavior or acculturation toward European behaviors. There are a few stone pipes recovered from the Village that were not purchased from the sale shop, but were handmade. Hoffman and Ross (1973) suggest that handcrafted objects would likely reflect cultural affinity, but employees were too busy to make items and thus made few of these items. However, assuming that these objects indicate any specific ethnic affiliation is too simplistic.

Village inhabitants possibly exchanged smoking practices, continued traditions through new material objects, or created new practices. In their study of tobacco pipes in Eastern North America, Rafferty and Mann (2004:xiii) emphasize that the function of pipes is not utilitarian as they are drug delivery devices and smoking can alter the user's state of consciousness, making "them ideally suited for addressing a host of ideational issues like symbolism and rituals" (Rafferty and Mann 2004:xiv). The pipes at Fort Vancouver also served these nonutilitarian functions, and while for some the consumption of tobacco was recreational, it could hold more symbolic meaning for others. As a significant part of the fur trade, tobacco use could likewise serve as a symbol of the general fur trade culture (Von Gernet 1988). Ethnogenesis (Voss 2008) may have 
created new meanings associated with the use of similar pipes, providing opportunities for the expression of ethnic difference or similarity as Village-wide norms developed. A shared Village culture may have included similar tobacco smoking behaviors. Further, households may not have used clay pipes in the same locations or disposed of them in the same way, potentially displaying ethnic-specific use of space visible in artifact distribution patterning (Lightfoot et al 1998). Similar use of clay pipes in the Village does not imply a corresponding conformity in smoking behaviors.

\section{Post-Depositional Effects}

Post-depositional effects have the potential to obscure behaviors in the spatial distribution of clay pipes. During the HBC-era, the frequently shifting Village population (Stone 2010) possibly built up a palimpsest of varying behaviors at the site. A multiethnic household might also blur behaviors if conceptions of space and rubbish differed. Later, the US Army rented houses in the Village beginning in the late 1840s (Hussey 1957), creating another layer of tobacco smoking behaviors. As will be described below, every effort was made to separate out the non-HBC context pipe fragments to eliminate the later US Army behavioral patterns. The later destruction of the Village by the US Army likely disturbed the $\mathrm{HBC}$ artifacts as well. However, it is assumed that destruction events would not move pipe fragments as significantly as the displacement of architectural artifacts suggested in Mullaley's (2011) study on Village architecture.

The construction of US Army buildings over the area in the 20th century has unquestionably disturbed HBC deposits. At House 1, the northern portion of the excavation area contained a 20th century debris pit (Larabee and Kardas 1968). This debris pit intruded into the HBC-era stratum in units F4-F5, F5-F6, H0-H1, H4-H5, H5- 
H6, K4-K5, and M4-M5, removing portions of the house and yard. The northern portion of House 5 was disturbed by the foundations of a 1904 granary building (Gembala et al 2004). These intrusions were encountered in units EU 2, 4, 5, 9, 14, 15, 16, 17, 18, and 19, disturbing the HBC-era stratum (Mullaley 2011). Interpretation of the spatial patterning of the pipes took these disturbances into account.

Another force that should be addressed is the effect of abandonment and the presence of defacto refuse (Schiffer 1987). The final abandonment of the Village occurred in 1860, but some houses appear to have been demolished earlier (Mulalley 2011). Inhabitants likely left objects behind when abandoning houses, possibly obscuring daily behaviors. For example, the final abandonment of a house may have left a clay or stone pipe on a house floor that otherwise would have been used and eventually deposited in a smoking or refuse pit location. Such an event would theoretically not produce as many pipe fragments as repeated daily behaviors, thus while defacto refuse may be present, it is not assumed to have a great influence on the final definition of activity areas.

\section{Research Questions}

The author composed three research questions to test the spatial distribution of pipe fragments for evidence of behaviors through patterning in assemblage characteristics. Expectations are based on the results of the few previous studies of pipe fragment distributions, and historical evidence summarized in the preceding chapters.

The research questions and expectations are:

1) Was tobacco smoking a significant and social practice in the Village?

This question has two expectations. The first expectation is: if smoking was a significant practice, then the pipe fragments are expected to show distributional 
patterning of regular smoking locations. Pipe fragments are expected to be clustered in high-density areas, rather than spread uniformly across the landscape. Also, high frequencies of fragments, high frequencies of fragments displaying use wear, and bowl to stem fragment ratios indicative of more regular smoking, are expected to be found in corresponding locations in areas regularly used for pipe smoking. The second expectation is: if smoking was a social practice, then smoking locations should be found in likely social gathering areas. The placement of smoking locations are expected to be in more public areas than private, or hidden, spaces.

2) Is there variation in maintenance behaviors implied by the spatial patterning? Assuming that maintenance behaviors are visible through the size distributions as seen through the Artifact Size Index, two expectations were tested. These expectations are: 1) if a household was performing little to no maintenance, then the pipe fragments are expected to display no size-sorting in their spatial distributions and 2) if a household was performing regular maintenance behaviors, then pipe fragments are expected to be size-sorted into discreet primary and secondary refuse areas.

3) Is there variation in smoking behaviors implied by the spatial patterning that may be tied to ethnic differences?

To test the presence of ethnic variation, three expectations were formed. The first is: if use of stone pipes were tied to Native American or Métis practices in the Village, then a spatial pattern of a lower amount of clay pipe fragments, possibly coupled with the presence of a stone pipe, is expected to be found for households 
with Native American or Métis inhabitants. The second expectation is: if tobacco usage was more strongly tied to religious or ceremonial importance within a household, then a decreased frequency of clay pipe usage is expected than a household that contained a more recreational, habitual use. Finally, if households had vastly different practices in their use of space as related to smoking activities, then smoking activity areas are expected to be variably located in relation to the house structure and surrounding yard.

The methods used to answer the research questions, and the basic characteristics of the assemblage, are described in the following chapter. 


\section{Chapter 4: Materials and Methods}

Historical and archaeological evidence indicate tobacco smoking in the Village was possibly a shared and social behavior, with potential for ethnic variation. A few previous studies found spatial patterning of pipe fragment distributions can indicate cultural and behavioral information. To assess the role of tobacco smoking in the Village and the degree of ethnic variation between households through spatial patterning, three research questions were formed. To test the expectations of the research questions, the study analyzed tobacco pipe assemblages from six archaeological excavations at the Village site (Figure 7). Projects include those associated with academic pursuits and cultural resource management. The details of the excavations are summarized in Table 1. The included number of pipe fragments and excavation units in this analysis are listed by project in Table 2 . The following is a discussion of the projects and why the data were chosen for this study.

\section{Projects Associated with the Study Assemblage}

Excavations in the Village, beginning in 1968, were initiated for different purposes with varying research goals. Academic projects included Kardas and Larabee, the Systemwide Archaeological Inventory Project (SAIP), and the 2010/2011 field schools. Each of these projects was designed around different research questions. As the first excavations in the Village, Kardas and Larabee (1971) excavated to find whether remains of Village houses could be found, using the results primarily for Kardas's dissertation on ethnic relations within the Village. The SAIP project continued excavations on Village houses, specifically Houses 1-3, and the newly discovered House 


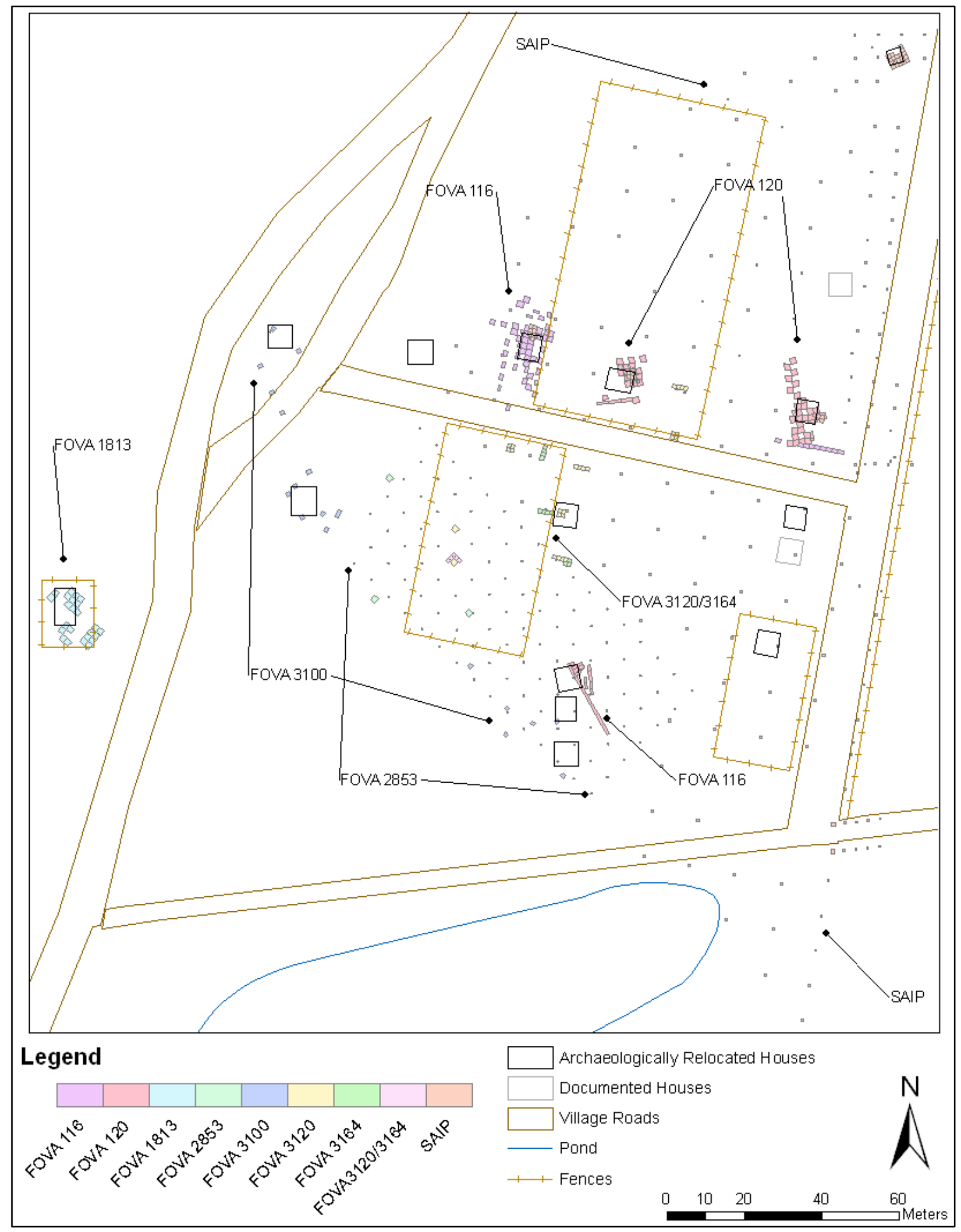

FIGURE 7. Study Area Units (Map by author, 2013) 
5 , and surveyed the NPS owned portion of 45CL300 not previously tested (Gembala et al 2004:40). The 2010/2011field school placed units to uncover House 7 and explore yard space use around Houses 2 and 7, moving from an emphasis on house sites toward use of the landscape and more ephemeral dwellings (Wilson 2010:7-9). The other three projects used in this analysis were construction related excavations. The Washington State Department of Transportation (WSDOT) 1980-1981 project, the Pedestrian Overpass Survey (1993) and the Columbia River Crossing (CRC) 2009 project all carried out excavations in response to potential ground disturbance within 45CL300.

The excavations used a variety of field methods, but general methodological trends can be seen through time. Excavations prior to the SAIP excavations in 2001 employed English units of measurement, used only 1/4 in. $(6 \mathrm{~mm})$ mesh for screening (or did not screen in some cases), and excavated in arbitrary levels of 6 in. $(15.24 \mathrm{~cm})$ with some effort to follow natural strata. Starting with the SAIP excavations, more refined techniques were used for excavation in the Village. Excavators used metric units of measurement and nested 1/8 in. $(3 \mathrm{~mm})$ and $1 / 4$ in. $(6 \mathrm{~mm})$ screens. Excavation units decreased in size, and levels were excavated in natural strata, with arbitrary levels of 10 $\mathrm{cm}$ where the natural strata exceeded $10 \mathrm{~cm}$ in depth.

Depending on the results of each of the projects, this study included a sample of the project's pipe fragment assemblage, or the complete assemblage of the pipe fragments. Kardas and Larabee's work uncovered various features and four HBC-era houses, designated Houses 1-4 (Kardas 1970,1971). Analysis incorporated a sample of the pipe fragment assemblage from the units containing house floors and units within a $15 \mathrm{~m}$ radius of the approximate center of the houses. Some units within this radius were 
TABLE 1 PROJECTS ASSOCIATED WITH THE STUDY ASSEMBLAGE

\begin{tabular}{|c|c|c|c|c|}
\hline $\begin{array}{l}\text { Project/ } \\
\text { Accession(s) }\end{array}$ & Reports(s) & Types of Units & Levels & Screening \\
\hline $\begin{array}{l}\text { Kardas and } \\
\text { Larabee } \\
(1968-1969) \\
\text { FOVA 116, } \\
120\end{array}$ & $\begin{array}{l}\text { Larabee and Kardas } \\
1968 ; \\
\text { Kardas and Larabee } \\
\text { 1970; } \\
\text { Kardas } 1971\end{array}$ & $\begin{array}{l}5 \times 5 \mathrm{ft} .(1.5 \times 1.5 \mathrm{~m}) \\
\text { units; } \\
2.5 \mathrm{ft} .(1.25 \mathrm{~m}) \\
\text { trenches of } \\
\text { varying lengths }\end{array}$ & $\begin{array}{l}\text { Arbitrary } 6 \text { in. } \\
(15.24 \mathrm{~cm}), \text { some } \\
\text { efforts to follow } \\
\text { stratigraphy }\end{array}$ & $\begin{array}{l}\text { 1968: } \\
\text { inconsistent } \\
1 / 4 \text { in. } \\
(6 \mathrm{~mm}) \\
\text { 1969: none }\end{array}$ \\
\hline $\begin{array}{l}\text { WSDOT } \\
(1980-1981) \\
\text { FOVA } 1813\end{array}$ & $\begin{array}{l}\text { Thomas and Hibbs } \\
1984\end{array}$ & $\begin{array}{l}5 \times 5 \mathrm{ft} .(1.5 \times 1.5 \mathrm{~m}) \\
\text { units }\end{array}$ & $\begin{array}{l}\text { Arbitrary } 6 \text { in. } \\
(15.24 \mathrm{~cm})\end{array}$ & $\begin{array}{l}1 / 4 \mathrm{in.} \\
(6 \mathrm{~mm})\end{array}$ \\
\hline $\begin{array}{l}\text { Pedestrian } \\
\text { Overpass } \\
(1993) \\
\text { FOVA } 2853\end{array}$ & Thomas 1993 & $\begin{array}{l}1 \mathrm{ft} .(40 \mathrm{~cm}) \text { diameter } \\
\text { shovel probes; } \\
5 \text { x } 5 \mathrm{ft} .(1.5 \times 1.5 \mathrm{~m}) \\
\text { units }\end{array}$ & $\begin{array}{l}\text { Probes: not } \\
\text { excavated by level } \\
\text { Units: arbitrary } 6 \text { in } \\
(15.24 \mathrm{~cm})\end{array}$ & $\begin{array}{l}1 / 4 \mathrm{in} . \\
(6 \mathrm{~mm})\end{array}$ \\
\hline $\begin{array}{l}\text { SAIP (2001- } \\
2003) \\
\text { FOVA } 2997, \\
3011,3023\end{array}$ & Gembala et al 2004 & $\begin{array}{l}50 \times 50 \mathrm{~cm}(19.6 \mathrm{x} \\
19.6 \mathrm{in} .) \text { shovel tests; } \\
1 \times 1 \mathrm{~m}(3.3 \times 3.3 \mathrm{ft}) \\
\text { and } 0.5 \times 1 \mathrm{~m}(1.6 \mathrm{x} \\
3.3 \mathrm{ft} .) \text { units }\end{array}$ & $\begin{array}{l}\text { Shovel tests: } \\
\text { arbitrary } 10 \mathrm{~cm} \\
(3.9 \text { in.); } \\
\text { Units: by natural } \\
\text { strata, arbitrary } 10 \\
\text { cm }(3.9 \text { in.) levels } \\
\text { when strata } \\
\text { exceeded } \\
10 \mathrm{~cm}(3.9 \text { in.) }\end{array}$ & $\begin{array}{l}\text { Nested } 1 / 4 \\
\text { in. }(6 \mathrm{~mm}) \\
\text { and } 1 / 8 \mathrm{in} . \\
(3 \mathrm{~mm})\end{array}$ \\
\hline $\begin{array}{l}\text { CRC (2009) } \\
\text { FOVA } 3100\end{array}$ & O’Rourke et al 2010 & $\begin{array}{l}50 \times 50 \mathrm{~cm}(19.6 \mathrm{x} \\
19.6 \mathrm{in} .) \text { shovel tests; } \\
1 \times 1 \mathrm{~m}(3.3 \times 3.3 \mathrm{ft}) \\
\text { units }\end{array}$ & $\begin{array}{l}\text { Shovel tests: } \\
\text { arbitrary } 10 \mathrm{~cm} \\
(3.9 \text { in); } \\
\text { Units: by natural } \\
\text { strata, arbitrary } 10 \\
\text { cm }(3.9 \text { in. levels } \\
\text { when strata } \\
\text { exceeded } \\
10 \mathrm{~cm}(3.9 \text { in. })\end{array}$ & $\begin{array}{l}\text { Nested } 1 / 4 \\
\text { in. }(6 \mathrm{~mm}) \\
\text { and } 1 / 8 \mathrm{in} . \\
(3 \mathrm{~mm})\end{array}$ \\
\hline $\begin{array}{l}\text { NPS/PSU/ } \\
\text { WSU-V } \\
\text { Field School } \\
\text { (2010-2011) } \\
\text { FOVA 3120, } \\
3164\end{array}$ & In-progress & $\begin{array}{l}1 \times 1 \mathrm{~m}(3.3 \times 3.3 \mathrm{ft}) \\
\text { units; } \\
\begin{array}{l}5 \times 5 \mathrm{ft} .(1.5 \times 1.5 \mathrm{~m}) \\
\text { re-excavated units }\end{array}\end{array}$ & $\begin{array}{l}\text { Units: by natural } \\
\text { strata, arbitrary } 10 \\
\mathrm{~cm}(3.9 \text { in. levels } \\
\text { when strata } \\
\text { exceeded } \\
10 \mathrm{~cm}(3.9 \text { in.) }\end{array}$ & $\begin{array}{l}\text { Nested } 1 / 4 \\
\text { in. }(6 \mathrm{~mm}) \\
\text { and } 1 / 8 \mathrm{in} . \\
(3 \mathrm{~mm})\end{array}$ \\
\hline
\end{tabular}


excluded because provenience information for the pipe artifacts was unclear. The $15 \mathrm{~m}$ radius inclusion is based on a visual assessment of the artifact density (per $\mathrm{ft}^{2}{ }^{2}$ ) map of the excavations (Kardas 1970:113), in order to include the highest density areas around the houses. Density usually diminishes beyond $15 \mathrm{~m}$, and in many cases, excavation units do not stretch this far from the center of the house. It is not assumed that this method captured all possible activity areas around a house. The author only included this sample of units as supplementary information for the houses because of the sampling biases in Kardas and Larabee's project. Their units were concentrated around the anticipated sites of houses because their project focused on locating houses. Their inconsistent screening of excavated matrix, and use of only $1 / 4$ in. mesh, biased artifact recovery, tending to find only the larger fragments.

A sample of pipe fragments from Operation 14, from the WSDOT 1980-1981 excavations, is included in this analysis. Bryn Thomas and Charles Hibbs uncovered a house in Operation 14 thought to belong to an employee named John Johnson based on historical research (Thomas and Hibbs 1984:111). A sample of 23 units out of 109 is included here, as the vast size of the tobacco pipe assemblage (3737 fragments) precludes its complete inclusion (Thomas and Hibbs 1984:113, 169). Units were selected based on a visual assessment of the clay pipe fragment relative frequency isopleths map (Thomas and Hibbs 1984:251, figure 14-68) that indicated two main depositional areas: one in the house interior and one to the east of the structure, and three smaller clusters of fragments: two to the south of the house and one to the west. The author chose nine units surrounding the high frequency area in the house interior, eight units from the eastern yard depositional area, one unit containing the cluster to the west, and five units 
containing the two clusters to the south. These units sample the high and low-density areas in an attempt to address different kinds of activity areas. As with the Kardas and Larabee project, the screening techniques of the 1980-1981 WSDOT excavations biased the assemblage toward larger pipe fragments and were treated separately from later projects that used nested screens in later analysis.

All pipe artifacts from the 1993 Pedestrian Overpass Survey are included. Thomas (1993:10) placed a $20 \mathrm{ft} .(6.1 \mathrm{~m})$ grid system over the one acre of potential impact to the north of SR-14. While the eastern portion of the area yielded high frequencies of HBCera artifacts, 20th century disturbance negatively impacted the southwestern survey area (Thomas 1993:13,23). The artifacts provide additional information about House 4, two additional dwellings based on high HBC-era artifact frequencies (Thomas 1993:13-16, 22-24), as well as a broad look at the landscape across the area through the shovel probe data. A later analysis of the shovel probe data by Lynch (2009), suggests slightly different locations than Thomas's analysis for additional structures in the project area. These interpretations were considered in this analysis. As with the other two projects mentioned above, the screening technique of this project biased the assemblage toward larger pipe fragments and was treated accordingly.

All of the 2001-2003 units excavated by the Systemwide Archaeological Inventory Project (SAIP), are included here. This project further explored Houses 1-3, excavated a portion of the newly located House 5, identified three other new houses (Houses 6-8) based on artifact density patterns, and surveyed the NPS owned portion of 45CL300 not previously tested (Gembala et al 2004:40). In particular, the testing data provides a uniquely broad view of land use across the site not provided by any of the 
other projects. In the testing, shovel tests were placed on a 6 by $6 \mathrm{~m}$ grid in 2001 and a 12 by $12 \mathrm{~m}$ grid in 2002-2003 (Gembala et al 2004:23). The grid stretched from SR-14 at the south, to the boundaries of the US Army Reserve land to the north and west, and to the fence line at the east thought to represent the historical eastern boundary of the Village . While this spacing was intended to increase the likelihood of encountering houses or the midden of artifacts expected to surround each house (based on the average house size: between 15 and $30 \mathrm{ft} .(4.6-9.1 \mathrm{~m}))$, it also serves as systematic random sample of the site. From this project onward, excavations in the Village used nested $1 / 8$ in. (3mm) and 1/4 in. $(6 \mathrm{~mm})$ screens, resulting in less size-biased assemblages (see Chapter 5 for assessment of differential screening techniques.)

A sample of 19 excavation units from the 2009 Columbia River Crossing project is included here. NPS archaeologists carried out testing in the western and southwestern portion of the Village as part of the response to a proposed new bridge on I-5 across the Columbia river (O'Rourke et al 2010:1). Six of the excavation units (TU 4-01, 02, 03, 04 $10,11)$ encountered intact sediments related to House 4 or another house in the area, identified as House 4B (O'Rourke et al 2010:207). In the western portion of the Village, excavation units in southern part of Testing Area 3 intersected deposits from two separate Village houses (O'Rourke et al 2010:122). These houses are identified on historical maps as the Kanaka House, and the other house as the home of Joseph Tayentas, an Iroquois guide employed from at least 1832-1845 (O'Rourke 2010:101). Thirteen units, out of the total 22 units, from this area contained HBC deposits related to these houses and are included in the study (TU 3-01, 02, 03, 05, 06, 07, 08, 09, 12, 13, 14, 15, 16). These units from the CRC project provide additional information on House 4 and the other possible 
houses in the area first posited by Thomas (1993) and Lynch (2009) hereto referred to as Houses 4+, as well as information on the Kanaka house and Tayentas house.

With the exception of one block of units, this study incorporates the entire pipe fragment assemblage from the National Park Service/Portland State University/Washington State University- Vancouver 2010/2011 field schools. The field schools uncovered a portion of the floor of House 7, a section of the floor of a previously unknown house, and some HBC-era features. At the date of writing, data from the 2010/2011 excavations are still in the process of analysis and interpretation. With the exception of units from Block $\mathrm{J}$, all pipe fragments from the 2010-2011 projects were analyzed for this study. The artifacts from Block $\mathrm{J}$ are almost entirely from the backfill of TABLE 2 STUDY ASSEMBLAGE BY EXCAVATION

\begin{tabular}{|c|c|c|c|c|}
\hline Project & Accession(s) & $\begin{array}{l}\text { Number \& Type } \\
\text { of Units }\end{array}$ & $\begin{array}{l}\text { All Pipe } \\
\text { Fragments }\end{array}$ & $\begin{array}{l}\text { HBC Context } \\
\text { Pipe Fragments }\end{array}$ \\
\hline $\begin{array}{l}\text { Kardas and } \\
\text { Larabee (1968- } \\
1969)\end{array}$ & $\begin{array}{l}\text { FOVA } 116, \\
120\end{array}$ & 129 units & 1668 & 1648 \\
\hline $\begin{array}{l}\text { WSDOT (1980- } \\
1981)\end{array}$ & FOVA 1813 & 23 units & 1879 & 1540 \\
\hline $\begin{array}{l}\text { Pedestrian } \\
\text { Overpass Survey } \\
\text { (1993) }\end{array}$ & FOVA 2853 & $\begin{array}{l}113 \text { probes } \\
5 \text { units }\end{array}$ & 54 & 54 \\
\hline $\begin{array}{l}\text { SAIP (2001- } \\
\text { 2003) }\end{array}$ & $\begin{array}{l}\text { FOVA } 2997 \\
3011,3023\end{array}$ & $\begin{array}{l}171 \text { shovel tests } \\
40 \text { units }\end{array}$ & 902 & 698 \\
\hline $\begin{array}{l}\text { Columbia River } \\
\text { Crossing Project } \\
(2009)\end{array}$ & FOVA 3100 & 19 units & 336 & 336 \\
\hline $\begin{array}{l}\text { Field Schools } \\
(2010-2011) \\
\end{array}$ & $\begin{array}{l}\text { FOVA } 3120, \\
3164\end{array}$ & 42 units & 594 & 523 \\
\hline TOTAL & & 542 & 5433 & 4799 \\
\hline
\end{tabular}


the 1960s excavations near a rock feature and are thus from disturbed contexts. The data from the field school excavations provide information on House 7, the newly relocated house floor between Houses 2 and 3, and the use of land around Houses 2 and 7.

\section{$\underline{\text { Summary }}$}

In total, this analysis examines excavation units containing portions of seven houses, areas surrounding those houses, and a number of units spread across the landscape. These were chosen in an effort to achieve a broad view of the use of space in regards to smoking and refuse behaviors. Both house interior and exterior locations are included, as well as areas that surround features such as fire pits and animal burials.

The screening techniques of the excavations varied, possibly leading to differential recovery of clay pipe fragments. Clay pipe assemblages from the Kardas and Larabee (1970, 1971), Thomas and Hibbs (1984), and Thomas (1993) excavations are likely biased toward larger fragments because of their limited screening or use of 1/4 in. (6mm mesh). Differential recovery was taken into account when exploring the data and performing statistical tests or comparisons of areas subjected to different screening techniques. The author analyzed or re-analyzed all pipe fragments from each of the units selected for the study.

\section{Materials}

The tobacco pipe artifacts in this study are molded clay and carved stone pipes. The molded clay pipes are made from white ball clay, red clay, or porcelain. They are primarily unglazed earthenware, with some of glazed earthenware and porcelain. The stone pipes are carved steatite. A total of 5433 pipe fragments were initially analyzed, 
representing all pipe fragments from units included in the analysis (Table 2). Further analysis of the spatial distribution included only the pipe fragments from $\mathrm{HBC}$ contexts in a unit, yielding a sample of 4799 fragments. Pipe fragments from non-HBC and disturbed contexts were excluded.

A challenge facing this study was separating tobacco pipe artifacts discarded by the HBC employees from those discarded by the US Army. The US Army rented houses in the Village beginning in the late 1840s (Hussey 1957) and used clay pipes similar to those used by the HBC employees. This overlap between the HBC and the US Army creates the possibility that some pipe artifacts included in this study were actually used by the military. Many pipe fragments have no marks, providing no information on date of manufacture. Further, there are only a few makers and designs that can specifically be attributed to either group. Post-depositional mixing is a likely factor as well, because of the reuse and eventual demolition of the houses by the US Army.

The assignment of artifacts to cultural component is further complicated by the variety of project excavation techniques. Excavation of arbitrary levels is assumed to have mixed post-HBC and $\mathrm{HBC}$ period pipe fragments in some unit levels, especially those of the Kardas and Larabee project. The stratigraphic levels within the Village site are problematic as well. There is often one thin stratum representing HBC and/or 19th century US Army deposition that is difficult to completely separate in the field. Consequently, excavators' methods did not separate the deposits in all units. For example, Thomas and Hibbs (1984) excavated everything pre-1861 as one stratum. The author reviewed the excavation records of each project, and the stratum designations, to exclude any pipe fragment that could clearly be attributed to non-HBC contexts. 
However, there may still be some "HBC context" designated pipes that were deposited by the US Army because of their stratigraphic coincidence. Table 2 indicates most pipe artifacts were from the HBC depositional contexts. Further, the HBC component of the Village was created by larger numbers of people who used the site over a longer period of time. Thus it is assumed that the overall spatial distributions of pipe fragments were more influenced by the HBC than the US Army.

\section{Analytical Methods}

\section{$\underline{\text { Artifact Analysis }}$}

The artifacts were analyzed according to Fort Vancouver Archaeology Lab standards (Wilson et al 2009:98-101). Following these standards, recorded attributes include: object, part, fragment size, surface modifications, description of material type and type classification based on decorations or maker's marks. The author analyzed all artifacts, including previously analyzed assemblages, to ensure consistency and obtain missing information.

Each of the artifacts was assessed for the six basic attributes listed above. The first characteristic was "object" and all fragments were identified as tobacco pipe fragments. It is assumed that all the pipes from which the fragments originated were used to consume tobacco and not another substance. The second attribute was part, i.e., what part of the pipe does the fragment represent, using the nomenclature: bowl, stem, spur, or any combination of the three. Size of the fragment was measured using a sizing target, following Fort Vancouver Archaeology Lab procedures (Wilson et al 2009:13). This resulted in eight size classes of fragments (based on the eight classes of the size target): 6 mm, $10 \mathrm{~mm}, 15 \mathrm{~mm}, 20 \mathrm{~mm}, 30 \mathrm{~mm}, 40 \mathrm{~mm}, 50 \mathrm{~mm}$, and over $50 \mathrm{~mm}$ (Figure 8). All 
fragments over $50 \mathrm{~mm}$ were measured using calipers. All spatial and statistical analysis regarding fragment size for this study used these eight size classes.

Surface modifications were assessed, looking for signs of use wear associated with use, intentional modification by the user for a variety of purposes, or postdepositional effects. Some of the possibilities for the surface modifications are: (1) burned interiors on bowls or stems from use represented by the clay turning black, (2) wear on the end of a stem fragment from prolonged use represented by erosion of the clay forming a rounded end, and (3) various other modifications like carving on the end of a stem fragment to rework a broken stem. Post-depositional modifications included signs of burning on the exterior of fragments, and staining or deposits thought to be the result of non-cultural events. For example, some fragments had orange/brown deposits on the surface similar to iron oxide, likely deposited from associated metal while in the ground. Only the surface modifications thought to be associated with use wear (Bradley 2000; Crossley 1990; Davies 2011; Hume 1970) were used for use wear distribution analysis, as they are indicative of cultural behaviors associated with smoking activities. Postdepositional modifications were not considered in further analysis as the scope of the study precluded their inclusion, but they may provide additional information to build on this study in future research.

The description category of the analysis recorded the material composition of the pipe fragment. Possible categories included clay, porcelain, and steatite. For the clay pipes, the color of the paste is listed, primarily shades of whites, browns and reds. Additionally, the presence of any glazing or paint was described. 


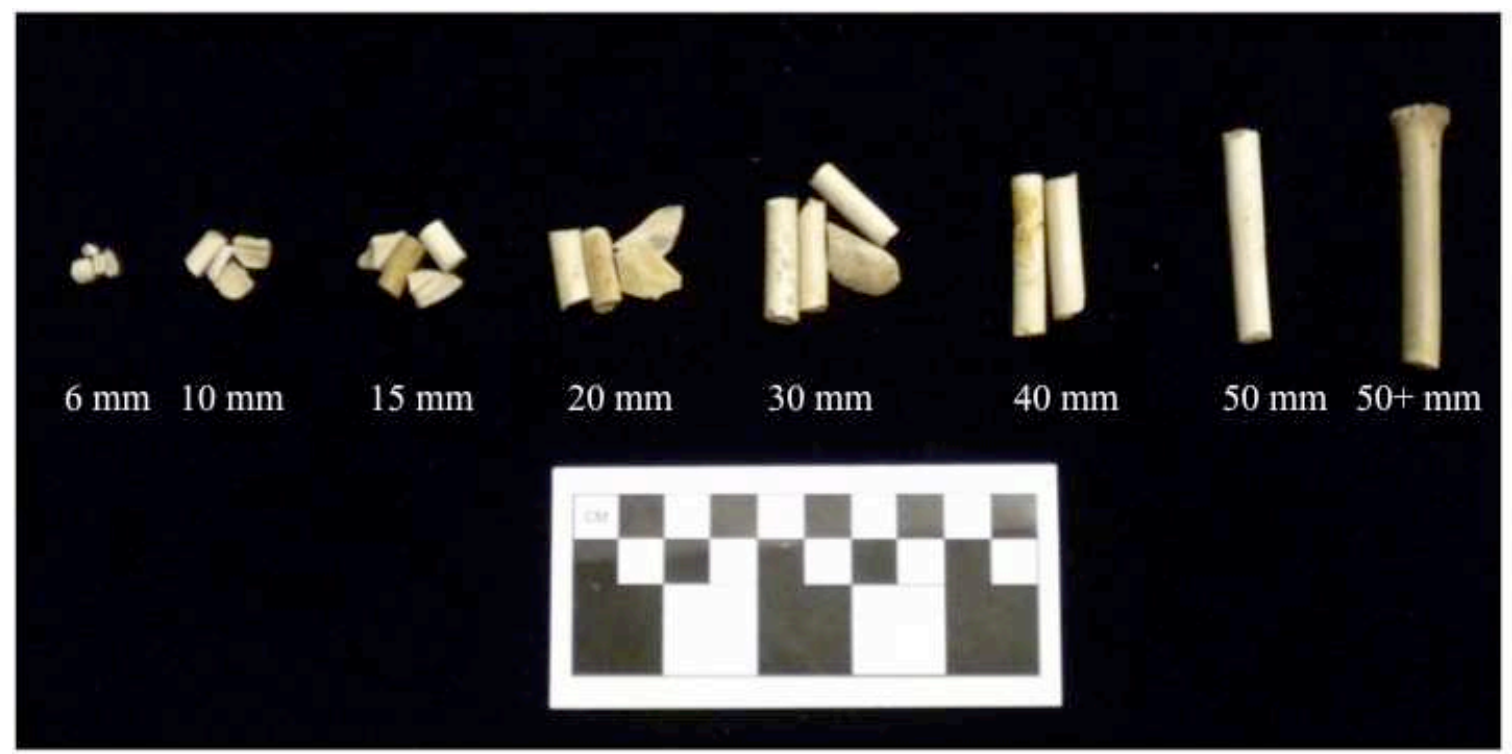

FIGURE 8. Pipe Fragments by Size Class from FOVA 3120 (Photo by author, 2011)

Carving, molded decorations and/or makers' marks were noted, and the fragments were assigned previously created type categories (Carley 1982; Chance and Chance 1974; Thomas and Hibbs 1984), along with associated dates and makers if possible. The alphanumeric type categorization developed by Thomas and Hibbs (1984) was given preference in subsequent analysis of types present in excavation units. This classification system can incorporate any kind of pipe fragment, while the types based on Chance and Chance (1974) and Carley (1982) only assigned type numbers to decorated clay pipes.

Stone pipes were included for comparison, and were not subjected to detailed analysis for this study. Table 3 provides their descriptions and locations. 
TABLE 3 STONE PIPES IN THE STUDY AREA

\begin{tabular}{|c|c|c|c|c|}
\hline Accession & Excavation Unit & Location & Material & Description \\
\hline FOVA 120 & 9U15N-9U16N & $\begin{array}{l}\text { House } 2 \\
\text { floor }\end{array}$ & Black Steatite & $\begin{array}{l}\text { Anthropomorphic } \\
\text { bowl }\end{array}$ \\
\hline FOVA 3023 & ST 93 & $\begin{array}{l}\text { Southeast } \\
\text { of House } 2\end{array}$ & Brown Steatite & Bowl/stem fragment \\
\hline FOVA 3023 & ST 121 & $\begin{array}{l}\text { South of } \\
\text { House } 6\end{array}$ & Black Steatite & $\begin{array}{l}\text { Stem fragment for } \\
\text { two-piece pipe }\end{array}$ \\
\hline FOVA 3164 & EU C7 & $\begin{array}{l}\text { Refuse feature } \\
\text { south of } \\
\text { House } 7\end{array}$ & Grey Steatite & $\begin{array}{l}\text { Stem/spur fragment, } \\
\text { form similar to } \\
\text { clay pipe }\end{array}$ \\
\hline FOVA 3164 & Feature 116 & $\begin{array}{l}\text { Refuse feature } \\
\text { south of } \\
\text { House } 7\end{array}$ & Black Steatite & Two bowl fragments \\
\hline
\end{tabular}

Distribution Maps

Before summarizing the analytical strategies for the research question in the following section, some general notes on the creation of the spatial distribution maps are included here. The author used the Geographic Information Systems computer program ArcGIS version 9.2 for the generation of the distributional maps. The distributions of the pipe fragments, and the fragments with use wear, mapped the frequency of the pipe fragments (fragments $/ \mathrm{m}^{2}$ ) in each unit rather than counts. This helps to control for the variety of sizes of the excavation units, shovel tests, trenches, and shovel probes. For the other distributional maps, bowl to stem fragment ratio and the ASI values, fragment counts were used because of the requirements of the calculations.

The GIS distribution maps contain a portrayal of the historical landscape, based primarily on the work of Mulalley (2011), with some additional information from other 
sources (Table 4) (Figure 9). House sites are archaeologically relocated, while roads and fence lines are primarily interpretations of historical maps.

The occupants of two houses, and the ethnicity of another are suggested by previous researchers (O’Rourke et al 2010; Thomas and Hibbs 1984) based on their research and the 1846 Covington Map. John Johnson, a Scotsman, and his wife Mary, identified as Umpqua, are believed to be the occupants of the house site in Thomas and Hibb's (1984) OP 14 and thus the house is named for him. The Kanaka House was uncovered in the approximate location of a structure labeled "Kanaka" on the Covington Map (O'Rourke et al 2010). O'Rourke et al $(2010: 101,190)$ determined that the structure referred to here as the Tayentas House, was the home of Joseph Tayentas, an Iroquois guide employed at least from 1832-1845 from historical maps and documents. Comparisons of pipe fragment distributions to landscape features assume this historical landscape is relatively accurate.

\section{TABLE 4 STRUCTURES WITHIN THE STUDY AREA}

\begin{tabular}{lll}
\hline Name & Interpretation & Source Used for Location \\
\hline House 1 & House ca. 1834-1850s & Mullaley 2011 \\
House 2 & House ca. 1840-1850s & Mullaley 2011 \\
House 3 & House ca. 1830-1850s & Mullaley 2011 \\
House 4/4+ & House ca. 1820s-1845 & \\
& surrounded by later houses & Mullaley 2011/Lynch 2009 \\
House 5 & House ca. 1830-1860 & Gembala et al 2004/ \\
House 6 & House ca. 1835-1850s & Mullaley 2011 \\
& & Gembala et al 2004/author \\
House 7 & House and yard area & Gembala et al 2004/ \\
House 8 & House ca. 1835-1850s & Mullaley 2011 \\
& & Gembala et al 2004/author \\
Block F House & Possible house & Thomas and Hibbs 1984 \\
John Johnson House & House ca. 1825-1857 & O'Rourke et al 2010 \\
Kanaka House & House ca. 1840s & O'Rourke et al 2010 \\
Joseph Tayentas & House ca. 1840s & \\
House & &
\end{tabular}




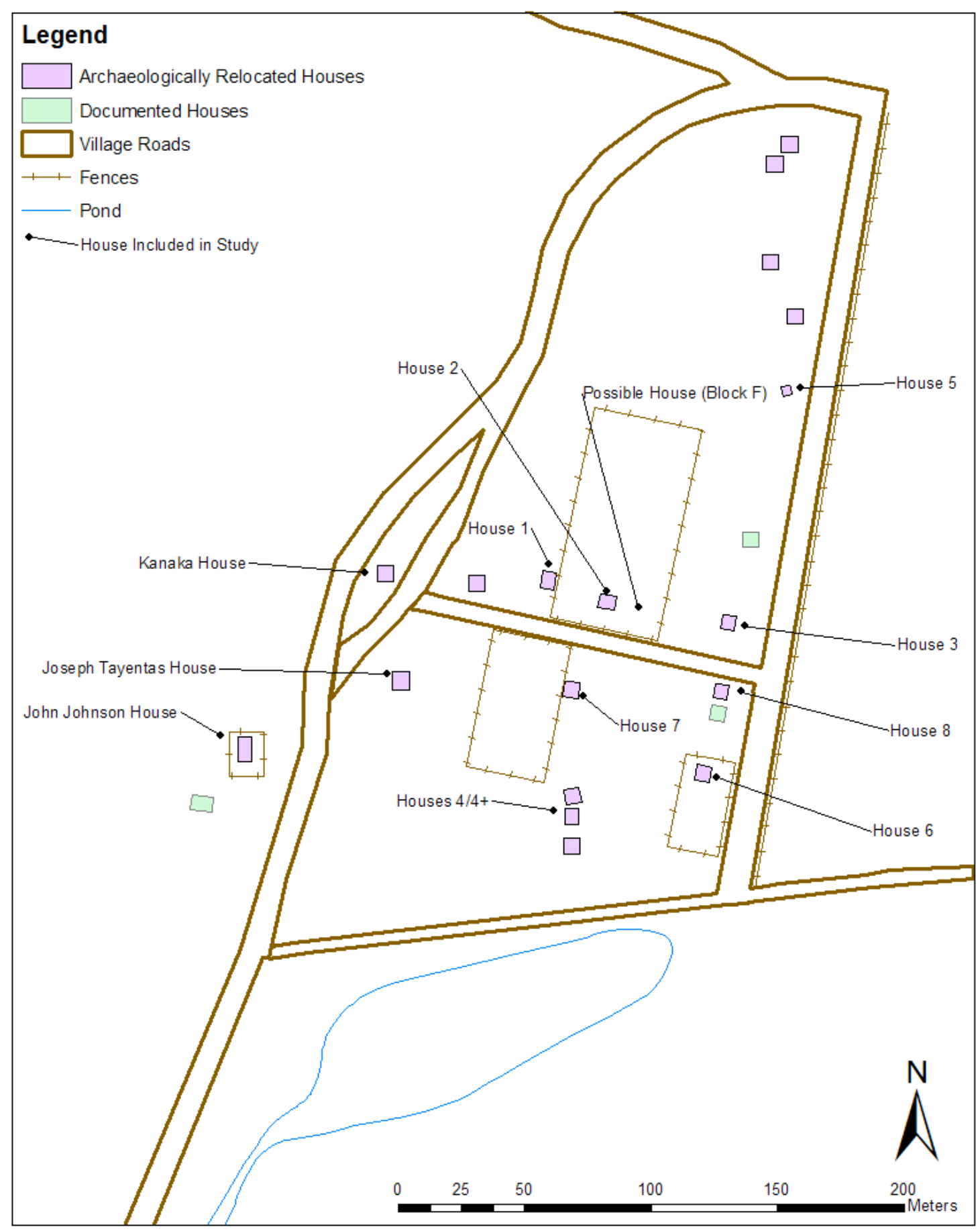

FIGURE 9. The Historical Landscape with the Study Area (Adapted from Mulalley (2011); map by author, 2013) 


\section{Analytical Strategies Associated with Research Questions}

To answer the research questions of this study, the author tested expectations based on the background research through statistical techniques and distributional maps. These strategies are summarized in this section, with each question addressed individually.

1) Was tobacco smoking a significant and social practice in the Village?

The first research question had two main expectations to determine the significance of smoking as a daily behavior and whether it was a social practice. To test the first expectation, this study synthesized assemblage characteristics mentioned in other studies to create a more detailed set of characteristics for regularly used smoking locations (Table 5). Coincidence of these characteristics in the distributional patterning of pipe fragments across the landscape was expected to indicate regular smoking activities in specific locations.

TABLE 5 HYPOTHETICAL CHARACTERISTICS OF PIPE FRAGMENT ASSEMBLAGES IN ACTIVITY AREAS

\begin{tabular}{llll}
\hline $\begin{array}{l}\text { Activity } \\
\text { Area }\end{array}$ & Total Frequency & $\begin{array}{l}\text { Use Wear } \\
\text { Frequency }\end{array}$ & $\begin{array}{l}\text { Bowl to Stem Fragment } \\
\text { Ratio }\end{array}$ \\
\hline $\begin{array}{l}\text { Smoking } \\
\text { Location }\end{array}$ & High & High & 0.75 or higher \\
$\begin{array}{l}\text { Non-Smoking } \\
\text { Location }\end{array}$ & Low & Low & Lower than 0.75 \\
\hline
\end{tabular}

The most basic characteristic of smoking activity areas mentioned in other studies is the clustering of clay tobacco pipe fragments. A Moran's I statistic was calculated for the SAIP shovel test data as a preliminary measure of whether the pipe fragments are clustered, rather than uniformly scattered across the site. The test was performed using 
the Spatial Statistics toolbox in ArcGIS 9.2. The Moran's I test is the most common method of measuring autocorrelation (Conolly and Lake 2006:158) and is available in ArcGIS. The test assesses the degree of spatial autocorrelation of features with certain attribute values. For this study the features are the shovel tests and the attribute values are the pipe fragment frequencies. A positive spatial autocorrelation indicates attribute values tend to be more similar the closer they are together (Conolly and Lake 2006: 158). The shovel tests are used as they provide a systematic random sample of a large portion of the site, and their grid layout pattern lowers the influence of unit placement on the outcome of the test. If pipe fragment frequencies are clustered into distinct smoking locations as expected, a positive autocorrelation producing a Moran's I value between 0 and 1 is expected. Additionally, intentions to interpolate distributions of the pipe fragment data, as described below, were only valid if the data has some degree of positive correlation (Conolly and Lake 2006: 158).

Further assessment of whether pipe fragments show distributional patterning of regular smoking locations tested the expectation that the three characteristics indicative of smoking activity areas, outlined in Table 3, are found in corresponding locations. These characteristics were used in conjunction to define smoking areas for the first time in this study. The distributions of these characteristics were mapped to determine their spatial patterning and where the three characteristics coincided on the landscape. For the bowl to stem fragment ratio, a slightly different ratio than Ritchie's (1978) was used based on the fragmentation within the Village. These calculations are described in Chapter 5. 
The distributional maps were created using the Inverse Distance Weighted (IDW) interpolation method. This created a derived, distributional surface across the landscape. Interpolation was used as it predicted data in unexcavated areas, providing a larger-scale picture of the pipe fragment distributions. The author chose the IDW method as it predicts unknown values by looking at neighboring values, giving more weight to closer points, and as an exact interpolation method it maintains the original data points in the derived surface (Conolly and Lake 2006: 95-96). The resulting surface displays the known values in the excavated areas and predicted values for the unexcavated areas.

The author created two sets of distribution maps of the three characteristics. The first set used only the SAIP shovel test data, containing 171 units, to examine what the spatial patterning looks like through a systematic, random sample of the landscape. The second set of maps used the data from all 542 excavation units included in the study. The maps were compared to evaluate possible biases in all units map interpolations due to the clustering of units around house sites, possibly influencing the prediction of unexcavated areas toward the house site values. The outcome of this comparison determined whether the all study units maps could be used to infer smoking locations or if its biases necessitated the use of only the SAIP data.

The distribution maps were compared to one another to determine likely smoking activity areas. Any location that contained all three characteristics was designated a smoking location, leading to the creation of a map of inferred activity areas. Areas with coincidence of only two of the characteristics were also marked on the map for additional information. The author used this inferred activity map to test the second expectation of the first research question and parts of the third research question. 
To test whether smoking locations were in likely social gathering areas, the locations of inferred smoking activities were examined for their placement on the landscape. These locations were compared to the site features, and other contextual information from project reports, to determine whether the smoking areas represent likely social gathering areas. This is based on the inferences of previous studies and background research that suggest smoking locations are often in social gathering areas like hearths (Davies 2011) and meeting areas (Hoffman and Ross 1973; 1974).

2) Is there variation in maintenance behaviors implied by the spatial patterning? Previous studies (King and Miller 1987; Pogue 1988) suggest clay pipe fragments are often found in refuse disposal locations, but little has been done to define these spatial patterns. To attempt to infer refuse disposal behaviors through the size- sorting of fragments, this analysis tested the applicability of the Artifact Size Index (ASI) technique (Bon-Harper and McReynolds 2011) to the clay pipe fragment assemblage. Bon-Harper and McReynolds (2011) indicate that the ASI technique does not work at all archaeological sites, especially if there were few, if any, maintenance behaviors performed on a site. Further, it may not work with tobacco pipe artifacts if there is not enough variation in size (Bon-Harper 2011, pers. comm.). In inferring the cause of the distribution of the ASI values, not only maintenance behaviors, but also other behaviors such as trampling, were taken into consideration.

Assuming the distribution of ASI values would display maintenance behaviors, the author formed the two expectations listed for research question 2 in Chapter 3. Maintenance behaviors and secondary refuse locations are predicated on cultural notions of cleanliness, safety, and acceptable locations for the deposition of rubbish (Beck and 
Hill 2004; Crane 2000; King and Miller 1987; Wilson 1994). Thus, comparisons of maintenance and refuse disposal behaviors between households and across the site, inferred from the ASI value distribution, could be used to assess the degree of variation in maintenance behaviors in the Village.

Archaeologists at Monticello created the ASI technique (Bon-Harper and McReynolds 2011) to map variation in artifact size between excavation units across a site. This distribution can show areas of primary vs. secondary refuse, based on Schiffer's (1983) definitions. Primary refuse is disposed of at the site of generation and "smaller items are more likely to become primary refuse in activity areas" (Schiffer 1983: 679). These smaller fragments could be left where they fell, however larger fragments would impede action. Activity areas need to be cleaned to allow continued use and this can lead to size sorting with smaller pieces left behind (Schiffer 1987:59; O'Connell et al 1991:67). Thus larger fragments tend to form as secondary refuse, which is transported and deposited at another location. Further, smaller items can be trampled into the ground, while larger items can accumulate as secondary refuse at the edges of activity areas (O’Connell et al 1991; Hutson et al 2007). Concentrations of small fragments can indicate primary refuse locations and larger fragments suggest secondary refuse.

An ASI value was calculated for each unit through an equation that compares the ratio of small artifacts to large artifacts in a unit compared to the site-wide mean. The differentiation between small and large artifacts is based on the mean size of the artifact within the total assemblage, with everything smaller than the mean designated small, and everything larger designated large. 
For each unit the ASI [is] calculated as

$$
A S I=\frac{(S-p r-5)}{w h(1-p)}
$$

where $S_{\mathrm{i}}$ is the number of small artifacts in the $i$ th excavated unit (the observed value), $\mathrm{N}_{\mathrm{i}}$ is the total number of artifacts in the $i$ th unit, and $p$ is the proportion of small artifacts site-wide (the product of which is the expected value). A factor of 0.5 is subtracted from the numerator as a correction for continuity in the Gaussian distribution. The numerator of this formula compares the proportion of small artifacts from each excavated unit with the sitewide proportion of small artifacts by calculating the difference between the expected and observed numbers of small artifacts. ...The denominator of the equation is a standard deviation, or square root of the variance in values for proportion of small artifacts per excavated unit, across the site. This takes into consideration the degree of spread (from the mean value) seen in the data set. (Bon-Harper 2011: 1112).

Within the equation, the expected number of small artifacts is based on the site-wide proportion and the number of artifacts in a unit. For example, if the side-wide proportion of small artifacts is 0.6 , than in a unit with 10 artifacts, 6 are expected to be small. The correction for continuity in the Gaussian distribution refers to the reliance of the ASI formula "on the Gaussian approximation for the binomial distribution to model variation," separating assemblages into two categories, rather than examining size sorting through another method such as mapping a continuum of size values (Bon-Harper 2011: 
6). For more details on ASI, see Bon-Harper (2011) and Bon-Harper and McReynolds (2011).

The equation produces either a positive or negative value for each excavation unit. A positive ASI value represents more small fragments than the site mean, and a negative value represents fewer small fragments (or more large fragments) than the site mean. The farther these values are from zero, the greater deviation from the site-wide mean. ASI values can then be mapped using GIS programs to create a graphic representation of the distribution of ASI values across a site. Clusters of positive ASI values indicate areas of primary refuse, or maintained areas, and clusters of negative ASI values indicate areas of secondary refuse, or refuse disposal locations, subsequently aiding examination of refuse disposal and site maintenance.

Prior to the calculation of ASI values, the size recovery biases of the varied screening techniques were assessed. This involved comparisons of mean and median fragment sizes for the screening techniques and the total study assemblage. The median fragment sizes were tested through the Kruskal-Wallis test to determine whether the difference was significant. The details of these calculations are included in Chapter 5.

3) Is there variation in smoking behaviors implied by the spatial patterning that may be tied to ethnic differences?

The background research of this study did not find any previous examination of clay or stone pipe fragment spatial patterning to examine ethnic differences. However, historical and archaeological evidence suggest smoking behaviors did vary between some ethnic groups. Based on this evidence, the author formed two expectations for question 3 (Chapter 3). Additionally, the spatial patterning of smoking activity areas was examined 
inductively for any other signs of differences because of the lack of other indicators of difference mentioned in the background research.

To test the first expectation, the locations of stone pipes were mapped for the study area. The locations of the stone pipes were then compared to the location of the smoking activity areas inferred from the clay pipe fragment distributions. The comparison allowed visual assessment of whether stone pipes are found in spatially distinct locations from the clay pipe smoking locations and whether any households used stone pipes instead of clay pipes.

Comparisons of house assemblages allowed assessment of the second expectation of lower rates of tobacco consumption in a household where behavioral prescriptions limited smoking behaviors. The author quantified clay pipe usage by analyzing the pipe fragments from units within the identified smoking locations as separate assemblages for each house. The three characteristics used to determine smoking locations were calculated for each house assemblage, as well as the minimum number of individual pipes (MNI), and number of decorative types represented within each household. The MNI values were calculated by determining the fewest number of pipes to achieve the number of bowl fragments, stem fragments, and types within an activity area. The number of bowl and stem fragments from a single pipe is based on the bowl to stem fragment ratio determined for the study area (Chapter 5). High values in all of these assemblage characteristics for a household were considered an indication of high consumption rates, while lower values a sign of relatively lower consumption.

Testing the third expectation of differential use of space related to smoking activities between households, involved inductive examination of the inferred smoking 
location map. Besides the two patterns mentioned above, no other ethnic spatial patterns could be determined from the background research. Smoking locations could only be examined for their placement on the landscape in relation to site features for any signs of differential use of space. On the other hand, similar placement of smoking locations between the households would suggest similar use of space for smoking activities. These inductive interpretations are included in Chapter 6. 


\section{Chapter 5. Results}

The chapter summarizes the results of the analysis, divided into sections based on the research questions and expectations. These results are interpreted and discussed in Chapter 6.

\section{Tobacco as Significant and Social Practice}

To determine whether the pipe fragments are clustered or uniformly spread across the landscape, the Moran's I statistical test was performed on the pipe fragment frequency values of the SAIP shovel test data. The test produced a value of 0.1 , indicating that units with similar pipe fragment frequency values are positively autocorrelated, with less than a 5\% chance that the patterning occurred randomly. Thus, the pipe fragments are clustered in a statistically significant way across the landscape. The test result numbers are included in the Appendix.

To define smoking activity areas, IDW interpolated maps of the three hypothetical assemblage characteristics of smoking locations were created. Interpolation in ArcGIS uses data points, thus the locations of units were converted to points located in the center the unit location. The black dots on the maps represent the locations of units. For the pipe fragment frequencies and use wear frequencies maps, darker colors indicate higher frequencies. On the bowl to stem fragment ratio map, areas with ratios suggestive of smoking locations, 0.75 or higher, are mapped in orange. Lower ratios are grey and the white space represents areas in which a ratio could not be calculated. Determination of the ratio is described below. The SAIP shovel test data maps are displayed in Figures 1012. The maps created with all of the study unit data are displayed in Figures 13-15. 
As mentioned above, the SAIP shovel tests maps were created to serve as a systematic, random sample of the Village landscape, reducing possible biases inherent in the house-centric sampling of the other excavation units. Comparison of the distributions displayed on the SAIP shovel test maps vs. maps created with all of the study units suggested no considerable difference between the spatial patterning. Thus, later delineation of activity areas used the all study unit data maps.

For the bowl to stem fragment ratios, Richie's determination of the number of bowl and stem fragments one pipe would produce, 4 and 8 respectively, was compared to the fragmentation seen within the study assemblage. Ritchie based the number of stem fragments on the average stem length of clay pipes post-1780: 6-8 inches. Within the study assemblage, the average length of a stem fragment is $20 \mathrm{~mm}(0.79 \mathrm{in})$, and thus roughly $1 / 8$ of a 6 in. stem. Bowl fragments at Fort Vancouver proved to be more fragmented than Ritchie's determination of 4 fragments per bowl. Measurements based on a complete Ford Stepney "Insect" type pipe bowl, a common type found at Fort Vancouver, determined that the average size of a bowl fragment within the study assemblage, $20 \mathrm{~mm}$, represents roughly $1 / 6$ of a complete pipe bowl. This was calculated by approximating the surface area of a pipe bowl as a cone, with a radius of $12.5 \mathrm{~mm}$ and a side length of $45 \mathrm{~mm}$. Thus, a slightly different ratio from Ritchie's was mapped for this study: 6 bowl to 8 stem fragments, or 3:4. Any area with a ratio of 0.75 or higher is then considered an area with more regular pipe deposition associated with smoking.

Based on the all study unit data distribution maps (Figure 13-15), the map in Figure 16 highlights the locations of the three smoking area pipe assemblage 


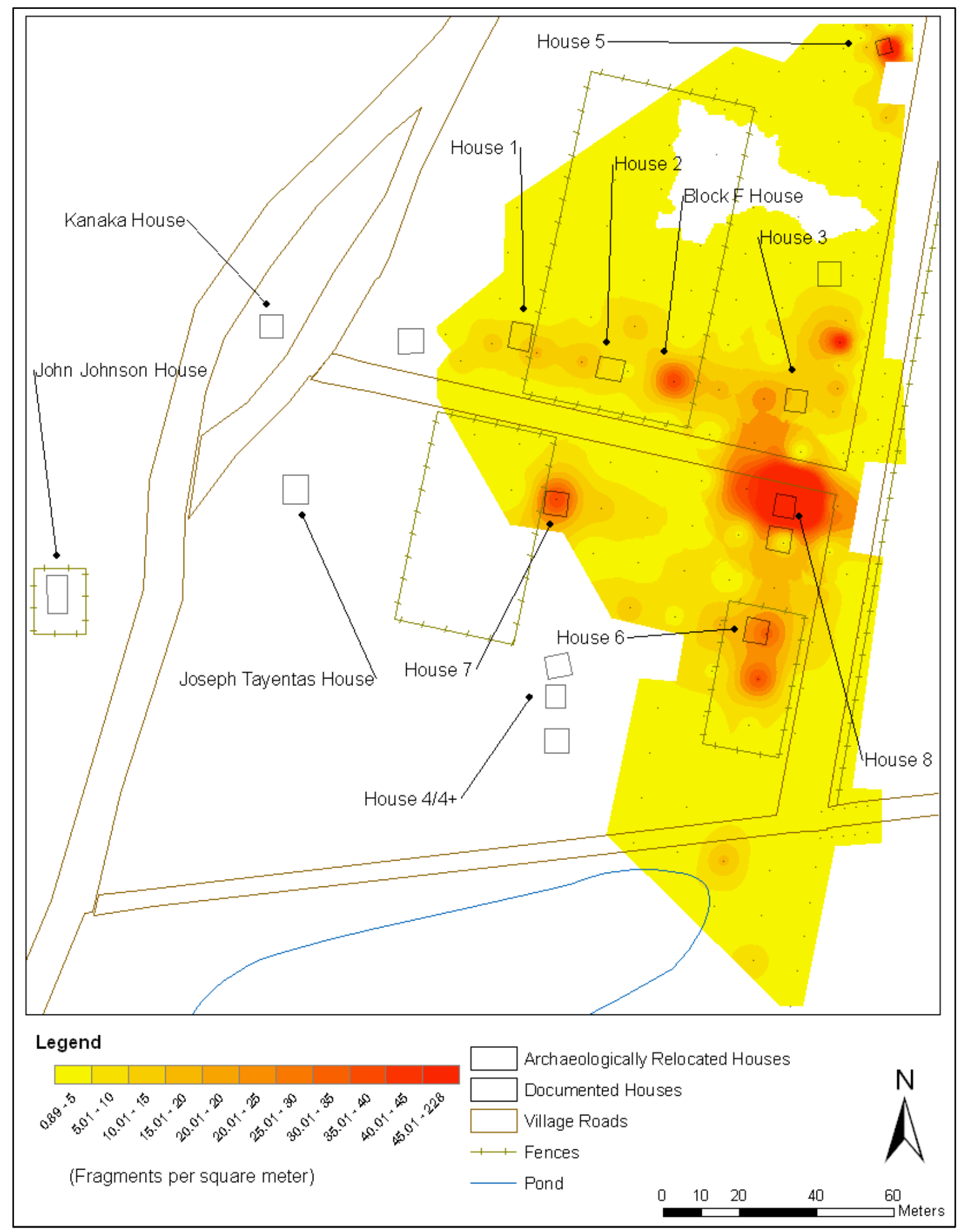

FIGURE 10. Shovel Test Fragment Frequency Distribution (Map by author, 2013) 


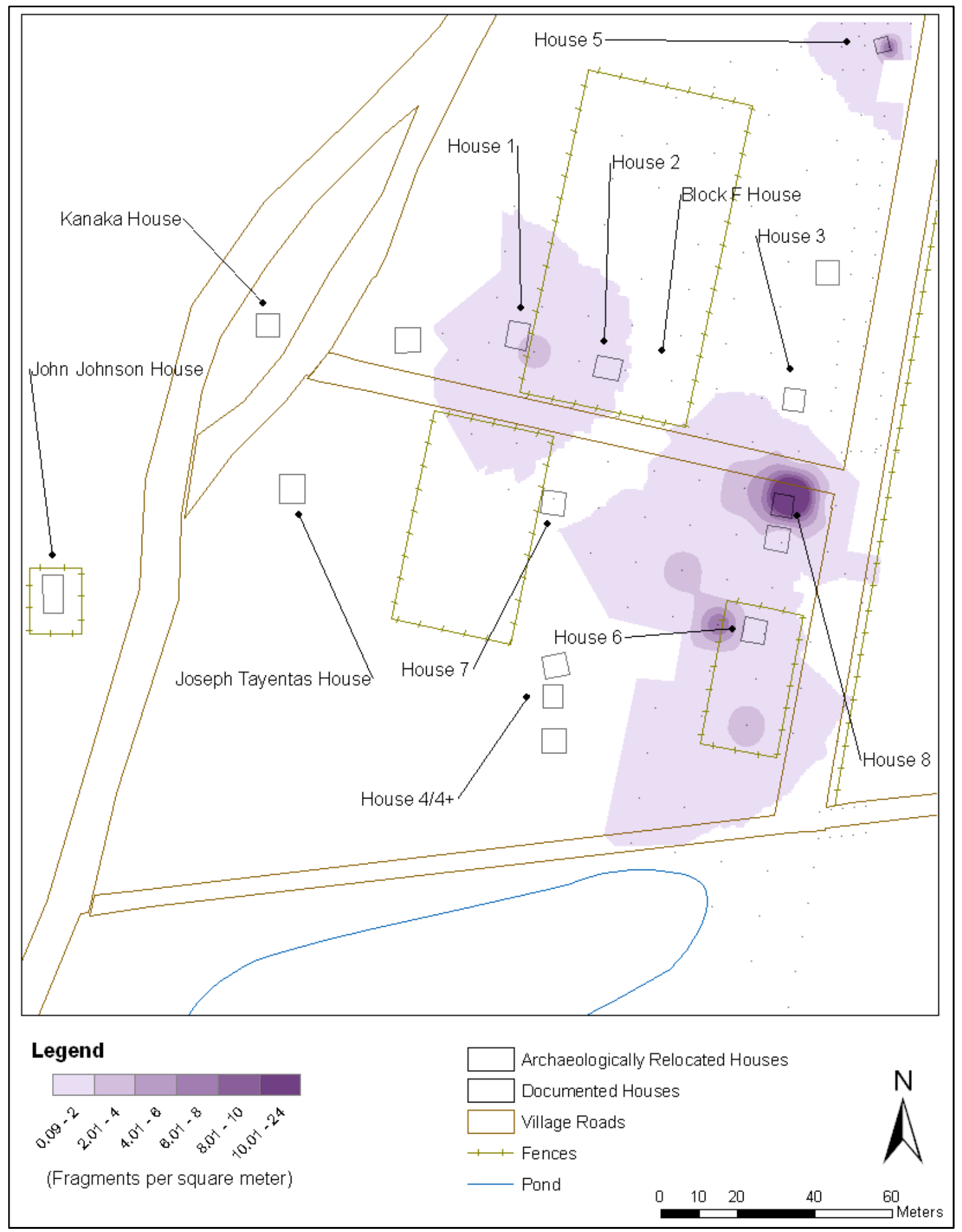

FIGURE 11. Shovel Test Use Wear Fragment Frequency Distribution (Map by author, 2013) 


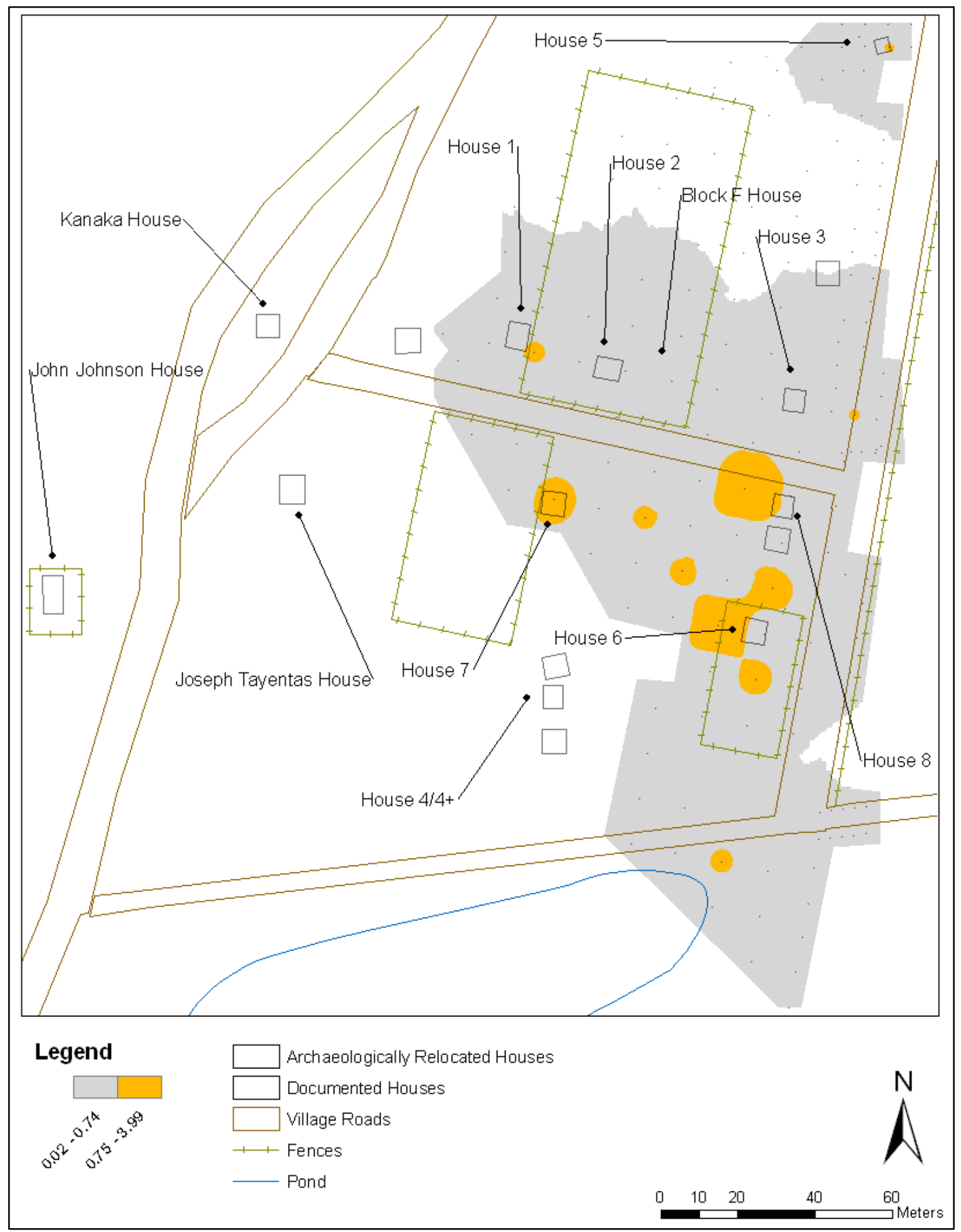

FIGURE 12. Shovel Test Bowl to Stem Ratio Distribution (Map by author, 2013) 


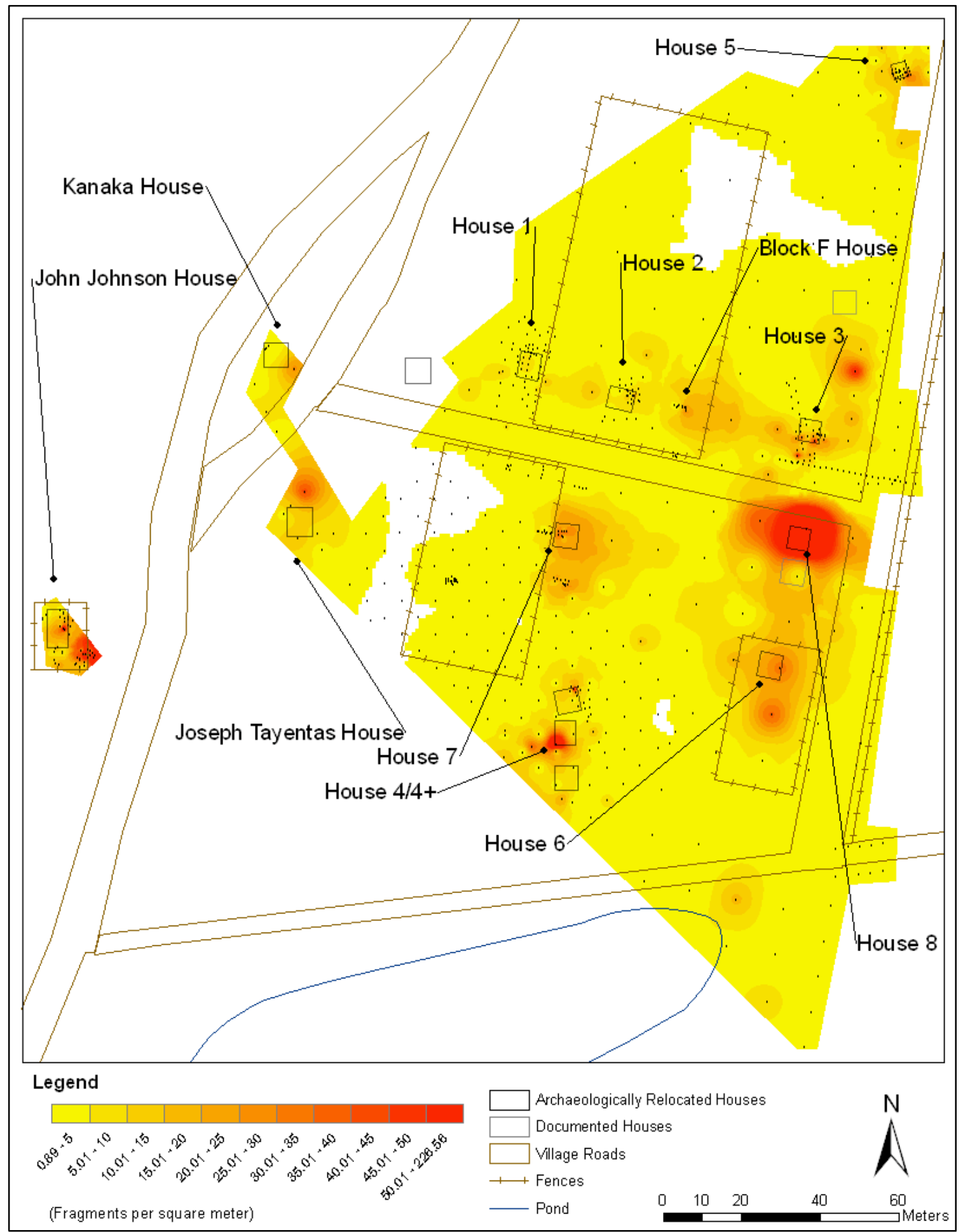

FIGURE 13. All Study Unit Data Fragment Frequency Distribution (Map by author, 2013) 


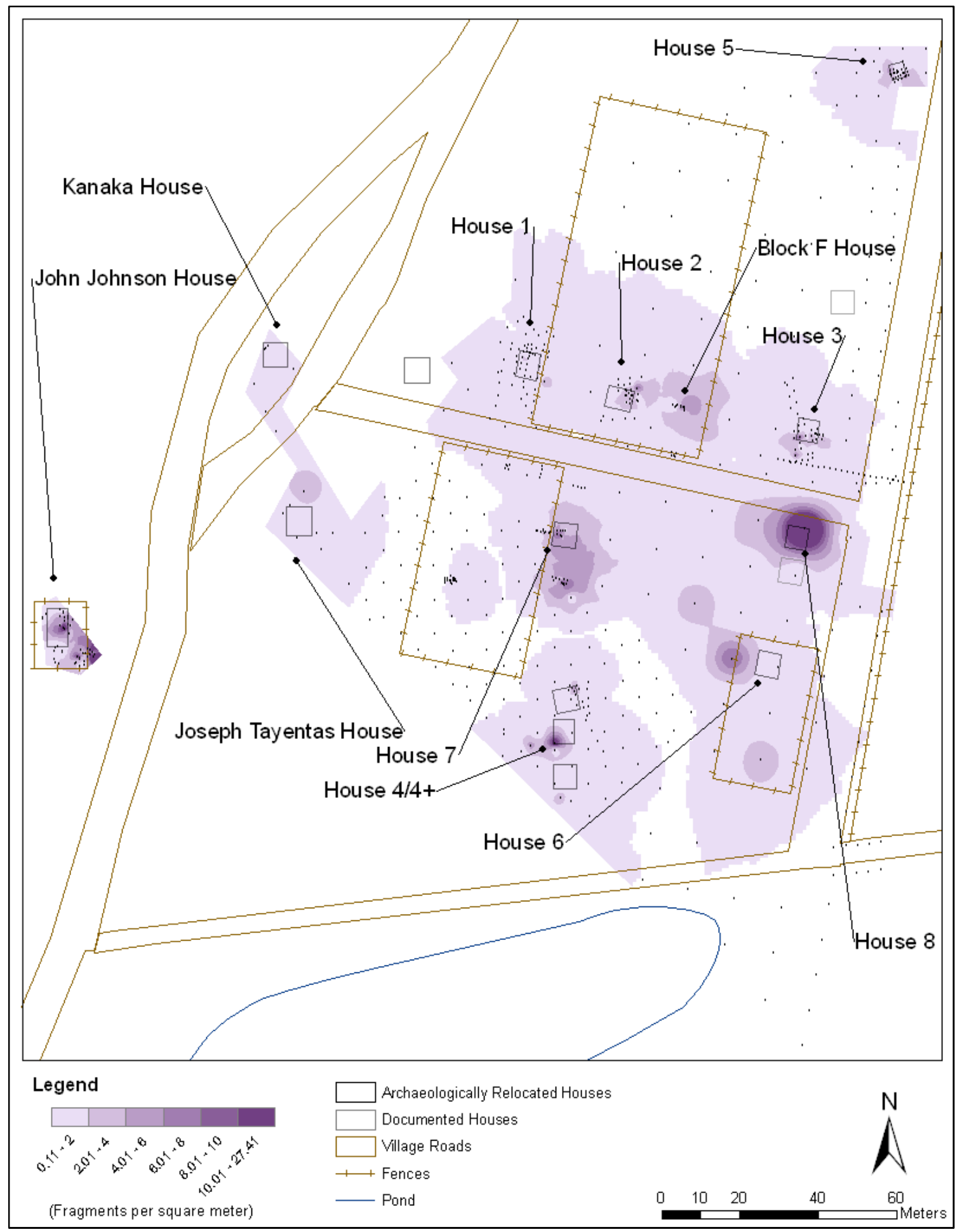

FIGURE 14. All Study Unit Data Use Wear Fragment Frequency Distribution (Map by author, 2013) 


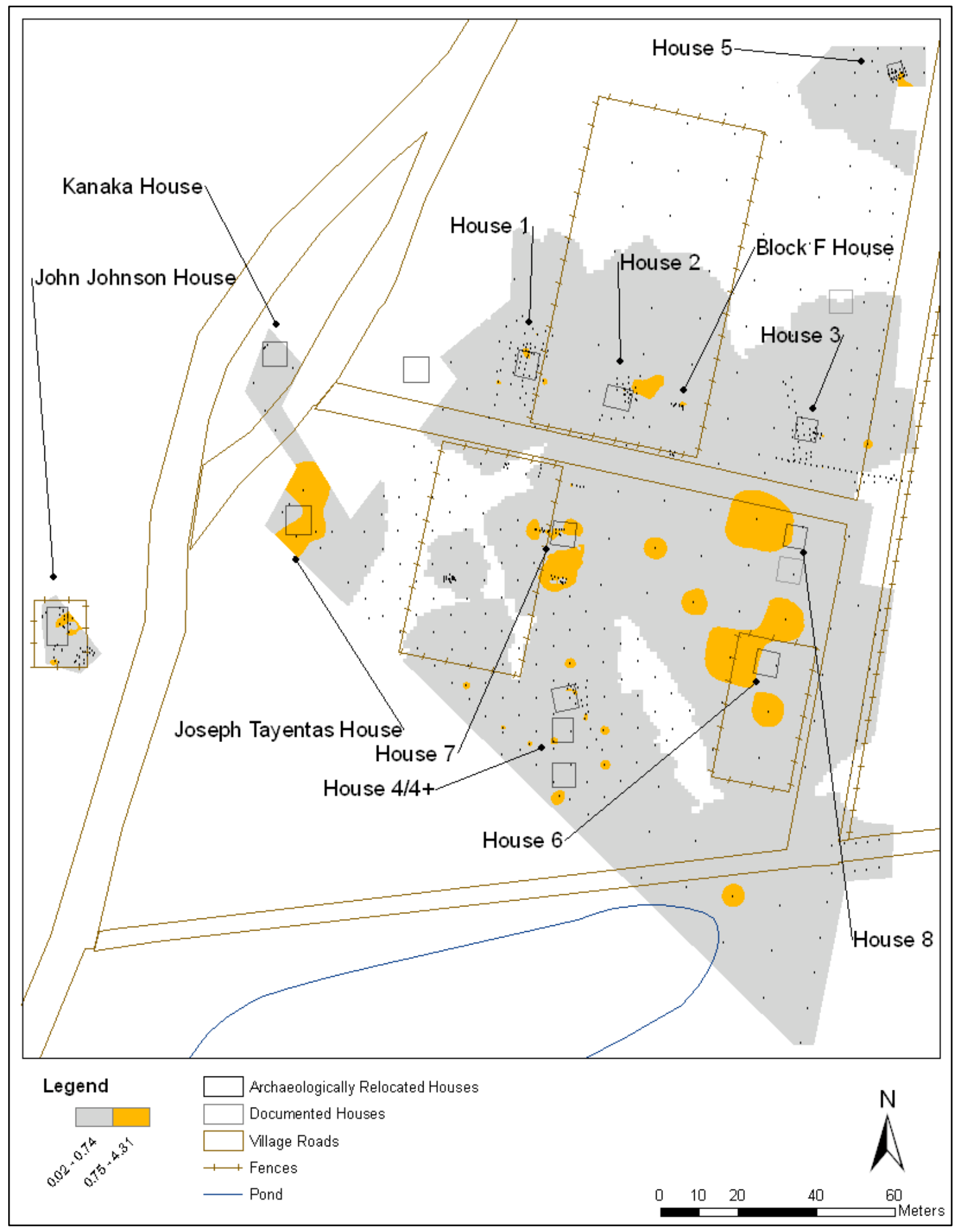

FIGURE 15. All Study Unit Data Bowl to Stem Ratio Distribution (Map by author, 2013) 
characteristics. High fragment frequencies are displayed as red circles, high use wear fragment frequencies as purple, and bowl to stem fragment ratios of 0.75 or higher as orange circles. The map shows that the three hypothesized assemblage characteristics for smoking locations do coincide in various areas on the landscape.

A map of inferred smoking activity areas was created based on the overlap of the three assemblage characteristics displayed in Figure 16. For smoking areas, locations with overlap of high pipe fragment frequencies, high frequencies of use wear, and a bowl to stem ratio of a smoking area were considered the most probable smoking locations (Figure 17). These areas are displayed in green. Areas of overlap of only two of the characteristics were also marked on the map; high frequency and use wear frequency in purple, and high frequency and smoking location ratio in tan. Areas with overlapping attributes of high use wear and a smoking location ratio, but not within high fragment frequency areas were not included on the map. Preference was given to higher fragment frequency areas, as these are more likely to represent areas associated with regular deposition of pipe fragments. The pipe assemblage values for each identified smoking location are listed in Table 6.

It should be noted that for both Figures 16 and 17, the sizes of the circles on the map reflect the interpolated area of the characteristic, not a scale of intensity. For areas with fewer surrounding excavation units, the resulting circle is larger as the interpolation was less constrained by surrounding values, for example those near House 6 and 8 . This resulted in a less precise interpolation of the boundaries. The actual values of the assemblage characteristics are listed in Table 6. 


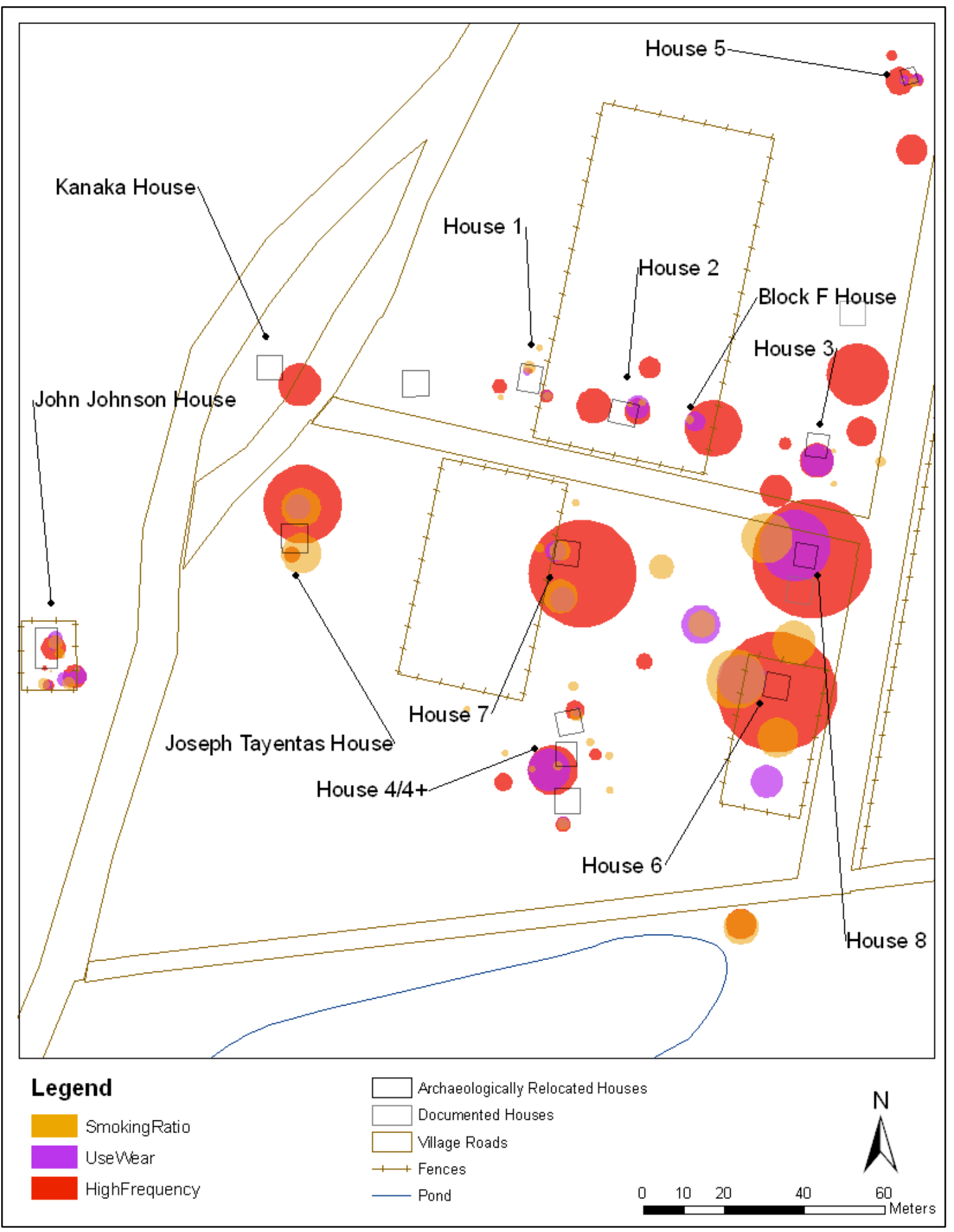

FIGURE 16. Pipe Fragment Smoking Location Attributes (Map by author, 2013) 


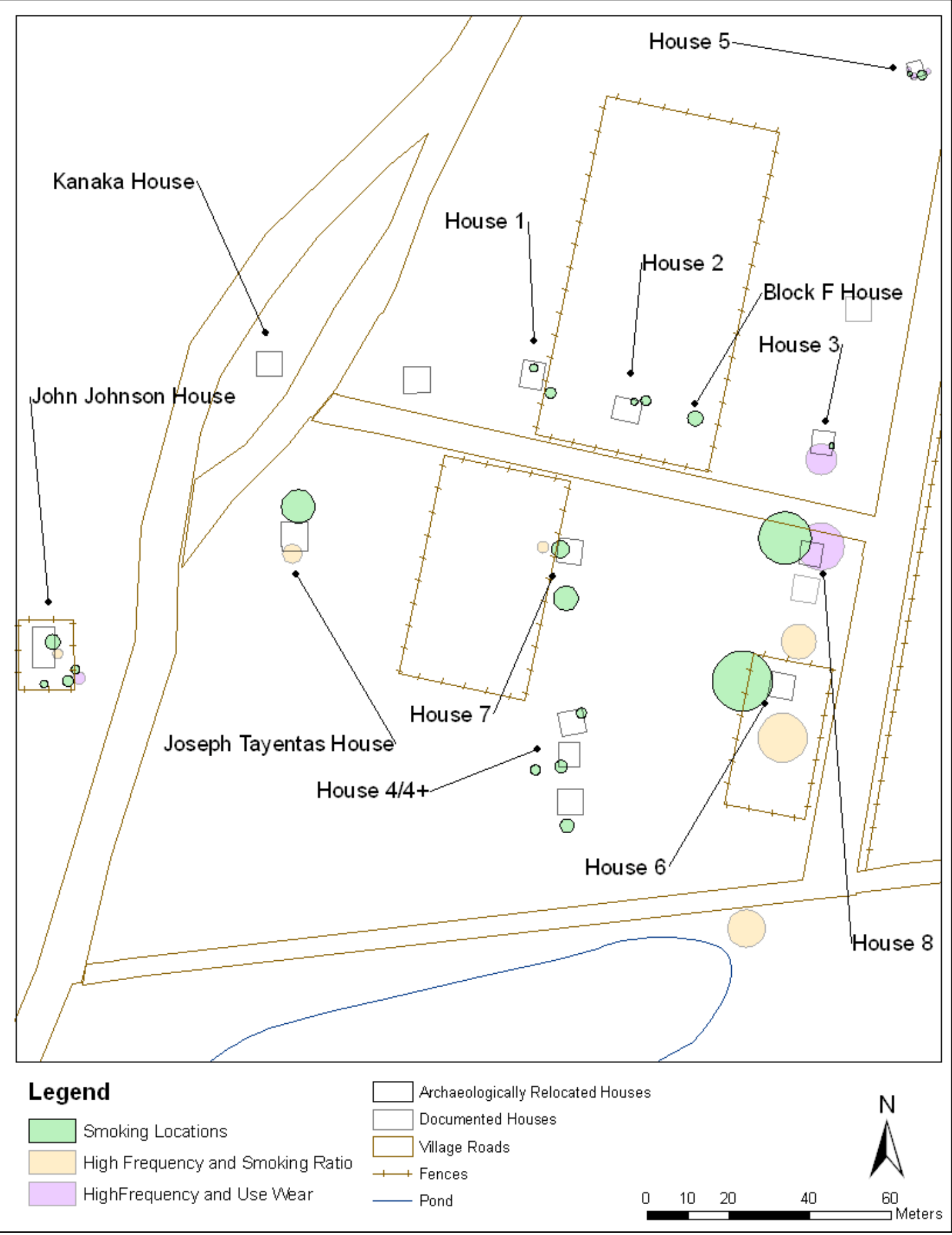

FIGURE 17. Smoking Activity Areas. (Map by author, 2013) 
At least one smoking area is located near each house in the study area, with the exception of Kanaka House. This could be an effect of the low number of excavation units near Kanaka House, possibly missing smoking area deposits. While the inferred smoking areas note smaller areas of coincidence of the three assemblage characteristics, the assemblage characteristic distributions cover larger portions of the study area. In general, the higher values of these characteristics are located around houses and lower values are found between the structures. Two areas that contain extremely low assemblage characteristics, or are devoid of pipe fragments in some portions, are visible between House 7 and Tayentas House, and the north-central portion of the study area south of House 5 and north of Houses 2 and 3. The characteristic distributions and the smoking locations suggest most smoking and deposition of pipe fragments occurred in and around the houses.

The identified smoking locations were compared to contextual data from previous research to determine whether the activity areas are in probable social areas. The smoking areas on the interiors of Houses 1-5 are adjacent to the hearth locations (Mullaley 2011), likely representing a focal point for gathering on the interior of the structures (Davies 2011). Another possible social gathering area is the smoking location north of House 8 , and the adjacent area of high fragment frequency and use wear frequency overlap, at the crossroads. Three smoking activity areas are not indicative of a social gathering area as they represent a refuse disposal location. These are the smoking location south of House 7 (House 7 South in Table 6) containing the refuse pit Feature 116, the location in the Johnson House (Johnson House North in Table 6) that includes the cellar pit Feature 54, and the area to the southeast of the Johnson House (Johnson House Southeast in Table 6) 
TABLE 6 SMOKING ACTIVITY AREAS

\begin{tabular}{|c|c|c|c|c|c|c|c|c|}
\hline Activity Area & Location & $\begin{array}{l}\text { Fragment } \\
\text { Count }\end{array}$ & $\begin{array}{l}\text { Area } \\
\left(\mathrm{m}^{2}\right)\end{array}$ & $\begin{array}{l}\text { Fragment } \\
\text { Frequency } \\
\left(\text { per } \mathrm{m}^{2}\right)\end{array}$ & $\begin{array}{l}\text { Bowl to } \\
\text { Stem } \\
\text { Ratio }\end{array}$ & $\begin{array}{l}\text { Use Wear } \\
\text { Frequency } \\
\left(\text { per } \mathrm{m}^{2}\right)\end{array}$ & $\begin{array}{l}\text { No. of } \\
\text { Types }\end{array}$ & MNI \\
\hline Block F House & $\begin{array}{l}\text { Possible } \\
\text { Interior }\end{array}$ & 65 & 3.12 & 20.83 & 0.91 & 5.77 & 3 & 6 \\
\hline House 1 East & Exterior & 4 & 0.25 & 16.00 & 1.00 & 4.00 & 1 & 1 \\
\hline House 1 North & Interior & 32 & 3.32 & 0.64 & 0.68 & 2.11 & 3 & 3 \\
\hline House 2 East & Exterior & 27 & 2.32 & 11.64 & 5.75 & 9.91 & 2 & 4 \\
\hline House 2 West & Interior & 24 & 3.32 & 7.23 & 1.18 & 3.01 & 3 & 3 \\
\hline House 3 & Interior & 16 & 1.35 & 11.85 & 0.60 & 0.74 & 1 & 2 \\
\hline House 4 & Interior & 117 & 2.79 & 41.94 & 0.67 & 6.09 & 8 & 9 \\
\hline $\begin{array}{l}\text { House 4+ } \\
\text { TU 4-01 }\end{array}$ & $\begin{array}{l}\text { Possible } \\
\text { Interior }\end{array}$ & 117 & 1.00 & 117.00 & 0.95 & 14.00 & 5 & 10 \\
\hline $\begin{array}{l}\text { House 4+ } \\
\text { TU 4-02 }\end{array}$ & Exterior & 21 & 1.00 & 21.00 & 1.33 & 3.00 & 0 & 2 \\
\hline $\begin{array}{l}\text { House 4+ } \\
\text { TU 4-03 }\end{array}$ & Exterior & 38 & 1.00 & 38.00 & 0.90 & 5.00 & 3 & 3 \\
\hline House 5 East & Both & 88 & 8.52 & 10.33 & 0.83 & 1.64 & 2 & 7 \\
\hline House 5 West & Both & 49 & 2.00 & 24.50 & 1.23 & 4.50 & 1 & 5 \\
\hline House 6 & Exterior & 4 & 0.25 & 16.00 & 3.00 & 8.00 & 0 & 1 \\
\hline House 7 North & Both & 168 & 5.00 & 33.60 & 1.00 & 8.20 & 5 & 14 \\
\hline House 7 South & Exterior & 212 & 5.00 & 23.98 & 0.94 & 5.77 & 8 & 18 \\
\hline House 8 & Exterior & 10 & 0.25 & 40.00 & 4.00 & 4.00 & 2 & 2 \\
\hline $\begin{array}{l}\text { Johnson House } \\
\text { East }\end{array}$ & Exterior & 64 & 2.32 & 27.59 & 0.83 & 6.03 & 0 & 5 \\
\hline $\begin{array}{l}\text { Johnson House } \\
\text { North }\end{array}$ & Both & 819 & 16.04 & 51.06 & 0.88 & 14.65 & 25 & 64 \\
\hline $\begin{array}{l}\text { Johnson House } \\
\text { South }\end{array}$ & Exterior & 67 & 2.77 & 24.19 & 0.46 & 3.61 & 1 & 6 \\
\hline $\begin{array}{l}\text { Johnson House } \\
\text { Southeast }\end{array}$ & Exterior & 173 & 8.62 & 20.07 & 0.70 & 2.44 & 6 & 13 \\
\hline Tayentas House & Exterior & 42 & 1.00 & 42.00 & 1.63 & 4.00 & 2 & 5 \\
\hline Average & & & 3.57 & 28.97 & 1.40 & 5.55 & 4 & 9 \\
\hline Median & & & 2.32 & 23.98 & 0.94 & 4.5 & 2 & 5 \\
\hline
\end{tabular}


near the refuse pit Feature 209. This result suggests that some of the identified smoking areas may not indicate the exact location of smoking, but the secondary deposits associated with the smoking behavior.

\section{Variation in Maintenance Behaviors}

To determine whether evidence of maintenance behaviors are visible in the sizesorting of pipe fragments, the ASI technique was performed on the study collection. First, assessment of the various screen techniques for size recovery biases determined that the pipe fragments collected from inconsistent 1/4 in. screening, and 1/4 in. screening techniques are biased toward recovery of larger fragments. The size biases are seen in the larger mean and median sizes (Table 7) for the 1/4 in. screening techniques, as well as relative proportions of fragment sizes (Figure 18). Further, a test of the median sizes through the Kruskal-Wallis one-way analysis of variance test calculated a test value of 492.39, which is greater than the chi square critical value of 9.210, at $\mathrm{p}=0.01$, and $\mathrm{df}=2$. Thus, the null hypothesis that the sample medians are similar is rejected (See Appendix for the calculations). Consequently, only the excavation units from projects that used nested $1 / 8$ in. and 1/4 in. screens were used in the ASI calculations of the pipe fragment sizes.

The ASI equation values were calculated for both the excavation units from projects that used the nested screens, and the SAIP shovel test data as a subset of the data. This created two different distributional maps for comparison, following the reasoning for assessing biases of units clustering around houses as described above. For both data sets, the mean fragment size determined for the nested screens, $16.6 \mathrm{~mm}$ (Table 7), was used to divide the fragments into "small" and "large" categories. Thus, fragments falling 
into the 6,10 , and $15 \mathrm{~mm}$ size categories are considered small fragments, and those in the size categories greater than $15 \mathrm{~mm}$ are considered large fragments. For the SAIP shovel test data, the site-wide average proportion of small artifacts is 0.65 . Using this as the $p$ value, the equation produces a value of -0.1048 for units matching the site-wide mean proportion. Thus, any unit with an ASI value of less than -0.1048 contains more large

TABLE 7 MEAN AND MEDIAN FRAGMENT SIZE BY SCREENING TECHNIQUE

\begin{tabular}{|c|c|c|c|c|c|}
\hline Screening Method & Excavations & $\begin{array}{l}\text { No. of } \\
\text { Units }\end{array}$ & $\begin{array}{l}\text { No. of } \\
\text { Fragments }\end{array}$ & $\begin{array}{l}\text { Mean } \\
\text { Fragment } \\
\text { Size }(\mathrm{mm}) \\
\end{array}$ & $\begin{array}{l}\text { Median } \\
\text { Fragment } \\
\text { Size }(\mathrm{mm}) \\
\end{array}$ \\
\hline $\begin{array}{l}\text { Inconsistent } 1 / 4 \text { in. } \\
(6 \mathrm{~mm}) \mathrm{mesh}\end{array}$ & FOVA 116,120 & 129 & 1648 & 24.0 & 30 \\
\hline $1 / 4$ in. $(6 \mathrm{~mm})$ mesh & FOVA 1813, 2853 & 141 & 1594 & 20.7 & 20 \\
\hline $\begin{array}{l}\text { Nested } 1 / 4 \text { in. }(6 \mathrm{~mm}) \\
\text { and } 1 / 8 \text { in. }(3 \mathrm{~mm}) \\
\text { mesh }\end{array}$ & $\begin{array}{l}\text { FOVA } 2997,3011, \\
3023,3100,3120, \\
3164\end{array}$ & 272 & 1557 & 16.6 & 15 \\
\hline All Fragments & & 542 & 4799 & 20.5 & 20 \\
\hline
\end{tabular}

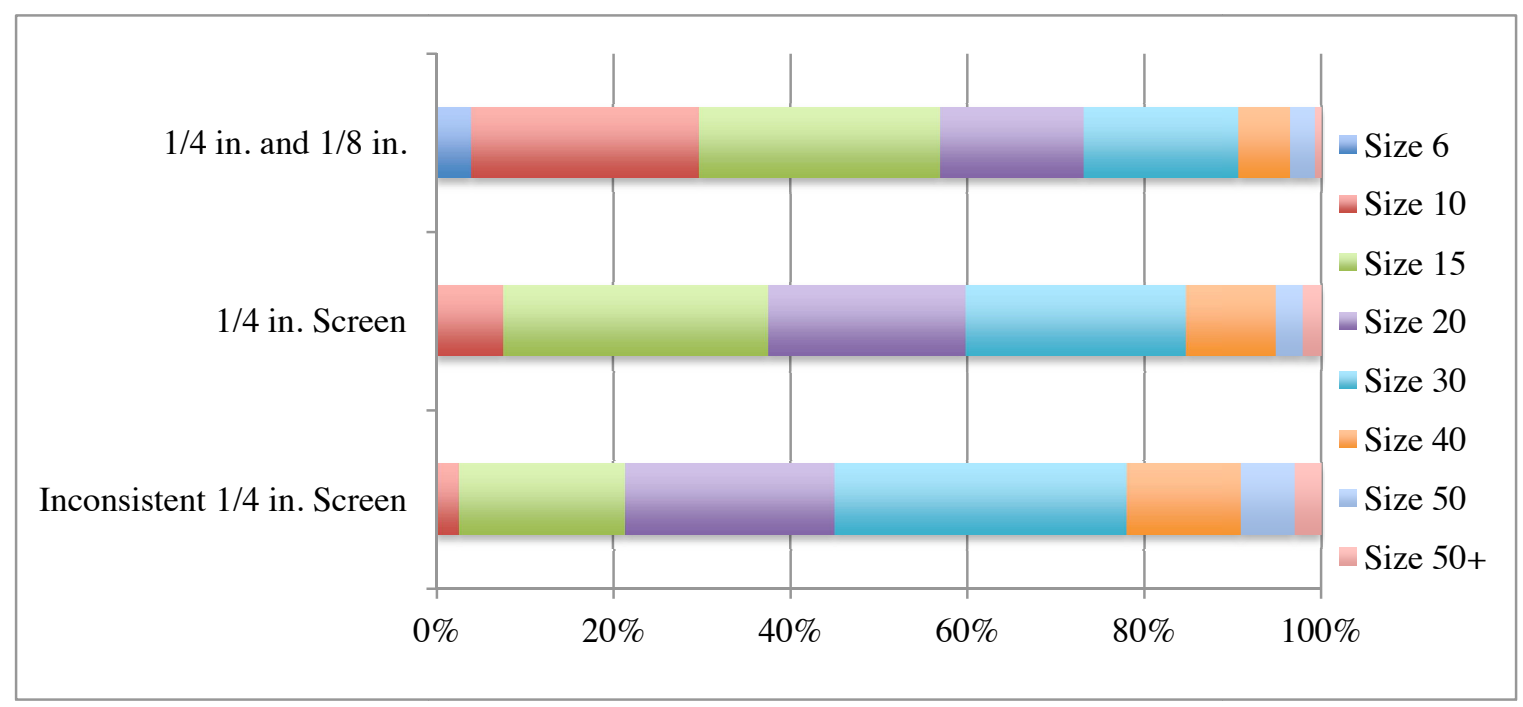

FIGURE 18. Percentage of Pipe Fragments by Size Class for Each Screening Method (Chart by author, 2013) 
fragments than average. Units with an ASI value of more than -0.1048 contain more small fragments than average. For the excavation unit data (from nested screens), the numbers differed slightly. The proportion decreases to 0.57 , resulting in the equation value for a unit with the average proportion of small fragments equaling -0.1010. So for the excavation unit data, any unit with an ASI value of less than -0.1010 contains more large fragments than average, and any unit with an ASI value greater than -0.1010 contains more small fragments than average. These equation values were used to calculate ASI values for the individual units. See the Appendix for additional information on the calculation of these values.

Interpolated maps of the ASI values of the SAIP shovel tests, and all of the nested screen units, are shown in Figures 19 and 20. Units containing primary refuse ASI values (more small fragments) are displayed in blue and units containing secondary refuse ASI values (more large fragment) are green. Darker colors indicate greater deviation from the site-wide mean proportion. The maps display similar clustering of primary and secondary refuse values on the landscape. The results of the ASI value distributions did not match expectations as house interiors contained secondary refuse values and exterior space contained primary refuse values. This seems unlikely as the patterning suggests that exterior space was maintained, while house interiors served as refuse dumps. Further interpretation of the maps is discussed in Chapter 6. 


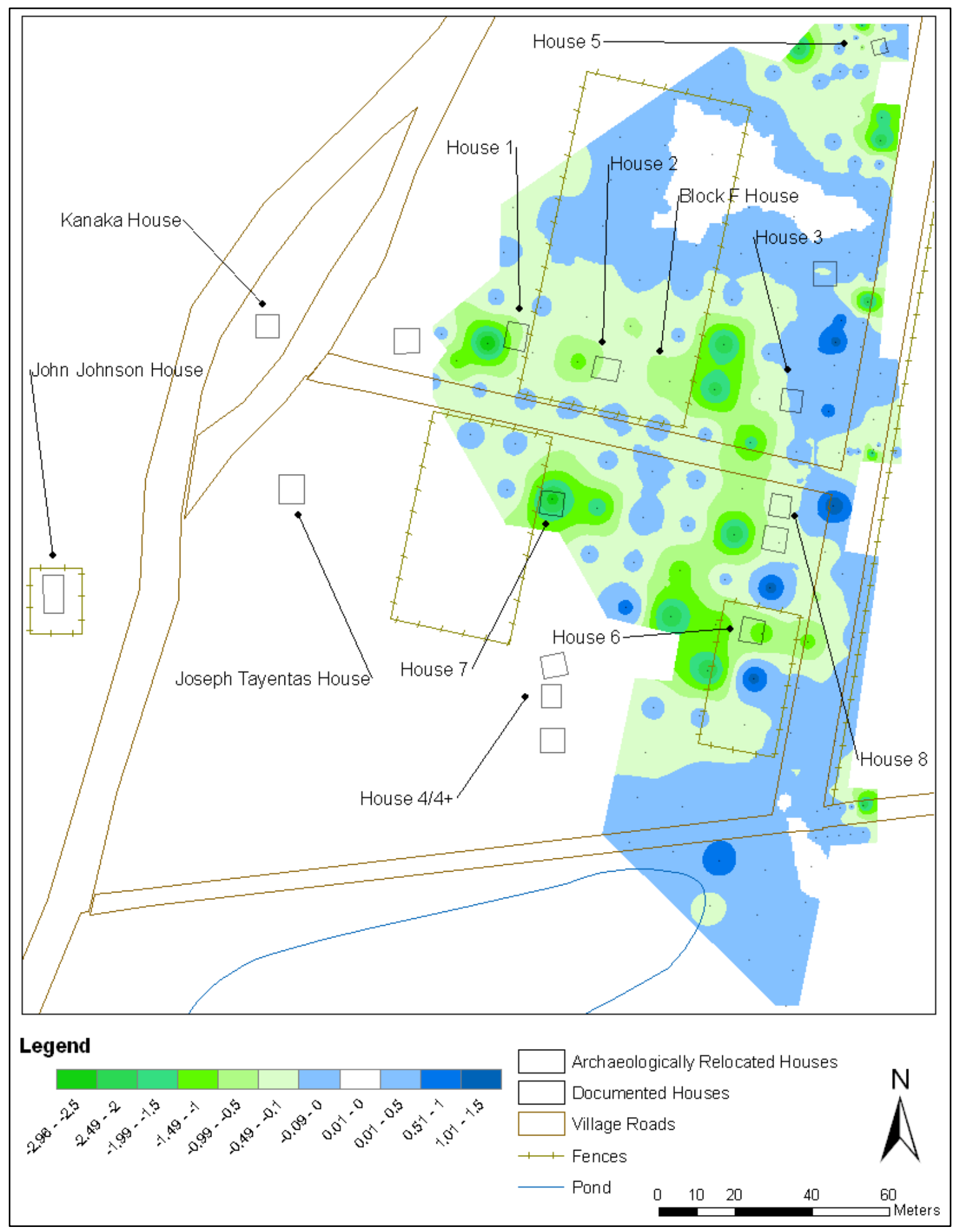

FIGURE 19. Shovel Test ASI Value Distribution (Map by author, 2013) 


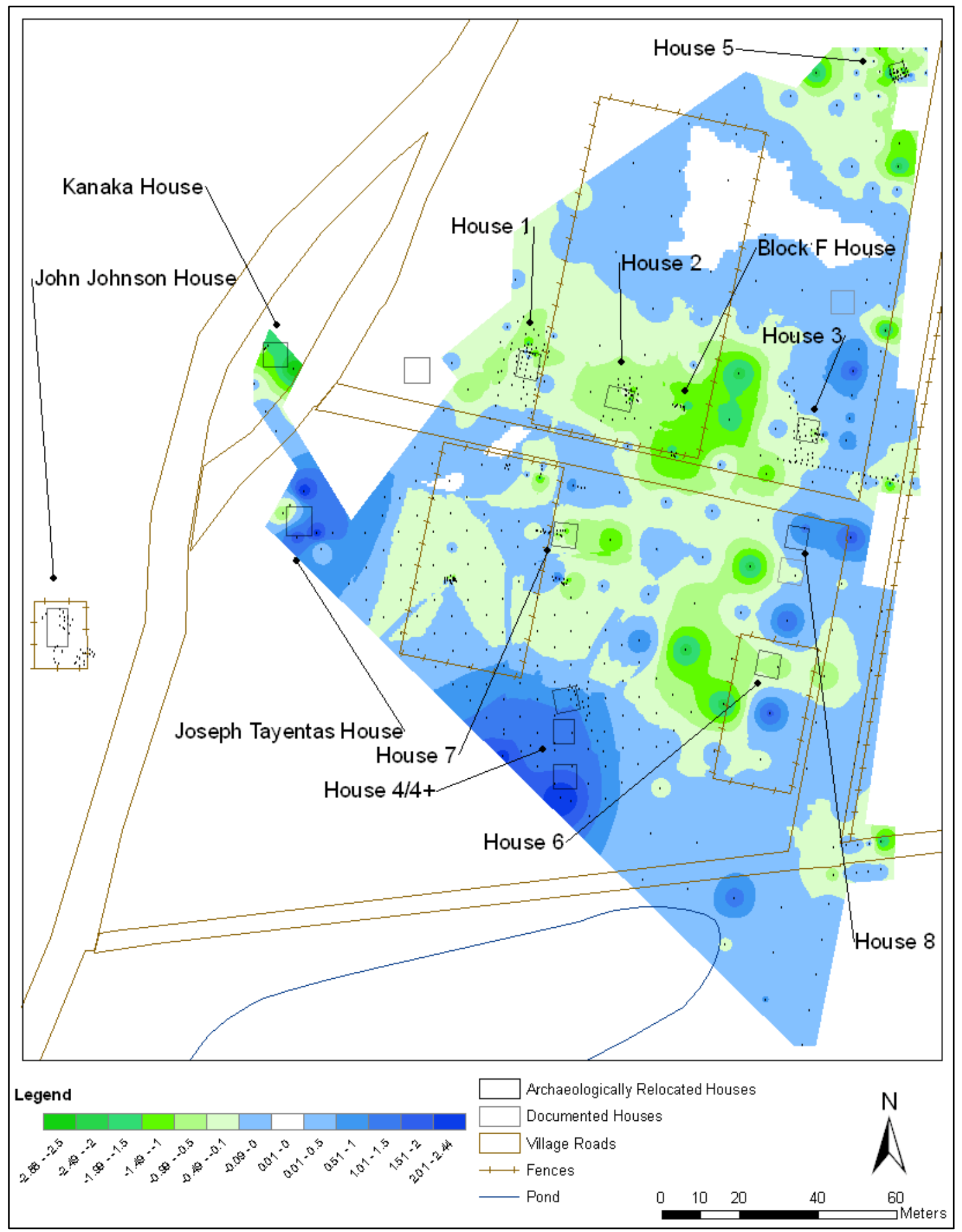

FIGURE 20. All Data ASI Value Distribution (Map by author, 2013) 


\section{Tobacco Consumption Tied to Ethnic Differences}

The locations of the six stone pipe fragment artifacts were mapped to compare with the distributions of clay pipes (Figure 21). The stone pipe artifacts proveniences are near Houses 2,6, and 7. Three of the stone pipes locations are in or near the refuse pit Feature 116, south of House 7. Two stone pipes are in the vicinity of House 2, one on the house floor and one to the southeast of the house. The final pipe provenience is located to the south of House 6. Four of the stone pipe fragments are in or near an identified smoking location, while the two fragments found on the exteriors of Houses 2 and 6 are near houses with signs of clay pipe usage. If one assumes that the pipes were deposited near the houses in which they were used, it appears that these households likewise used clay pipes.

Variation in tobacco consumption between households was measured through quantification of the clay pipe fragments. The assemblage values were calculated for the smoking activity areas identified on the smoking location map (Figure 17) for each house (Table 8). If more than one smoking location was determined near a house, these units were combined as one assemblage for the assessment of tobacco consumption rates. Areas in which smoking areas were combined have "Total" in their Activity Area designation in Table 8.

The clay pipe fragment values of the smoking locations vary between households. The houses with the highest values in general are the John Johnson House, House 4, House 4+ North (seen on the maps as the center house in the House 4/4+ area), House 5, and House 7. On the lower end of the spectrum in pipe assemblage values are Houses 1, 3, 6, and 8. The possible Block F House, House 2, House 4+ TU4-02, and Tayentas 


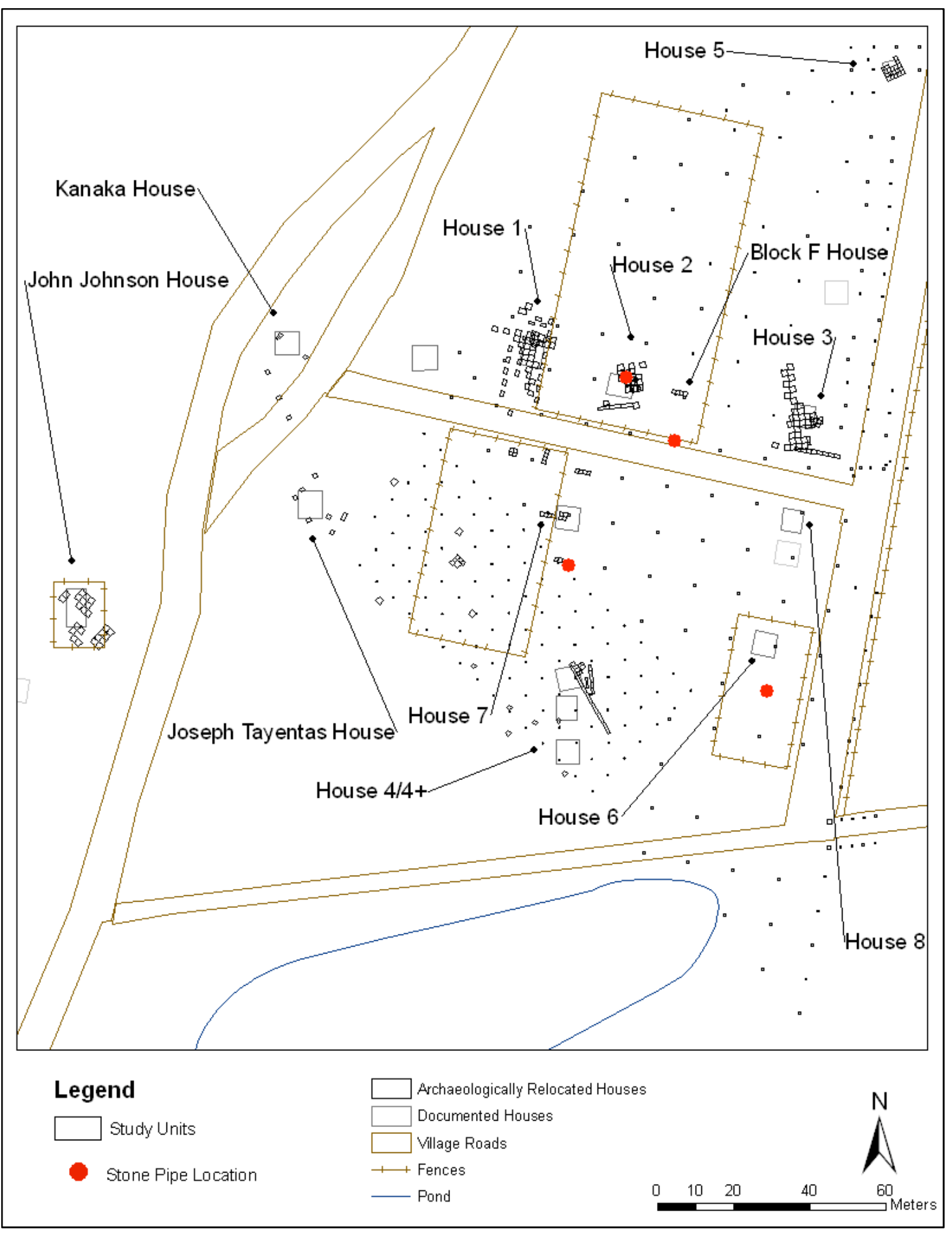

FIGURE 21. Stone Pipe Artifact Locations (Map by author, 2013) 
TABLE 8 SMOKING ACTIVITY AREA CLAY PIPE ASSEMBLAGES BY HOUSE

\begin{tabular}{|c|c|c|c|c|c|c|c|c|}
\hline Activity Area & Location & $\begin{array}{l}\text { Fragment } \\
\text { Count }\end{array}$ & $\begin{array}{l}\text { Area } \\
\left(\mathrm{m}^{2}\right)\end{array}$ & $\begin{array}{l}\text { Fragment } \\
\text { Frequency } \\
\left(\text { per m}^{2}\right)\end{array}$ & $\begin{array}{l}\text { Bowl to } \\
\text { Stem } \\
\text { Ratio }\end{array}$ & $\begin{array}{l}\text { Use Wear } \\
\text { Frequency } \\
\left(\text { per } \mathrm{m}^{2}\right)\end{array}$ & $\begin{array}{l}\text { No. of } \\
\text { Types }\end{array}$ & $\mathrm{MNI}$ \\
\hline Block F House & $\begin{array}{l}\text { Possible } \\
\text { Interior }\end{array}$ & 65 & 3.12 & 20.83 & 0.91 & 5.77 & 3 & 6 \\
\hline House 1 Total & Both & 36 & 3.57 & 10.08 & 0.71 & 2.24 & 3 & 3 \\
\hline House 2 Total & Both & 51 & 5.64 & 9.04 & 2.40 & 5.85 & 4 & 6 \\
\hline House 3 & Interior & 16 & 1.35 & 11.85 & 0.60 & 0.74 & 1 & 2 \\
\hline House 4 & Interior & 117 & 2.79 & 41.94 & 0.67 & 6.09 & 8 & 9 \\
\hline $\begin{array}{l}\text { House 4+ } \\
\text { North Total }\end{array}$ & Both & 155 & 2.00 & 77.50 & 0.94 & 9.50 & 7 & 13 \\
\hline $\begin{array}{l}\text { House 4+ } \\
\text { TU 4-02 }\end{array}$ & Exterior & 21 & 1.00 & 21.00 & 1.33 & 3.00 & 0 & 2 \\
\hline House 5 Total & Both & 137 & 10.52 & 13.02 & 0.96 & 2.19 & 3 & 12 \\
\hline House 6 & Exterior & 4 & 0.25 & 16.00 & 3.00 & 8.00 & 0 & 1 \\
\hline House 7 Total & Both & 380 & 13.84 & 27.46 & 0.97 & 6.65 & 9 & 32 \\
\hline House 8 & Exterior & 10 & 0.25 & 40.00 & 4.00 & 4.00 & 2 & 2 \\
\hline $\begin{array}{l}\text { Johnson House } \\
\text { Total }\end{array}$ & Both & 1123 & 29.75 & 37.75 & 0.82 & 9.41 & 26 & 85 \\
\hline Tayentas House & Exterior & 42 & 1.00 & 42.00 & 1.63 & 4.00 & 2 & 5 \\
\hline Mean & & 166 & 5.78 & 28.34 & 1.46 & 5.19 & 5 & 14 \\
\hline Median & & 51 & 2.79 & 21.00 & 0.96 & 5.77 & 3 & 6 \\
\hline
\end{tabular}

house values lie more in the middle. This variation proposes higher rates of consumption rates in some houses and lower rates in others.

Finally, the map of smoking locations was examined for variations in placement in reference to landscape features. This was done inductively, and only serves as a preliminary assessment of variation in the use of space for tobacco smoking behaviors. The smoking locations are similarly found in proximity to houses and five are found adjacent to hearths. However, there is no directional patterning to these locations, such as 
being found on a certain side of a structure. The ASI values do not appear to be indicative of size-sorting maintenance behaviors, and so the distribution was not evaluated for variation in use of space for maintained areas and refuse disposal areas.

\section{Summary}

The analysis results found that the pipe fragment distributions contain spatial patterning indicative of some behaviors. The pipe fragments are spatially clustered in a statistically significant way, and the smoking location characteristics coincide in various locations. These indicate smoking activity areas across the Village landscape primarily near structures. Some of these smoking locations are found in likely social gathering areas. Analysis of fragment size recovery determined the assemblages recovered with $1 / 4$ in. and 1/8 in. nested screens are a more representative sample of the pipe fragment sizes. The spatial distribution of ASI values did display size sorting of fragments into clusters across the landscape, but not as expected. The values may not be indicative of maintenance behaviors. No unique spatial patterning was found in the location of stone pipe fragments vs. the clay pipe fragments. The clay pipe assemblage characteristic values for the smoking areas, grouped by household, hint at possible differences in consumption rates. An inductive examination of use of space seen through the smoking locations found similarities in all but one house having a smoking location in proximity, smoking locations in five houses were near the hearths and the smoking locations varied directionally in relation to houses. 


\section{Chapter 6. Discussion}

This chapter discusses interpretations based on the expectations of the research questions and the results of the study. Next, post-depositional effects on the artifact distributions are considered. Finally, the study is compared to others from nearby fur trade posts and contact-era Native American village sites.

\section{Tobacco Consumption as a Shared and Social Practice}

The spatial patterning of the pipe fragments and the assemblage characteristics confirmed the expectations of the first research question, suggesting that smoking in the Village was a significant and social practice. The pipe fragments are clustered rather than uniformly spread across the landscape, and the hypothesized characteristics of smoking locations coincide at various locations. These patterns indicate regular smoking activity areas as suggested by previous clay pipe studies (Davies 2011; Fox 1998; Hamilton 1990; Hartnett 2004; Ritchie 1978). Further, the presence of smoking locations at virtually all households suggest smoking was a shared practice within the Village.

The concentrations of pipe fragments found within the Village lend support to the connection between tobacco smoking and sociality evinced in historical and archaeological evidence from Fort Vancouver. Houses 1-5 have an interior smoking location adjacent to the hearth area (Mullaley 2011) representing likely focal points for congregating (Davies 2011). Certainly, individuals used hearths for purposes other than sociality, such as warmth, light, or cooking, and individuals could smoke alone inside their homes. However, it is probable at least some social gatherings occurred on house interiors, especially in the rainy climate of the Pacific Northwest. 
Another possible social smoking area is located near the crossroads at the eastern side of the Village, represented by the identified smoking location and associated area of high fragment frequency and use wear fragment frequency immediately to the east. This adjacent area to the east is shovel test ST117, and is the basis for the location of House 8 (Gembala et al 2004). However, the fragment frequency of 228 fragments $/ \mathrm{m}^{2}$, and the use wear fragment frequency of 24 fragments $/ \mathrm{m}^{2}$ are higher than other house interiors (Figure 22) and exterior activity locations (Table 6). This suggests that the location of ST117 is a unique activity area of intense pipe fragment usage within the study area. While there may appear to be a sampling issue due to the small size of area covered by the shovel test, $0.25 \mathrm{~m}^{2}$, the shovel test contained 57 fragments. This is higher than 11 of the 21 identified smoking locations (Table 6).

Similar correspondence between high pipe fragment concentrations and meeting, or waiting areas, was found within the Fort stockade at the southeast fence corner of the Chief Factor's House, and near the Sale Shop door as previously discussed. In particular, Hoffman and Ross (1973) believe the location near the Chief Factor's House represented a likely meeting place because of the path of traffic between the house and the Bachelors' Quarters. Once again, ST117 has a higher frequency of fragments than this location: 26 fragments/ $/ \mathrm{ft}^{3}$ compared to 0.48 fragments/ $\mathrm{ft}^{3}$ at Chief Factor's House fence corner, but is similar to the Sale Shop highest frequency of 28.9 fragments/ft ${ }^{3}$ (Hoffman and Ross 1974:74). The crossroads area in the Village was likely a purposeful and/or fortuitous meeting place because of the intersection of two high traffic roads. The presence of this and other exterior smoking locations suggest some public, possibly social, aspect to smoking as locations are not restricted to house interiors, or more private spaces. 


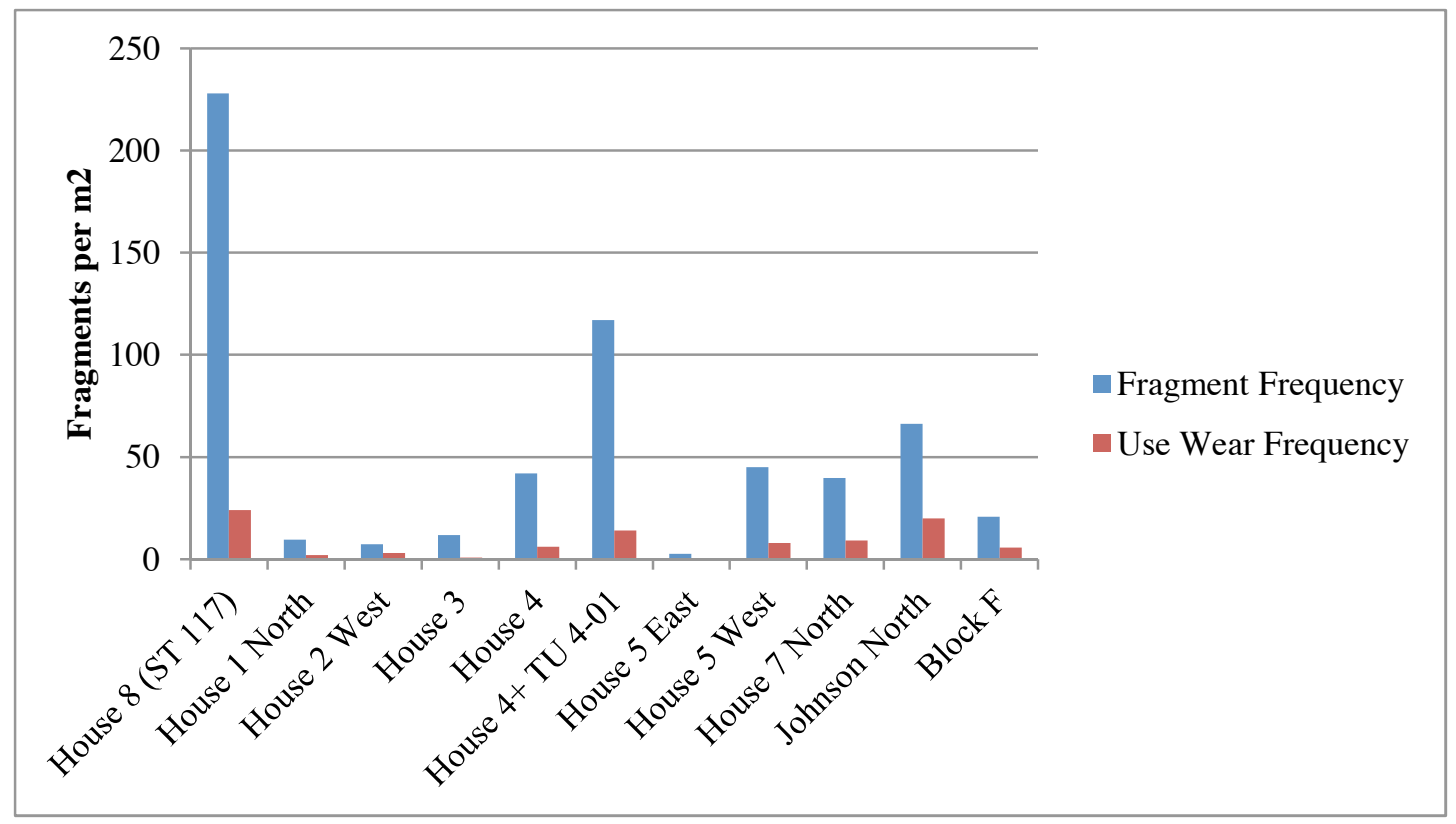

FIGURE 22. Fragment and Use Wear Fragment Frequencies for ST 117 and Interior Smoking Activity Areas (Chart by author, 2013)

\section{ASI Values as Indicators of Traffic Patterns}

The distribution of the ASI values is not considered indicative of size-sorting maintenance behaviors tied to primary and secondary refuse. Village inhabitants using house sites as refuse dumps, combined with maintained exterior space is an unlikely use of space. Possible alternative explanations for issues with the ASI technique include those given by Bon Harper and McReynold (2011): the technique may not work if there is not enough variation in size of the artifacts, or if there were few, if any maintenance behaviors performed on a site. However, the distributions of the pipe fragments do suggest pipe fragment size sorting by some force.

The association with small fragments (primary values) and high traffic locations like roads suggest the effects of trampling. Cultural notions of refuse may have conceptualized pipe fragments as non-offensive, or non-hazardous, debris that did not 
require removal from activity areas or house floors to refuse dumps (Wilson 1994). Left where they fell, the fragile pipe fragments may have been subjected to trampling in high traffic areas, and fragmented further into small pieces.

The concentrations of large fragments on house floors and adjacent to high traffic areas could indicate low traffic areas and/or "woogleys" (Schiffer 1987:127). Schiffer (1987:127) describes the lateral movement of artifacts from high traffic zones to the peripheries, collecting into "woogleys." They are common near features like fences, paths, and along interior and exterior structure walls. If pipe fragments were often left where they fell, human traffic could create size sorting by breaking fragments within higher traffic areas to a greater degree than those outside of high traffic areas. Traffic could also move some fragments within high traffic areas to peripheries where they were no longer trampled, forming “woogleys." In the case of house floors, fragments may have also fallen underneath furniture or in other areas out of the way of the inhabitants' activities.

The additional concentrations of small fragments found in-between houses and diagonally across areas between the roads might then suggest possible pathways (Figure 23). Gembala et al (2004:26) identified one of these areas, to the east of House 3 , as a possible activity area. The secondary values in house interiors, and adjacent to the primary values in exterior locations, may represent lower traffic amounts or "woogleys." Given the associations between fragment size and features like houses and roads, human traffic is a possible explanation for the size distribution patterning seen on the Village landscape. 


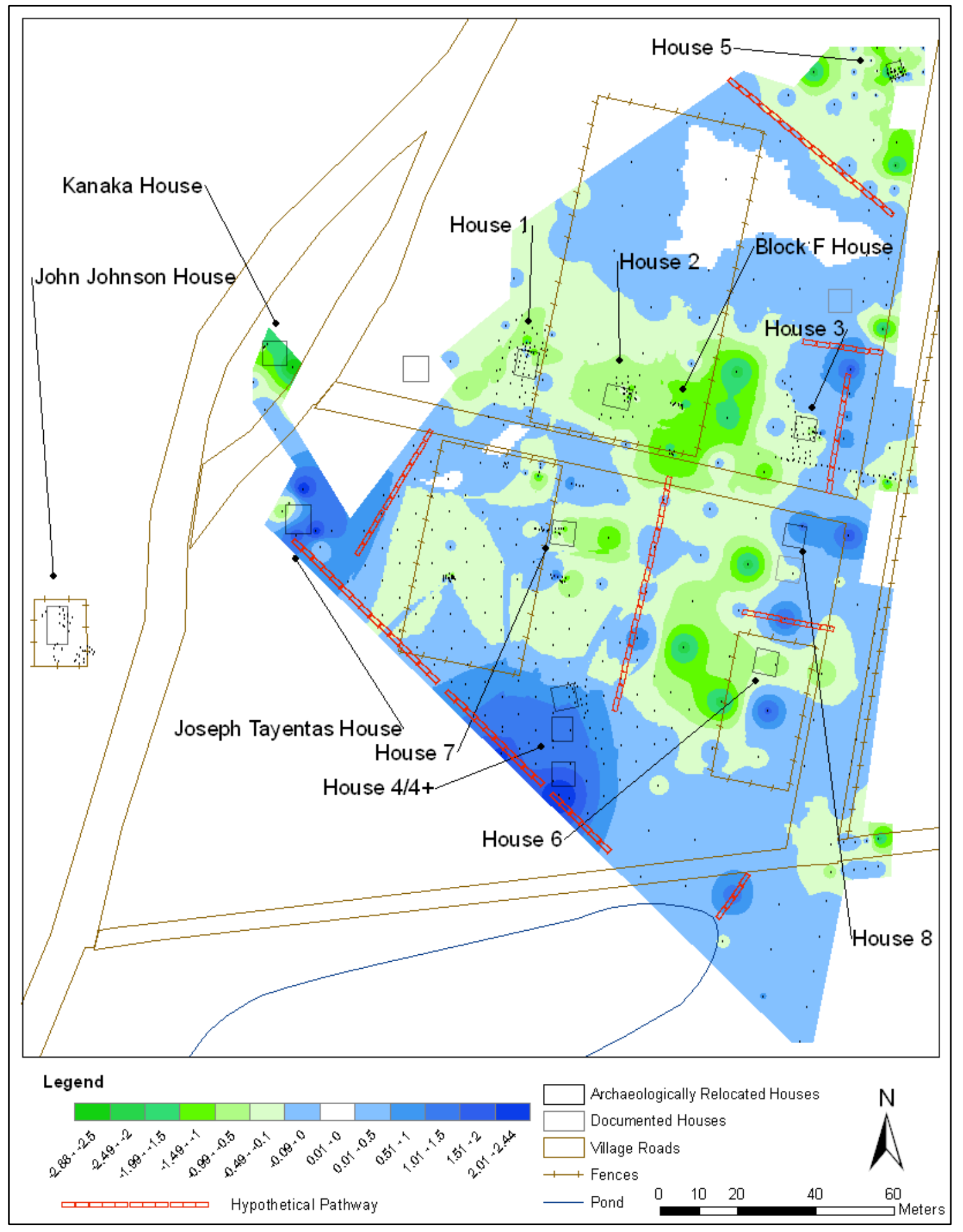

FIGURE 23. Map of Hypothetical Pathways Based on Small Pipe Fragment Clusters (Map by author, 2013) 


\section{Ethnic Variation in Spatial Distribution Patterns}

This study looked for ethnic variation, rather than gender or class variation, as the author did not feel gender or class variation was visible through the analysis methods. Ultimately, the data set and methods of this study did not find any conclusive evidence of ethnic variation in tobacco consumption in the spatial distributions and consumption rates.

The stone pipe fragments do not indicate unique patterning separate from the clay pipe fragments. The distributions suggest stone and clay pipes were used in the same households, showing no clear segregation between material types. Individuals may have favored one type over another for a myriad of reasons, but no site-wide pattern of differential usage is visible. It is possible that differences are obscured due to factors like occupations, multi-cultural households, or shifting residents. If employees with mobile occupations at Fort Vancouver did favor the durable stone pipes (Burley et al 1992; Pollard 1990), their temporary, seasonal stays in the Village would have contributed to the spatial patterning at a lesser extent than the use of clay pipes by more permanent residents. The frequent overturn of employees (Stone 2010) and the multi-cultural compositions of households possibly created palimpsests of multiple behaviors.

The quantification of clay pipe assemblages for house sites to assess consumption rates suggested lower rates for some households. Whether this lower rate is tied to religious or other behavioral prescriptions is unclear. The houses with lower consumption rates, as inferred from the clay pipe assemblage values (Table 8), are possibly affected by sampling issues. The clay pipe fragments from Houses 1,2 and 3 may be underrepresented as the Kardas and Larabee project excavated most of the units 
containing these house sites. Their project did not screen most, if any, of the matrix from these units, likely missing smaller pipe fragments. The pipe fragments from other houses with lower consumption rates may be underrepresented because of fewer excavation units at the house site. The smoking activity areas for Houses 6, 8, Tayentas House, and the southernmost house in the Houses 4/4+ area (listed in Table 6 as House 4+ TU4-02) are based on only one unit. The Kanaka House may be considered the house with the lowest consumption rate as it does not have an identified smoking location in its proximity, but there are few excavation units near the house site. There may be more pipe fragments in the adjacent unexcavated areas for these houses.

Finally, there may also be a temporal relation between length of occupation and pipe deposition rate that is affecting the values used to measure consumption rates. Higher consumption households such as the John Johnson House, Houses 4/4+, and House 5 existed for ca. 30 years (Table 4), while lower consumption households such as Kanaka House, Houses 1-3, and Tayentas House were occupied for ca. 10-25 years. Various factors beyond behavioral prescriptions could have influenced the number of pipe fragments at a house site, subsequently affecting interpretation of consumption rates. Despite these issues, some of these lower household consumption rates may hint at ethnic variation. One house, the Tayentas House, was home to an Iroquois employee. Stone pipe usage is tied to Iroquois smoking behaviors (Jameson 2007), and one of the expectations for stone pipe usage was for lower quantities of clay pipe fragments. Houses 1-3 may be part of a group of Hawaiian households based on the Covington Map (Figure 3), and these three houses, in addition to the identified Hawaiian Kanaka House, have 
lower consumption rates. These should only be considered tentative interpretations until performance of further analysis or excavations.

The lack of archaeological evidence of ethnic difference may be informative rather than limiting. As Ames (2008) proposes, analysis of phenomena that are historically documented but do not have an archaeological component may require looking at multiple lines of evidence separately, testing the connections between them, and subsequently building stronger cables of inference. The ethnic variation in the Village is emphasized in the historical documents, written by outside observers who ethnically stereotyped servant class employees (Burley 1997; Jameson 2007; Roulstone 1975). Lack of archaeological evidence of ethnic variation (Kardas 1971; Thomas and Hibbs 1984; Cromwell 2006; Mullaley 2011) may suggest Village inhabitants did not share this importance placed on ethnic variation, possibly even forming a Village culture. Burley (1997) suggests servant class employees saw themselves as similar in their shared lower rank in the HBC hierarchy, despite their various ethnic backgrounds. Other lines of evidence, such as pipe residue analysis (Tushingham et al 2013), may find evidence of Village inhabitants smoking other substances, providing more information on change in smoking behaviors through time. DNA analysis may be the most definitive method to attribute clay pipe usage to men vs. women (Dixon 2006; Schablitsky 2006), supplying more information on gendered usage between ethnic groups. This study provides only one line of evidence that should be combined with others to build a better understanding of the role of ethnic variation, and measuring persistence and change, in the Village. 


\section{Use of Space}

The limited amount of previous spatial analysis of clay pipes, and lack of information on patterns for specific ethnic groups, allowed only an inductive examination of the use of space across the landscape. Overall, the smoking locations vary in relation to houses, with no site wide pattern of placement. For example, the distribution does not show that all smoking activity areas were outside and to the west of each house.

One common pattern in smoking activity area locations, and other high frequency areas, is proximity to a significant landscape feature, be it a structure, a road, or even the pond. These areas are likely loci of human activity, or where people were most often on the landscape. This suggests smoking was not restricted to areas only used for smoking, but coincided with other activities, and tobacco pipe users commonly deposited pipe fragments as they moved across the landscape. Other studies found pipe fragments in similar locations as other domestic artifacts in the Village (Thomas and Hibbs 1984; Gembala et al 2004; O'Rourke et al 2010), further suggesting no significant separation of smoking from other domestic activities.

High pipe fragment frequencies in the stockade were also found near structures. As previously mentioned, smoking locations are inferred from high pipe fragment frequencies near the Sale Shop door: 19.3 to 28.9 fragments $/ \mathrm{ft}^{3}$ (Hoffman and Ross 1974:74) and the fence corner of the Chief Factor's house: 0.48 fragments/ $/ \mathrm{ft}^{3}$ (Hoffman and Ross 1973). Another smoking location is interpreted near the Indian Trade Store door: 0.72 fragments/ $\mathrm{ft}^{3}$ (Hoffman and Ross 1975: 158). If the Village smoking locations with higher assemblage characteristics are converted to fragments $/ \mathrm{ft}^{3}$, (House 7 North: 329.41, House 4+ TU 4-01: 14.41, ST 117: 26.00, John Johnson House North: 3.59, 
House 4: 2.79) and compared to those in the stockade, the Village smoking locations are higher in density (frequency $/ \mathrm{m}^{3}$ ) than those at the Indian Trade Store and the Chief Factor's House, but only some of the Village frequencies are higher than those at the Sale Shop. Overall, the Village smoking locations appear to be sites of higher density than those within the stockade, suggesting more regular use of the smoking activity areas. Social smoking in both the stockade and the Village may point to a shared participation in the wider fur trade culture in which tobacco smoking was an inseparable aspect.

Those portions of the Village landscape devoid of pipe fragments may represent areas of dissimilar use, possibly reserved for less human-intensive activities. For example, the north-central portion of the map is thought to represent a field or pasture (Gembala et al 2004) based on the lower density of artifacts in general, and the pipe fragments match this pattern. Other possibilities for low pipe fragment densities include areas of lower human traffic, or areas used for activities in which smoking was deemed undesirable, and areas that were also kept clear of refuse.

In general, high fragment frequency areas are more widely dispersed than the other two attributes (use wear and bowl to stem ratio). If the areas in which the three attributes overlap are the strongest candidates for regular smoking activities, then other high frequency areas may represent less regular smoking. Additionally, these wider areas of high fragment frequency (Figures 10 and 13), especially in areas where they surround a structure, could be indicative of the sheet trash surrounding Village houses, as suggested by Thomas and Hibbs (1984). Wilson (1994) states that sheet trash, representing intentional, though informal, discard can include primary refuse locations, or in this case, smoking activity areas within the larger distributions of clay pipe fragments. 
Secondary refuse locations could not be delineated as outlined in the methods using the ASI technique, but can be addressed through contextual information and previous interpretations. In certain instances, the smoking activity area indicated by the pipe fragment attributes contains a refuse disposal location. These include the House 7 South area containing the refuse pit Feature 116, the Johnson House North area that includes the cellar pit Feature 54, and the Johnson House Southeast area near the refuse pit Feature 209. It is inferred that Village inhabitants collected at least some pipe fragments from primary use locations, and deposited them in secondary refuse locations. This also suggests that while the coincidence of the three pipe fragment assemblage characteristics may indeed indicate high levels of smoking activity, the overlap locations may not be the exact areas in which the smoking occurred. This highlights the need for other contextual information to determine behaviors from the fragment distributions, rather than sole reliance on distributional maps. Future refinement of methods may determine better ways to separate smoking activity areas from refuse disposal locations.

\section{Post-Depositional Effects}

The influence of post-depositional forces on the distributions of pipe fragments may have affected the spatial patterns found in this study. The behaviors of Village inhabitants, with the frequently shifting population and multi-ethnic households, possibly built up a palimpsest of varying behaviors at the site. Smoking locations may represent the culmination of various residents over time. Future spatial analyses of temporally diagnostic characteristics of artifacts may indicate deposits tied to different occupancies, aiding separation of smoking locations. 
The later destruction of the Village by the US Army likely disturbed the HBC artifacts. Previous studies suggested that while there are signs of disturbance from the house demolition in some areas, many features were still intact, including portions of house floors and other activity areas (Kardas and Larabee 1968; Thomas and Hibbs 1984; Gembala et al 2004; O'Rourke 2010). The indications of clustering from the Moran's I test suggest at the very least that the pipe fragments were not spread uniformly across the site due to post-depositional forces.

The construction of US Army buildings over the area in the 20th century unquestionably disturbed HBC deposits. As found in previous studies (Gembala et al 2004; Larabee and Kardas 1968; Mullaley 2011) disturbances in the HBC-era stratum at House 1 and House 5 affected the amount of material culture. Lower numbers of pipe fragments are seen in these disturbed areas than in surrounding units.

\section{Regional Comparison}

A cursory examination of other fur trade forts and contact-era site reports found that clay pipes are often only reported in counts and type descriptions, and only rarely subjected to detailed spatial analysis (Table 9). Overall, the clay pipe assemblages are smaller, but this could be the result of lack of screening for some projects (Caywood 1954a; 1954b) and use of $1 / 4$ in. mesh by others (Minor et al 1989). The number of stone pipe fragments are higher than the study assemblage at the two Native American sites the Middle Village and 45SA11, and at Fort Okanogan. The prevalence of stone pipes at the Native American sites is expected as their use in the Pacific Northwest is well documented. Fort Okanogan is unusual as the number of stone pipe fragments and other steatite fragments are interpreted as results of a steatite industry by HBC employees 
(Caywood 1954a; Grabert 1968). Reasons for this production are unclear, but some of the pipes are in the shape of clay pipes. This is similar to one of the stone pipes in this study's assemblage (Figure 6). The use of stone pipes by Fort Okanogan employees may explain the lower numbers of clay pipe fragments.

The number of clay pipe fragments, in relation to stone pipe fragments, roughly increases through time. Earlier sites contain higher numbers of stone fragments, such as Fort Okanogan, Middle Village, and SA11. SA11 also has a later 19th century component, likely explaining the higher numbers of both clay and stone pipe fragments. The later 19th century sites such as Fort Vancouver and Fort Nisqually contain a larger TABLE 9 REPORTED PIPE ASSEMBLAGES OF FUR TRADE ERA SITES IN THE PACIFIC NORTHWEST

\begin{tabular}{llrr}
\hline Site & Report & $\begin{array}{l}\text { Number of Clay } \\
\text { Pipe Fragments }\end{array}$ & $\begin{array}{c}\text { Number of Stone } \\
\text { Pipe Fragments }\end{array}$ \\
\hline Fort Okanogan & Caywood 1954a & Present & Present \\
Grabert 1968 & 264 & 4 \\
$\begin{array}{l}\text { Fort Nisqually } \\
\text { Village }\end{array}$ & Stilson 1991 & 1433 & 3 \\
$\begin{array}{l}\text { Fort Spokane } \\
\text { Middle Village }\end{array}$ & Caywood 1954b & Present & 34 \\
$\begin{array}{l}\text { W5SA11 } \\
\text { (Clahclellah) }\end{array}$ & Minor et al 1989 & 14 & 24 \\
$\begin{array}{l}\text { Fort Vancouver } \\
\text { Village } \\
\text { (Study sample) }\end{array}$ & See Table 1 & 1206 & 6 \\
\hline
\end{tabular}

ratio of clay pipes to stone pipe fragments. This temporal relation may reflect an increased availability of imported goods, resulting in higher clay pipe usage. One 
possible reason users shifted to clay pipes is because clay pipes could be acquired without expending the higher amount of time and effort required in carving a stone pipe.

Three studies, Minor et al (1989), Stilson et al (1991), and Wilson et al (2009) provided spatial distribution information on the clay pipes. Unfortunately, at SA11, the clay pipes were included in the distributions of all European ceramic artifacts (Minor et al 1989: 170), so the spatial distribution of clay pipes could not be evaluated. At the time of writing, some of the clay pipe types found at SA11 had only previously been found at known HBC sites suggesting evidence of trade with the HBC (Minor et al 1989: 162). At Middle Village, only 14 fragments of clay pipe were recovered, but 8 fragments were from one plankhouse (Wilson et al 2009: 340). Wilson (et al 2009:34) states "If the Chinook saw clay tobacco pipes as a prestige item, or an item indispensable to trade or other forms of exchange, then their relative abundance in the Area F plankhouse argues that this house was of a high-status individual and his family.” At the Native American sites, clay tobacco pipes are used to suggest trade relations, and possible symbols of prestige.

Stilson's (1991) analysis of the clay tobacco pipes at the Fort Nisqually Village is the most comparable to this study. While not mapped, the spatial location of clay pipes concentrations is described as highest along the east and south walls of structures and low on interiors (Stilson 1991:8.21). These concentrations are interpreted as exterior smoking locations, suggesting sheltering against the prevailing winds. There are some issues with Stilson's analysis, as overall fragment density (fragments/ $/ \mathrm{f}^{2}$ ) was not calculated for individual structures, but for all three structures within the project area: 0.57. Stilson did analyze the ratio bowl and stem fragments, but differently than this study. For the Fort 
Nisqually Village analysis, the total number of stem fragments was divided by the total number of bowl fragments as an indicator of the level of population transience. The size of bowl and stem fragments at the site was not taken into account (Stilson 1991:8.18, 8.20). These results are compared to the John Johnson house, finding signs of higher consumption rates at Fort Vancouver (Stilson 1991: 8.16). However, the presence of high frequencies of pipe fragments at the John Johnson house is interpreted as the product of the later US Army inhabitants' consumption rates (Stilson 1991:8.15). The results of this study suggest otherwise, and did not assume men smoked more than women as Stilson suggests (1991:8.15-8.16), as this is not historically documented.

The analysis methods of the clay pipe fragment assemblages in previous reports are not consistent, and many do not go beyond object description. Relative to these other assemblages, the Village contains a uniquely high number of fragments. This could indicate a higher consumption rate, but might also reflect the higher population and increased access to goods at the regional headquarters. Those studies that did examine pipe fragment distributions, such as Stilson (1991) and Minor et al (1989), possibly obscured information contained within the pipe fragment distributions through their methods. Further analysis of these assemblages may likely produce additional information, possibly providing behavioral spatial patterns for comparison at other sites.

\section{Summary}

The clay tobacco pipe distributions in the Village suggest tobacco was a significant daily practice, with aspects of sociality for residents. The size distribution of clay tobacco pipe fragments, as measured through the ASI values, does not indicate maintenance behaviors as expected, but may show traffic patterns. Stone pipes do not 
exhibit a unique spatial pattern from the clay tobacco pipes. Consumption rates between households differ and some may hint at possible ethnic differences, but interpretations remain tentative due to possible sampling issues. Further work on comparing and building multiple lines of evidence, may prove informative on the role of ethnic variation in the Village. An examination of studies of other fur trade and contact-era sites suggests more analysis could be performed on clay pipe assemblages, providing additional behavioral information beyond counts and types. 


\section{Chapter 7. Conclusion}

This study aimed to find daily behaviors and diversity in the Village by using a spatially focused analysis. It was thought that by shifting from a conception of artifacts as ethnic markers (Silliman 2005) to an analysis of spatial patterning (Lightfoot et al 1998), the study might find the diversity and behaviors missed in earlier research. The results indicate daily behaviors of tobacco consumption, and possibly traffic, but do not show definitive variation tied to ethnicity. This study represents one of the few detailed, systematic analyses of the intrasite spatial patterning of tobacco pipe fragments. The results of the study hint at the usefulness of spatial analysis for understanding daily life not only in the Village, but possibly at other sites as well.

The results of this analysis further demonstrate the difficulty in finding ethnic variation between households in the Village. Three possibilities seem the most likely explanations for the lack of archaeological evidence of ethnicity in the Village. The shifting populations, or multi-cultural households, created a palimpsest of behaviors in the archaeological record. The restricted number of sources for material items led to expressions of identity that cannot be easily measured through the material evidence in the archaeological record. Lastly, ethnicity was not as critical for Village inhabitants as it was to HBC officials, leading to a Village-wide culture. Interplay between traits of the wider fur trade culture, and those specific to the ethnic groups in the Village, possibly led to the ethnogenesis of a new culture. These explanations are not mutually exclusive, and aspects of all three likely affect the interpretation of the archaeology of the Village. For tobacco smoking behaviors, the significant and social aspects of their distributions point 
toward the third explanation of a shared practice.

A comparison to reports from fur trade post and contact-era village sites in the region found only one similar analysis of clay pipe fragments (Stilson 1991). At these, and other sites including Fort Vancouver, if analysis of clay pipes went beyond object description, researchers only mapped the fragment frequencies. This is a common deficit in clay pipe research, despite indications by a few studies that clay pipes have informative spatial patterning related to behaviors (Bradley 2000; Davies 2011; Fox 1998; Hamilton 1990; Hartnett 2004; King and Miller 1987; Pfeiffer 1982; Pogue 1988; Ritchie 1978). As suggested by Rafferty and Mann (2008), more focus needs to be placed on the behavioral and cultural information contained within tobacco pipes. The insight gained from examining additional assemblage characteristics than just fragment frequency suggests future analyses can benefit from examining the spatial distribution of other diagnostic characteristics of not only clay pipes, but also other artifact types.

\section{Future Directions}

This study demonstrates the value of spatial analysis of clay pipe fragment distributions for behavioral information. Re-analysis of clay pipe assemblages at other sites would aid the understanding of their use, possibly building patterns of specific ethnic, gender, or class behaviors for comparison. More detailed spatial analyses of archaeological assemblages in general have the potential to provide insight into daily life and associated cultural worldviews. This can provide an additional line of evidence to better understand the nuanced use of material culture, and measure continuity and change, at sites of cultural interaction. 


\section{References}

Ames, Kenneth M.

2008 Slavery, Household Production, and Demography on the Southern Northwest Coast:

Cables, Tacking and Ropewalking. In Invisible Citizens: Captives and Their Consequences,

Catherine M. Cameron, edition, pp 138-158. University of Utah Press, Salt Lake City.

Apperson, G. L.

1914 The Social History of Smoking. Ballantyne Press, London.

Barman, Jean and Bruce McIntyre Watson

2006 Leaving Paradise: Indigenous Hawaiians in the Pacific Northwest, 1787-1895.

University of Hawai'i Press, Honolulu.

Barrett, John C.

2001 Agency, the Duality of Structure, and the Problem of the Archaeological

Record. In Archaeological Theory Today, Ian Hodder, editor, pp 141-164. Polity, Cambridge.

Beck, Margaret E. and Matthew E. Hill, Jr.

2004 Rubbish, Relatives, and Residence: The Family Use of Middens. Journal of Archaeological Method and Theory 11(3):297-333.

Binford, Lewis

1962 A New Method of Calculating Dates from Kaolin Pipe Stem Samples. Southeastern Archaeological Conference Newsletter 9(1):19-21.

1978 A New Method of Calculating Dates from Kaolin Pipe Stem Samples. In, Historical Archaeology: A Guide to Substantive and Theoretical Contributions, edited by Robert L Schuyler, pp66-67. Baywood Publishing Company, Farmingdale.

Blakeslee, Donald J

1981 The Origin and Spread of the Calumet Ceremony. American Antiquity 46(4):759768.

Bon-Harper, Sara

2011 Site Maintenance and the Identification of Yard Space: an Analytical Technique Using Artifact Size, Demonstrated at Monticello's Site 8. Manuscript, Monticello Department of Archaeology, Charlottesville, VA.

Bon-Harper, Sara and Theresa McReynolds

2011 Who Sweeps Here? Site Maintenance and Cultural Tradition in Historical Contexts. Paper presented at 2011 Society for Historical Archaeology Conference. 
Bourdieu, Pierre

1977 Outline of a Theory of Practice. Cambridge University Press, Cambridge.

Bradley, Charles $S$

2000 Smoking Pipes for the Archaeologist. In Studies in Material Culture Research, Karlis Karklins, editor, pp. 104-133. The Society for Historical Archaeology, California, PA.

British and American Joint Commission on Hudson's Bay and Puget's Sound Agricultural Company's Claims (BAJC) 1865-1869 British and American Joint Commission on Hudson's Bay and Puget's Sound Agricultural Company's Claims. 14 Volumes, Washington, D.C., Montreal.

Broeze, Frank J (editor) 1988 A Merchant's Perspective: Captain Jacobus Boeler's Narrative of his Visit to Hawai'i in 1828. Hawaiian Historical Society, Honolulu.

Brown, Ian W

1989 The Calumet Ceremony in the Southeast and its Archaeological Manifestations. American Antiquity 54(2):311-331.

Brubaker, Roger and Frederick Cooper

2000 Beyond "Identity." Theory and Society 29(1):1-47.

Burley, Edith I.

1997 Servants of the Honourable Company: Work, Discipline, and Conflict in the Hudson's Bay Company, 1770-1870. Oxford University Press, Toronto.

Burley, David V.

2000 Creolization and Late Nineteenth Century Metis Vernacular Log Architecture on the South Saskatchewan River. Historical Archaeology 34(3):27-35.

Burley, David V., Gayel A. Horsfall and John D. Brandon

1992 Structural Considerations of Métis Ethnicity: an archaeological, architectural, and historical study. University of South Dakota Press, Vermillion.

Campbell, Archibald

1822 A Voyage Round the World from 1806 to 1812 in which Japan, Kamschatka, the Aleutian Islands and the Sandwich Islands were Visited. Reprinted 1976. Hawaiian Historical Society, Honolulu.

Carley, Caroline D.

1982 HBC Kanaka Village/Vancouver Barracks 1977. Reports in Highway Archaeology 8. University of Washington, Office of Public Archaeology, Seattle, Washington. 
Carlson, Catherine C.

2006 Indigenous Historic Archaeology of the 19th-Century Secwepemc Village at Thompson's

River Post, Kamloops, British Columbia. Canadian Journal of Archaeology 30:193-250.

Carr, Christopher

1991 Left in the Dust: Contextual Information in Model-Focused Archaeology. In The Interpretation of Archaeological Spatial Patterning, edited by Ellen M Kroll and T Douglas Price, pp 221-256. Plenum Press, New York.

Caywood, Louis R.

1954a Excavations at Two Fort Okanogan Sites, 1952. National Park Service

1954b Archeological Excavations at Fort Spokane, 1951, 1952, 1953. National Park Service.

1955 Final Report: Fort Vancouver Excavations. National Park Service, San Francisco.

Chance, David H. and Jennifer V. Chance

1976 Kanaka Village/Vancouver Barracks, 1974. Office of Public Archaeology, University of Washington.

Chamberlayne, John

1682 The Natural History of Coffee, Thee, Chocolate, Tobacco. In Four Several Sections; with a Tract of Elder and Juniper-Berries, Shewing how Useful They May be in our Coffee-Houses: and Also the Way of Making Mum, with Some Remarks upon that Liquor. Printed for Christopher Wilkinson, London.

Clarke, David L.

1977 Spatial Information in Archaeology. In Spatial Archaeology, David L. Clarke, editor, pp 1-32. Academic Press, London.

Cleland, Henry W.

1840 On the History and Properties Chemical and Medical of Tobacco: A

Probationary Essay. Maclure and Macdonald, Glasgow.

Conolly, James and Mark Lake

2006 Geographic Information Systems in Archaeology. Cambridge University Press, Cambridge.

Crane, Brian D.

2000 Filth, Garbage, and Rubbish: Refuse Disposal, Sanitary Reform, and NineteethCentury Yard Deposits in Washington, D.C. Historical Archaeology 34(1):20-38. 
Cromwell, Robert J.

2006 "Where Ornament and Function Are So Agreeably Combined": Consumer Choice Studies of English Ceramic Wares at Hudson's Bay Company Fort Vancouver, PhD Dissertation, Graduate School, Syracuse University.

Crossley, David

1990 Post-medieval Archaeology in Britain. Leicester University Press, London.

Cox, Ross

1957 The Columbia River or Scenes and adventures during a residence of six years on the western side of the Rocky Mountains among various tribes if Indians hitherto unknown: Together with a journey across the American Continent. University of Oklahoma Press, Norman.

Davies, Peter

2011 Destitute Women and Smoking at the Hyde Park Barracks, Sydney, Australia. International Journal of Historical Archaeology 15:82-101.

De Laguna, Frederica 1990 Tlingit. In Handbook of North American Indians, Volume 7 Northwest Coast, Wayne Suttles editor, pp203-228. Smithsonian Institution, Washington D.C.

Deetz, James F

1996 In Small Things Forgotten: An Archaeology of Early American Life. Anchor Books, New York.

Diaz-Andreu, Margarita and Sam Lucy

2005 Introduction. In The Archaeology of Identity: Approaches to Gender, Age, Status, Ethnicity, and Religion, Margarita Diaz-Andreu, Sam Lucy, Stasa Babic, and David N Edwards, editors, pp1-12. Routledge, New York.

Dixon, Kelly J

2006 Survival of Biological Evidence on Artifacts: Applying Forensic Techniques at the Boston Saloon, Virginia City, Nevada. Historical Archaeology 4(3):20-30.

Dorset, Elaine

2013 A Home Away From Home: Pollen Analysis Provides Insight into Working Class Life at Fort Vancouver, a 19th Century Fur Trade Post. Paper presented at the 2013 Northwest Anthropological Conference.

Douglas, David

1904 Sketch of a Journey to the North Western Parts of the Continent of North America During the Years 1824-25-26-27. Quarterly of the Oregon Historical Society 5(3-4):215271, 325-369. 
Dunn, John

1845 The Oregon territory, and the British North American Fur Trade: With an Account of the Habits and Customs of the Principal Native Tribes on the Northern Continent. G.B. Zieber and Co., Philadelphia.

Erigero, Patricia C

1992a Cultural Landscape Report: Fort Vancouver National Historic Site Volume II. National Park Service, Pacific Northwest Region, Cultural Resources.

1992b Historic Overview and Evaluation of Significant Resources of Fort Vancouver, Vancouver Barracks, Providence Academy, Kaiser Shipyards. Cultural Resources Study, National Park Service, Pacific Northwest Regional Office.

Fladmark, Knut R

1973 The Richardson Ranch Site: A 19th Century Haida House. In Historical Archaeology in Northwestern North America, DM Getty and KR Fladmark, editors, pp 53-95. University of Calgary Press, Calgary.

Franchére, Gabriel

1969 Journal of a Voyage on the North West Coast of North America During the Years, 1811, 1812, 1813, and 1814J. Champlain Society, Toronto.

Fox, Georgia L

1998 The Study and Analysis of the Kaolin Clay Tobacco Pipe Collection from the Seventeenth-Century Archaeological Site of Port Royal, Jamaica. Unpublished PhD Dissertation, Department of Anthropology, Texas A\&M University, College Station, Texas.

2002 Interpreting Socioeconomic Changes in 17th-Century England and Port Royal, Jamaica, Through Analysis of the Port Royal Kaolin Clay Pipes. International Journal of Historical Archaeology 6(1):61-78.

Ferguson, Leland

1992 Uncommon Ground: Archaeology and Early African America, 1650-1800. Smithsonian Institution Press, Washington DC.

Gembala, Danielle D.M., Robert J. Cromwell and Douglas C. Wilson 2004 Results of the Systemwide Archaeological Inventory Project Excavations in the HBC Village Site (45CL300) Fort Vancouver National Historic Site 2001-2003. National Park Service. Draft.

Grabert, GF

1968 The Astor Fort Okanogan: A Final Report on Salvage Archaeology in the Wells Reservoir-Part II. Reports in Archaeology No. 2. University of Washington Department of Anthropology, Seattle. 
Goodman, Jordan

1993 Tobacco in History: The Cultures of Dependence. Routledge, London.

Hamilton, Scott

1990 Fur Trade Social Inequality and the Role of Non-Verbal Communication.

Doctoral Dissertation, Department of Anthropology, Simon Fraser University.

2000 Dynamics of Social Complexity in Early Nineteeth-Century British Fur-Trade

Posts. International Journal of Historical Archaeology 4(3)217-273.

Harrington, J. C.

1954 Dating Stem Fragments of seventeenth and Eighteenth Century Clay Tobacco

Pipes. Quarterly Bulletin, Archeological Society of Virginia 9(1).

Hartnett, Alexandra

2004 The Politics of the Pipe: Clay Pipes and Tobacco Consumption in Galway, Ireland. International Journal of Historical Archaeology 8(2):133-147.

Heath, Barbara J. and Amber Bennett

2000 "The little Spots allow'd them": The Archaeological Study of African-American Yards. Historical Archaeology 34(2):38-55.

Hietala, Harold

1984 Intrasite Spatial Analysis in Archaeology. Cambridge University Press, Cambridge.

Hodder, Ian and Clive Orton

1976 Spatial Analysis in Archaeology. Cambridge University Press, Cambridge.

Hoffman, JJ and Lester A Ross

1973 Fort Vancouver Excavations IV Chief Factor's House and Kitchen. US

Department of the Interior, National Park Service.

1974 Fort Vancouver Excavations VI Sales Shop and Powder Magazine. US

Department of the Interior, National Park Service.

Hudson's Bay Company Archives (HBCA)

1833 Outfit 1832 Inventory Remaining on Hand at Fort Vancouver Depot Spring 1833. B223/d/2b fo. 18-21. Hudson's Bay Company Archives, Winnipeg.

1844 Fort Vancouver, Columbia District Account Books, 1843-1844. B223/d/155. Hudson's Bay Company Archives, Winnipeg. 
Hume, Ivor Noel

1970 A Guide to Artifacts of Colonial America. Alfred A Knopf, Inc., New York.

Hussey, John

1957 History of Fort Vancouver and its Physical Structure. Washington State Historical Society and U.S. Department of the Interior, National Park Service.

1962 Hawaii History 1778-1910: Special Study. United States Department of the Interior, National Park Service, Denver Service Center.

1972 Historic Structures Report, Historical Data, Volume I, Fort Vancouver National Historic Site, Washington. U.S.D.I., National Park Service, Denver Service Center.

1977 The Women of Fort Vancouver. On file, Fort Vancouver National Historic Site.

Hutson, Scott R, Travis W Stanton, Aline Magnoni, Richard Terry, and Jason Craner 2007 Beyond the Buildings: Formation Processes of Ancient Maya Houselots and Methods for the Study of Non-Architectural Space. Journal of Anthropological Archaeology 26:442-473.

James, King of England.

1616 The Workes. Reprinted 1971. G. Olms, New York.

Jackson, R.G., and R. H. Price

1974 Bristol Clay Pipes: A Study of Makers and their Marks. Bristol City Museum Research Monograph 1. Bristol City Museum, Bristol.

Jacobs, Melville

1958 Clackamas Chinook Texts. Indiana University, Bloomington.

Jacobstein, Meyer

1907 The Tobacco Industry in the United States. Reprinted 1968. AMS Press, New York.

Jameson, Jennifer E

2007 Iroquois in the Pacific Northwest Fur Trade: Their Archaeology and History. Unpublished Masters Thesis, Oregon State University

Janiger, Oscar, and Marlene Dobkin de Rios

1973 Suggestive Hallucinogenic Properties of Tobacco. Medical Anthropology

Newsletter 4(4):6-11.

1976 Nicotiana an Hallucinogen? Economic Botany 30(3):295-297. 
Kardas, Susan

1971 The People Bought This and the Clatsop Became Rich: a View of Nineteenth Century Fur Trade Relationships on the Lower Columbia between Chinookan Speakers, Whites, and Kanakas, Bryn Mawr College.

Kardas, Susan and Edward M. Larrabee

19701969 Excavations at Kanaka Village Site, Fort Vancouver, Washington. Report to National Park Service, Fort Vancouver National Historic Site in cooperation with Bryn Mawr College.

Kent, Susan

1990 Activity Areas and Architecture: An Interdisciplinary View of the Relationship Between Use of Space and Domestic Built Environments. In, Domestic Architecture and the Use of Space: An Interdisciplinary Cross-Cultural Study, Susan Kent, editor, pp1-8. Cambridge University Press, New York.

King, Julia A. and Henry M. Miller

1987 The View from the Midden: An Analysis of Midden Distribution and Composition at the van Sweringen Site, St. Mary's City, Maryland. Historical Archaeology 21(2):37-59.

Koetje, Todd A.

1993 Site Formation Processes and Behavioral Deposition Episodes: The View from Le Flageolet II. In Formation Processes in Archaeological Context, Paul Goldberg, David T. Nash, and Michael D. Petraglia, editors, pp 113-124. Prehistory Press, Madison.

Kuhn, Robert D. and Martha L. Sempowski

2001 A New Approach to Dating the League of the Iroquois. American Antiquity 66(2):301-314.

Larabee, Edward M. and Susan Kardas

1968 Exploratory Excavations for the Kanaka Village Fort Vancouver National Historic Site, Vancouver Washington. Report to National Park Service, Fort Vancouver National Historic Site, Vancouver, WA.

Lightfoot, Kent G

1995 Culture Contact Studies: Redefining the Relationship between Prehistoric and Historical Archaeology. American Antiquity 60(2):199-217

Lightfoot, Kent G., Antoinette Martinez and Ann M. Schiff 1998 Daily Practice and Material Culture in Pluralistic Social Settings: An Archaeological Study of Culture Change and Persistence from Fort Ross, California. American Antiquity 63(2):199-222. 
Linton, Ralph

1924 Use of Tobacco Among North American Indians. Field Museum of Natural History, Chicago.

Lynch, Michelle

2009 Testing the Boundaries: New Interpretations on the Locations of Probable Hudson's Bay Company Village Household Locations Using Previous Archaeological Survey Data. Paper presented at the 2010 Northwest Anthropological Conference.

MacKay, Douglas

1938 The Honourable Company: A History of the Hudson's Bay Company. Tudor Publishing Co., New York.

Mallios, Seth

2005 Back to the Bowl: Using English Tobacco Pipebowls to Calculate Mean SiteOccupation Dates. Historical Archaeology 39(2):89-104.

Mann, Rob

2008 From Ethnogenesis to Ethnic Segmentation in the Wabash Valley: Constructing Identity and Houses in the Great Laeks Fur Trade Society. International Journal of Historical Archaeology 12:319-337.

Martindale, Andrew

2009 Entanglement and Tinkering: Structural History in the Archaeology of the Northern Tsimshian. Journal of Social Archaeology 9(1):59-91.

Martindale, A. and I. Jurakic

2006 Identifying Expedient Glass Tools in a Post-Contact Tsimshian Village. Journal of Archaeological Science 33(3):414-427.

McGuire, Randall H.

1982 The Study of Ethnicity in Historical Archaeology. Journal of Anthropological Archaeology 1(2):159.

McLoughlin, John

1941 The Letters of John McLoughlin, from Fort Vancouver to the Governor and Committee, first series, 1825-1838, E.E. Rich, editor. Champlain Society, Toronto.

1943 The Letters of John McLoughlin, from Fort Vancouver to the Governor and Committee, second series, 1839-1844, E.E. Rich, editor. Champlain Society, Toronto.

Merk, Frederick (editor)

1931 Fur Trade and Empire: George Simpson's journal; remarks connected with the fur trade in the course of a voyage from York Factory to Fort George and back to York Factory 1824-1825; together with accompanying documents. Harvard University Press, 
Cambridge.

Minor, Rick, Kathryn Anne Toepel, and Stephen Dow Beckham

1989 An Overview of Investigations at 45SA11: Archaeology in the Columbia River Gorge.

Heritage Research Associates Report No. 83. US Army Corps of Engineers, Portland.

Mitchell, Donald

1990 Prehistory of the Coasts of Southern British Columbia and Northern Washington.

In Handbook of North American Indians, Volume 7 Northwest Coast, Wayne Suttles

editor, pp340-358. Smithsonian Institution, Washington D.C.

Mulalley, Meredith J.

2011 Rebuilding the Architectural History of the Fort Vancouver Village. Masters

thesis, Department of Anthropology, Portland State University. University Microfilms

International, Ann Arbor, MI.

Mullins, Paul R and Robert Bynter

2000 Representing Colonizers: An Archaeology of Creolization, Ethnogenesis, and Indigenous Material Culture among the Haida. Historical Archaeology 34(3):73-84.

Nassaney, Michael S

2004 Men and Women, Pipes and Power in Native New England. In Smoking and Culture: The Archaeology of Tobacco Pipes in Eastern North America, Sean Rafferty and Rob Mann, editors, pp 125-141. University of Tennessee Press, Knoxville.

Norton, Marcy

2008 Sacred Gifts, Profane Pleasures: A History of Tobacco and Chocolate in the Atlantic World. Cornell University Press, Ithaca.

Nute, Grace Lee

1931 The Voyager. D. Appleton and Co., New York.

O'Connell, James F, Kristen Hawkes, and Nicholas Blurton Jones

1991 Distribution of Refuse-Producing Activities at Hadza Residential base Camps:

Implications for Analyses of Archaeological Site Structure. In The Interpretation of

Archaeological Spatial Patterning, edited by Ellen M Kroll and T Douglas Price, pp 61-76.

Plenum Press, New York.

O'Rourke, Leslie M., Todd A. Miles, and Douglas C. Wilson

2010 Results of National Park Service Archaeological Evaluation and Testing on the Vancouver National Historic Reserve for the Columbia River Crossing Project.

Northwest Cultural Resources Institute Report No. 8. Fort Vancouver National Historic Site, Vancouver. 
Ortner, Sherry B.

1996 Making Gender: The Politics and Erotics of Culture. Beacon Press, Boston.

2006 Anthropology and Social Theory. Duke University Press, Durham.

Paper, Jordan

1988 Offering Smoke: the Sacred Pipe and Native American Religion. University of Idaho Press, Moscow.

Pettigrew, Richard M

1990 Prehistory of the Lower Columbia. In Handbook of North American Indians, Volume 7 Northwest Coast, Wayne Suttles editor, pp518-529. Smithsonian Institution, Washington D.C.

Pfeiffer, Michael A

1982 Clay Tobacco Pipes and the Fur Trade of the Pacific Northwest and Northern Plains. Masters Thesis, Department of Anthropology, University of Idaho.

Pierson, Heidi

2010 Within the Collection: A Look Inside the Fort Vancouver Museum, Tobacco Pipes. NCRI Curation Series No. 2. Fort Vancouver National Historic Site, Vancouver.

Pollard, Juliet Thelma

1990 The Making of the Métis in the Pacific Northwest Fur Trade Children: Race, Class, and Gender. Doctoral Dissertation, Department of Social and Educational Studies, University of British Columbia.

2003 A Most Remarkable Phenomenon: Growing Up Métis: Fur Traders' Children in the Pacific Northwest. In Histories of Canadian Children and Youth, Nancy Janovicek and Joy Parr, editors, pp 57-70. Oxford University Press, Ontario.

Pogue, Dennis J.

1988 Spatial Analysis of the King's Reach Plantation Homelot, ca. 1690-1715. Historical Archaeology 22(2):40-56.

Powers, Kate NB (editor)

1902 Across the Continent Seventy Years Ago. Extracts from the Journal of John Ball of his trip across the Rocky Mountains, and his life in Oregon, complied by this daughter. The Quarterly of the Oregon Historical Society 3(1):82-106.

Rafferty, Sean M

2004 "They Pass Their Lives in Smoke and at Death Fall into the Fire:" Smoking Pipes and Mortuary Ritual During the Early Woodland Period. In Smoking and Culture: The Archaeology of Tobacco Pipes in Eastern North America, Sean Rafferty and Rob Mann, editors, pp 1-41. University of Tennessee Press, Knoxville. 
Rafferty, Sean and Rob Mann

2004 Introduction: Smoking Pipes and Culture. In Smoking and Culture: The

Archaeology of Tobacco Pipes in Eastern North America, Sean Rafferty and Rob Mann, editors, pp xi-xx. University of Tennessee Press, Knoxville.

Rapoport, Amos

1990 Systems of Activities and Systems of Settings. In Domestic Architecture and the Use of Space: An Interdisciplinary Cross-Cultural Study, Susan Kent, editor, pp9-20. Cambridge University Press, New York.

Ray, Verne F

1938 Lower Chinook Ethnographic Notes. University of Washington Publications in Anthropology. University of Washington Press, Seattle.

Rich, E. E.

1958 The History of the Hudson's Bay Company 1670-1870, Vol. 1, 1670-1763. The Hudson's Bay Record Society, London.

Richter, Daniel K

1992 The Ordeal of the Longhouse: The Peoples of the Iroquois League in the Era of European Colonization. University of North Carolina Press, Chapel Hill.

Ritchie, C. F.

1978 Nineteenth-Century Clay Tobacco-Pipes from the High Arctic. Canadian Journal of Archaeology 2: 123-137.

Robertson, Elizabeth C, Jeffrey D Seibert, Deepika C Fernandez, and Marc U Zender 2006 Space and Spatial Analysis in Archaeology. University of Calgary Press, Calgary.

Robinson, Gary G.

1994 Material Culture and Settlement Pattern among the Germans in the New World:

The View from Frankenmuth, Michigan. In Spatial Patterning in Historical Archaeology: Selected Studies of Settlement, Donald W. Linebaugh and Gary G.

Robinson, editors, pp 91-115. King and Queen Press, Williamsburg.

Rogers, Donnell J

$1993 \mathrm{Ku}$ on the Columbia: Hawaiian Laborers in the Pacific Northwest Fur Industry. Master's Thesis. Interdisciplinary Studies, Oregon State University, Corvallis.

Ross, Alexander

1855 The Fur Hunters of the Far West. Reprinted 1956. University of Oklahoma Press, Norman. 
1856 The Red River Settlement: its Rise, Progress, and Present State. With Some Account of the Native Races and its General History, to the Present Day. Reprinted 1957. Ross and Haines, Inc, Minneapolis.

Ross, Lester A.

1976 Fort Vancouver 1829-1860: A Historical Archaeological Investigation of the Goods Imported and Manufactured by the Hudson's Bay Company. Manuscript, Fort Vancouver National Historic Site, Vancouver, WA.

1979 Hudson's Bay Company Suppliers: Volume 1: An Illustrated directory of the British Commercial Suppliers who Provided Manufactures, products and provisions shipped to the Hudson's Bay Company Columbia Department 1821-1852.

Ross, Richard E

1990 Prehistory of the Oregon Coast. In Handbook of North American Indians, Volume 7 Northwest Coast, Wayne Suttles editor, pp554-559. Smithsonian Institution, Washington D.C.

Roulstone, Thomas B.

1975 A Social History of Fort Vancouver 1829-1849. Master's Thesis, Department of History, Utah State University, Logan.

Rubin, Rick

1999 Naked Against the Rain: The People of the Lower Columbia River 1770-1830. Far Shore Press, Portland.

Rutsch, Edward S

1973 Smoking Technology of the Aborigines of the Iroquois Area of New York State.

Fair Leigh Dickinson University Press, Rutherford.

Schablitsky, Julie

2006 Genetic Archaeology: The Recovery and Interpretation of Nuclear DNA from a Nineteenth Century Hypodermic Syringe. Historical Archaeology 4(3):8-19.

Schiffer, Michael B.

1983 Towards the Identification of Formation Processes. American Antiquity 48(4):675-706.

1987 Formation Processes of the Archaeological Record. University of Utah Press, Salt Lake.

Scott, Elizabeth M.

2001 "An Indolent Slothfull Set of Vagabonds": Ethnicity and Race in a Colonial FurTrading Community. In Race and the Archaeology of Identity, Charles E Orser Jr., editor, pp 14-33. University of Utah Press, Salt Lake City. 
Seibert, Jeffery D.

2006 Introduction. In Space and Spatial Analysis in Archaeology, Elizabeth C.

Robertson, Jeffery D. Seibert, Deepika C. Fernandez, and Marc U. Zender, editors, pp

xiii-xxiv. University of Calgary Press, Calgary.

Silliman, Stephen W.

2005 Culture Contact or Colonialism? Challenges in the Archaeology of Native North America. American Antiquity. 70(1): 55-74.

2009 Change and Continuity, Practice and Memory: Native American Persistence in Colonial New England. American Antiquity 74(2): 211-230/

Stahl, Ann Brower

2002 Colonial Entanglements and the Practices of Taste: An Alternative to Logocentric Approaches. American Anthropologist 104(3):827-845.

Stilson, M. Leland

1991 A Data Recovery of 45-PI-405, The 1843 Fort Nisqually Village at Northwest Landing,

Pierce County, Washington. Prepared for Weyerhaeuser Real Estate Company Land

Management Division, Tacoma.

Stone, Helen Delight

2010 Cultural Contact and Gender in the Hudson's Bay Company of the Lower

Columbia River 1824-1860. Doctoral Dissertation, University of Leicester.

Suttles, Wayne and Barbara Lane

1990 Southern Coast Salish. In Handbook of North American Indians, Volume 7

Northwest Coast, Wayne Suttles editor, pp485-502. Smithsonian Institution, Washington

D.C.

Thomas, Bryn and Charles Hibbs Jr.

1984 Report of Investigations of Excavations at Kanaka Village/Vancouver Barracks,

Washington, 1980/1981. Washington State Department.

Thomas, Bryn

1993 Archaeological Test Excavations for the Washington State Department of

Transportation's SR14 Pedestrian Undercrossing Project at Fort Vancouver National

Historic Site, Clark County, Washington. Archaeological and Historical Services, Eastern

Washington University.

Thomas, Nicholas

1991 Entangled Objects: Exchange, Material Culture, and Colonialism in the

Pacific.Harvard University Press, Cambridge. 
Thwaites, Reuben G (editor)

1959 Original Journals of the Lewis and Clark Expedition 1804-1806, Volume 3 1805-

1806. Antiquarian Press, New York.

Towner, Ron

1984 Demographic of Kanaka Village 1827-1843. In Report of Investigations at Kanaka Village Vancouver Barracks Washington 1980/1981, Vol. 2., Bryn Thomas and Charles Hibbs Jr, editors. Washington State Department of Transportation.

Townsend, John Kirk

1839 Narrative of a Journey Across the Rocky Mountains to the Columbia River. Reprinted 1978. University of Nebraska Press, Lincoln.

Trubowitz, Neal L

2004 Smoking Pipes: An Archaeological Measure of Native American Cultural Stability and Survival in Eastern North America, AD 1500-1850. In Smoking and Culture: The Archaeology of Tobacco Pipes in Eastern North America, Sean Rafferty and Rob Mann, editors, pp143-164. University of Tennessee Press, Knoxville.

Tuck, James A.

1971 Onondaga Iroquois Prehistory: A Study in Settlement Archaeology. Syracuse University

Press, Syracuse.

Turgeon, Laurie

2004 Beads, Bodies and Regimes of Value: From France to North America, c. 1500-c. 1650. In The Archaeology of Contact in Settler Societies, Tim Murray, editor, pp 19-47. Cambridge University Press, Cambridge.

Turnbaugh, William M

1979 Calumet Ceremonialism as a Nativistic Response. American Antiquity 44(4):685-

691.

Tushingham, Shannon, Dominique Ardura, Jelmer W. Eerkens, Mine Palazoglu, Sevini Shahbaz, and Oliver Fiehn.

2003 Hunter-Gatherer Tobacco Smoking: Earliest Evidence from the Pacific Northwest Coast of North America. Journal of Archaeological Science 40:1397-1407.

Vancouver, George

1798 A Voyage of Discovery to the North Pacific Ocean and Round the World 17911795, W. Kaye Lamb, editor. Reprinted 1984. Hakluyt Society, London.

Von Gernet, Alexander D.

1982 Analysis of Intrasite Artifact Spatial Distributions: The Draper Site Smoking

Pipes. Masters Thesis. Department of Anthropology, McGill University, Montreal, 
Quebec.

1988 The Transculturation of the Amerindian Pipe/Tobacco/Smoking Complex and its Impact on the Intellectual Boundaries between "Savagery" and "Civilization," 15351935. Doctoral dissertation, Department of Anthropology, McGill University, Montreal, Quebec. National Library of Canada, Canadian Theses Service, Ottawa.

1995 Nicotiana Dreams; The Prehistory and Early History of Tobacco in Eastern North America. In Consuming Habits: Drugs in History and Anthropology, Jordan Goodman, Paul E. Lovejoy, and Andrew Sherratt, editors, pp. 67-87. Routledge, London.

Voss, Barbara L

2008 The Archaeology of Ethnogenesis: Race and Sexuality in Colonial San Francisco. University of California Press, Berkeley.

Wagner, M.J.

1998 Some Think It Impossible to Civilize Them At All: Cultural Change and Continuity Among the Early Nineteenth-Century Potawatomi. In, Studies in Culture Contact. Incteraction, Culture Change, and Archaeology, edited by J.G. Cusick, pp 430456, Center for Archaeological Investigations, Occasional Paper 25, Southern Illinois University, Carbondale.

Walker, Iain C.

1977 Clay Tobacco Pipes, with Particular Reference to the Bristol Industry, Vol. IIA, History and Archaeology. Parks Canada, Ottawa.

Warner, Mikell de Lore Wormell, and Harriet Duncan Munnick 1972 Catholic Church Records of the Pacific Northwest: Vancouver, Volumes I \& II, and Stellamaris Mission. French Prairie Press, St. Paul.

Whelan, Elizabeth M.

1984 A Smoking Gun: How the Tobacco Industry Gets Away with Murder. George F. Stickley Co., Philadelphia.

Wilkie, Laurie A

2000 Culture Bought: Evidence of Creolization in the Consumer Goods of an Enslaved Bahamian Family. Historical Archaeology 34(3):10-26.

Wilson, Douglas C.

1994 Identification and Assessment of Secondary Refuse Aggregates. Journal of Archaeological Method and Theory 1(1):41-68.

2010 Research Design: 2010 Public Archaeology Field School and Associated Processing of Artifacts at Fort Vancouver National Historic Site, Vancouver, Washington. 
Manuscript, Fort Vancouver National Historic Site, Vancouver.

Wilson, Douglas C, Kenneth M Ames, Kristine M Bovy, Virginia L Butler, Robert J Cromwell, Loren G Davis, Christoper R DeCorse, Brian F Harrison, R Lee Lyman, Michele L Punke, Cameron M Smith, and Nancy A Stenholm.

2009 Historical Archaeology at the Middle Village, Station Camp/McGowan Site (45PC106), Station Camp Unit, Lewis and Clark National Historic Park, Pacific County, Washington. Prepared for the Washington State Historical Society and Washington State Department of Transportation. Northwest Cultural Resources Institute No. 1.

Wilson, Douglas, Robert Cromwell, Danielle Gembala, Theresa Langford, Heidi Pierson, and Debra Semrau 2009 Archaeology Lab Manual. 2nd Edition. Fort Vancouver National Historic Site, Vancouver.

Winter, Joseph C.

2000a Introduction to the North American Tobacco Species. In Tobacco Use by Native North Americans: Sacred Smoke and Silent Killer, Joseph C. Winter, editor, pp 3-8. University of Oklahoma Press, Norman.

2000b Traditional Uses of Tobacco by Native Americans. In Tobacco Use by Native North Americans: Sacred Smoke and Silent Killer, Joseph C. Winter, editor pp 9-58. University of Oklahoma Press, Norman.

Wynndette, Olive

1968 Islands of Destiny: A History of Hawaii. Charles E Tuttle Company, Rutland.

Zenk, Henry B

1990 Siuslawans and Coosans. In Handbook of North American Indians, Volume 7 Northwest Coast, Wayne Suttles editor, pp572-579. Smithsonian Institution, Washington D.C. 


\section{Appendix: Statistical Test Results}

\section{Moran's I Results}

\section{From ArcGIS 9.2}

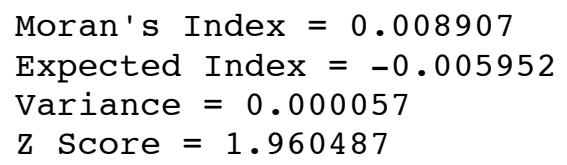

\section{Spatial Autocorrelation (Global Moran's I)}

Moran's I Index $=0.01$

$Z$ Score $=1.96$ standard deviations

Dispersed
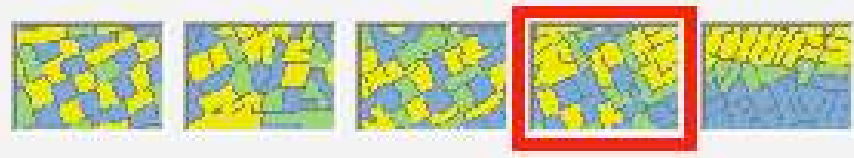

Clustered

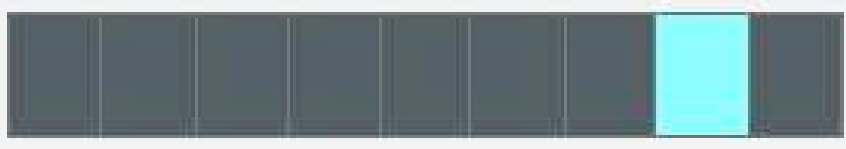

Significonce Level:

Critical Volues:

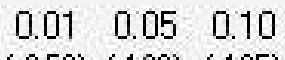

RANDOM

$0.10 \quad 0.05 \quad 0.01$

$(-2.58)(-1.96) \quad(-1.65)$

(1.65) (1.96) (2.58)

There is less than $5 \%$ likelihood that this clustered pattern is the result of random chance.

\section{Close}

Figure A-1. Results of Moran's I Test on Shovel Test Data (ArcGIS 9.2, 2013). 


\section{Kruskal-Wallis Results}

\section{TABLE A-1}

\section{KRUSKAL-WALLIS TEST VALUES}

\begin{tabular}{llccl}
\hline Screening Technique & Excavations & Group Number & $\mathrm{n}$ & $\mathrm{R}$ \\
\hline Inconsistent 1/4 in. & FOVA 116, 120 & 1 & 1648 & 4784140 \\
& FOVA 1813, 2853 & 2 & 1594 & 3900528 \\
$1 / 4$ in. & FOVA 2997, 3011, & 3 & 1557 & 2832932 \\
$1 / 4$ in. and 1/8 in. & $\begin{array}{l}\text { 3023, 3100, } \\
\text { 3120,3164 }\end{array}$ & & & \\
& & & & \\
\hline Total & & & $\mathbf{4 7 9 9}$ \\
\hline
\end{tabular}

Hypotheses:

$\mathrm{H}_{0}$ : All medians are equal

$\mathrm{H}_{1}$ : Not all of the population medians are equal

Formula and Calculations:

$$
\begin{aligned}
\mathrm{H}= & \frac{12}{\mathrm{~N}(\mathrm{~N}+1)} \sum \frac{\mathrm{R}_{i}{ }^{2}}{\mathrm{n}_{i}}-3(\mathrm{~N}+1) \\
& \mathrm{N}=\text { overall sample size } \\
& \mathrm{n}_{i}=\text { number of items in a group } i \\
& \mathrm{R}_{i}=\text { sum of ranks in group } i
\end{aligned}
$$

$\mathrm{H}=492.39$

$\chi^{2}$ critical value $=9.210, \mathrm{p}=0.01, \mathrm{df}=2$

$\mathrm{H}>9.210$

Reject $\mathrm{H}_{0}$ 
ASI Results

TABLE A-2

ASI TEST VALUES

\begin{tabular}{lllcc}
\hline Data Set & $\begin{array}{l}\text { Total Number of } \\
\text { Artifacts }\end{array}$ & $\begin{array}{l}\text { Number of } \\
\text { Small Artifacts }\end{array}$ & $\begin{array}{c}\text { Proportion } \\
(\mathrm{p})\end{array}$ & $\begin{array}{c}\text { ASI Value } \\
\text { using p }\end{array}$ \\
\hline $\begin{array}{l}\text { SAIP } \\
\text { Shovel Tests }\end{array}$ & 231 & 151 & 0.65 & -0.1048 \\
All Units & 1557 & 886 & & \\
\hline
\end{tabular}

